$$
\text { QL644 }
$$
.F62 1912 ** 


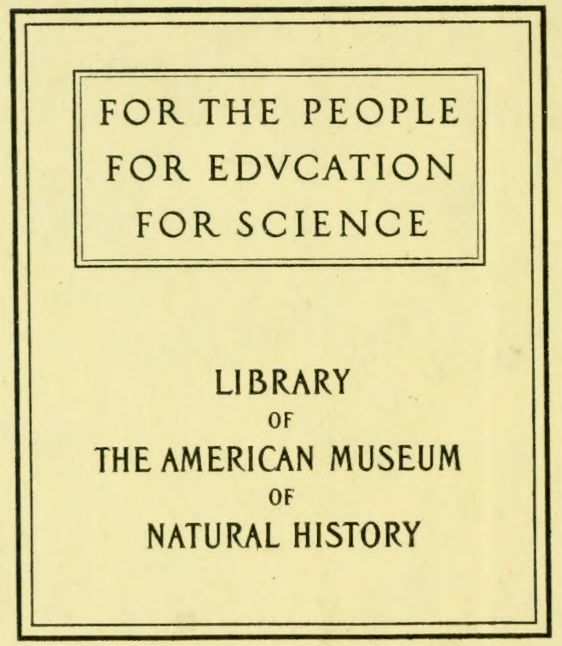








\section{Dr. R.Floericke}

Rriechtiere u. Eutede fremder ränder

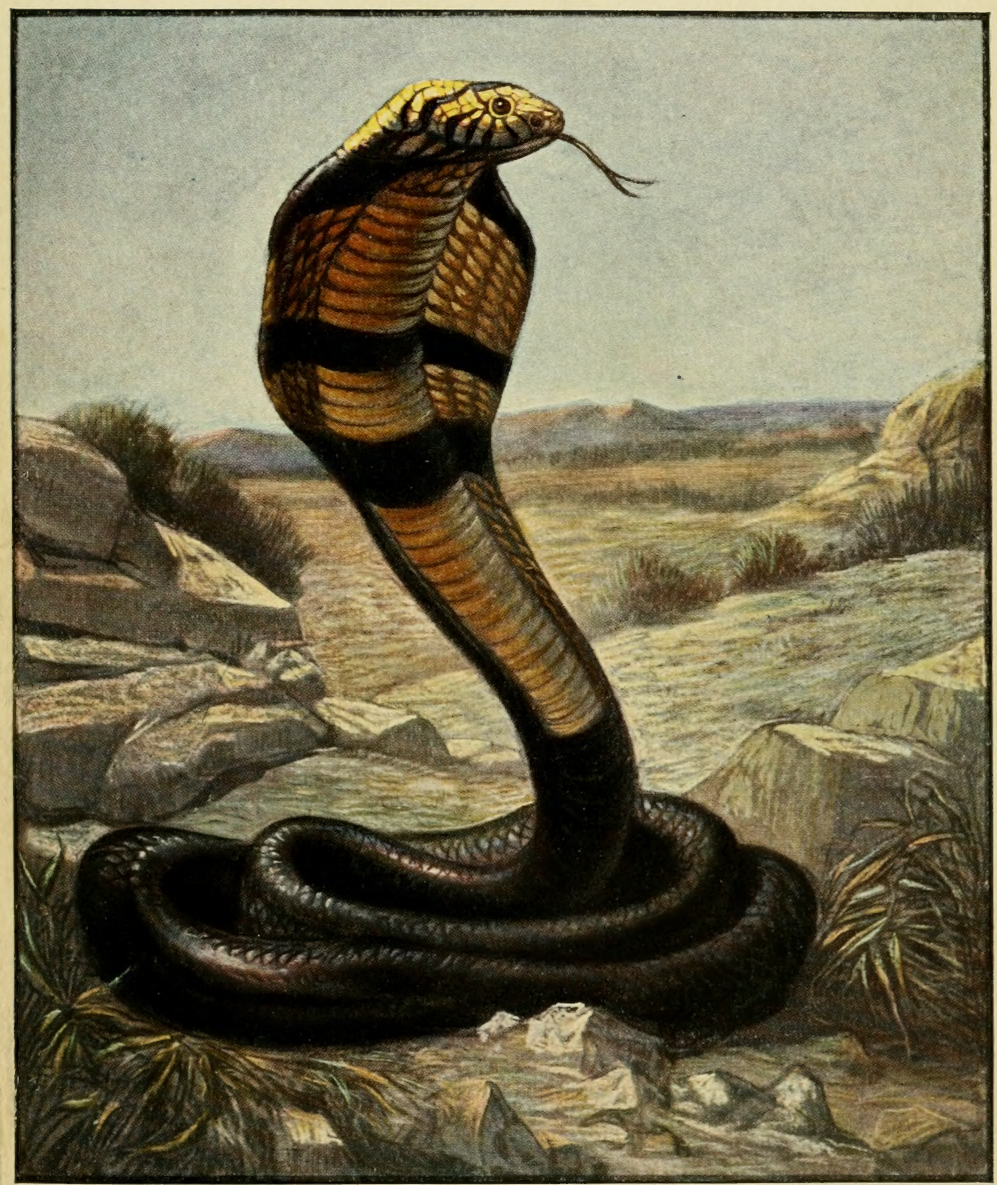

Rosmos. (Besellschaft der Maturfreunde Franckh'sche 'Berlagshandlung. Stuttgart 

$59.81: 08$

Krieçtiere und surçe fremder Eänder

ㅁ 
Rożmoz, Gejellichaft Der Naturfreunde, Stuttgart

(9) Gefellfichaft Sosmoz will die Renntniz der Ratur. miffenjchaften uno Damit bie Freude an Der Natur und Das Zeritänoniz ibrer Eridseinungen in ben weiteiten Rreifen unjeres Bolfez verbreiten. - Diefes Biel glaubt die Gejell= (c)aft ourch Berbreitung guter naturwiffenichaftlicher Diteratur के erreicben mittelz dez

Rosmoz, Sbanbweifer für Raturfreunde Säbrlich 12 Sefte. Preiz $\mathfrak{M} 2.80$;

ferner Durch Soerauzgabe nevar, von erften 2lutoren verfaßjter, im guten Ginne gemeinwer, (ändlicher Werfe naturwififenf(baft=

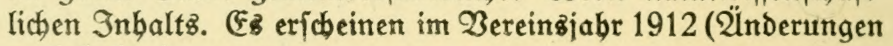
vorbebalten):

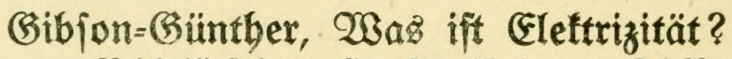

Reid illuftriert. (Bebeftet $\mathfrak{N} 1 .-=\Re 1.20$ G B.. $2 B$.

(Sannemann, Wie unjer Weltbild entitand.

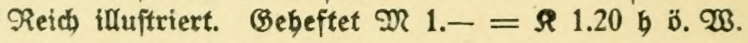

Floerife, Priechtiere u. Qurbe frember Länder. Reid) illuftriert. Gebeftet $\mathfrak{N} 1 .-=\Re 1.20 \mathfrak{h}$ b̈. $\mathscr{W}$.

Weule, Slrformen ber Wirtidaft u. Gejellichaft.

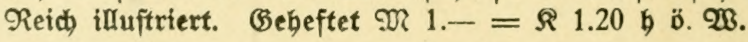

Roelīh, Die Errichaffung Der Eeele.

Reic illuftriert. (Sebeftet $\mathfrak{M} 1 .-=\Re 1.20$ b

Dieje Berbffentlidungen fino burd alle $\mathfrak{B}$ ubband $=$ lungen zu bezieben; Dafelbit werhen BeitrittBertlärungen

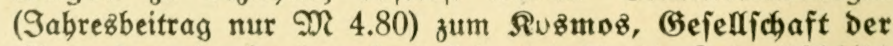
Naturfreunde (auch) nachträglich) noch für die Sabre 1904/11 unter ben gleichen günftigen Bebingungen), entgegengenommen.

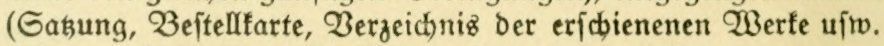
fiebe am Edyluffe biefés Werfez.)

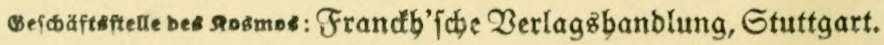




\section{Kriechtiere und surche frember sänder}

pon

Dr. Kurt floericke

Mit einem farbigen Titelblatt und zahlreiḑ̧en zeithnungen (nađ) Tieren des frankfurter zoolo= gijḩen (bartens) von J. Kuttner

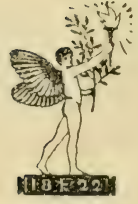

\section{Stuttgart}

Kosmos, (bejellidiaft der Katurfreunde

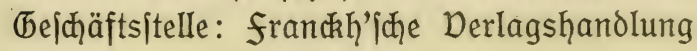


Copyright 1912 by Franckh'sche Verlagshandlung,

Stuttgart

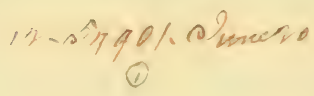

Stuttgarter Segmafdinen. Dructerel Bolginge: \& Eo., Stuttgart. 


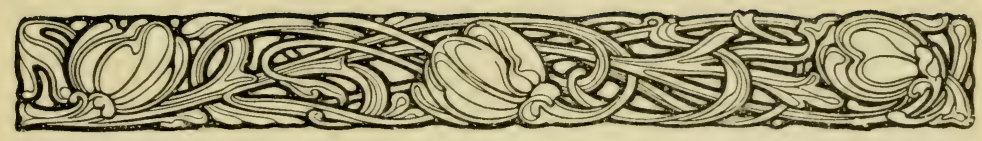

D

ie gegenwärtig zu ungeą̧nter Blüte entwiđaelte đierliebs haberei ift eine एođ̧ter der zoologifḑen Woiffenfdaft. Freilid, eine uneḩeliḑ̨e, denn die Junftgeleḩrten wollen fie noḑ niđ̧t reç̧t für vollgültig anerkennen. Das ichadet aber niđhts, denn es ift eine alte Erfaḩrungstatjache, daj illegitime Kinder oft die kräftigiten und nad dem Gustreten der Kinderidquhe die leiftungsfähigiten find, weil jie eben in leidenfdhaftlidjer Eiebe unt rüdzhaltlojer hingabe gezeugt wurden. So entroidkeln fie fid wegen iḩrer gejunden körperiäfte gewöhnlich troł mangelḩafter Pflege beffer und vielveripreḑender als ihre legitimen Stief= gejd̨wijter. Sind fie dann groß geworden, fo vermögen fie if̧ren Eltern eine ganz wejentliḑe Stüge zu fein. (⿹勹nau jo iit's mit der anfangs viel veripotteten Eiebhaberei für fif ḩe oder gar für ḱrieđtiere und surḑe und dergleiđgen, "häßlihes und ckel= haftes Diehzeug" gegangen. Siebe zur Katur hat fie geboren, aber ein erit fpielender und unbeholfen tajtender, dann immer erniter und gemiffenhafter werdender forfąungsorang hat fie grokgezogen.

In ganz ungeahnter weife hat fid mit dem Anwadjien und der weiteren Gusbreitung der Eiebḩaberei namentlid für a us =

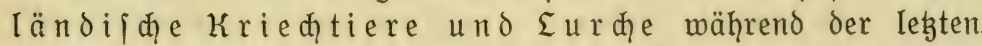
beiden Jahrzę̧nte unjere Kenntnis von der Eebensmeije, der fort= pflanzungsart, den körperliçen und geijtigen fäḩigkeiten diefer jeltiamen und oft jo porjintflutlich anmutenden Eebewejen ver= tieft und ermeitert. Manḑes merkmüroige (நejđ̄öpf, das wir bisher nur aus kümmerliđg̨en Mujeumseremplaren kannten, ḩat jeitoem erit Eeben und farbe in unjerer Doritellung gewonnen. Man darf woh̆l jagen, daß̧ die Terrarienliebḩaberei, wo fie ver= ftänonisooll und zielbemuß̧ betrieben wurde, der wiffenfḑaft

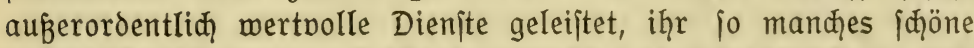

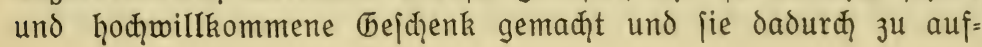




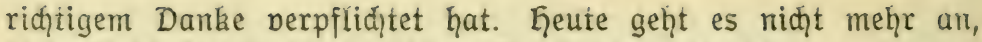
dieje Eiebhaberei als eine blok̂e Spielerei zu bezeiđ̧nen und vom erhabenen Stanopunkte des Tujeumsgelehrten aus verächttich auf

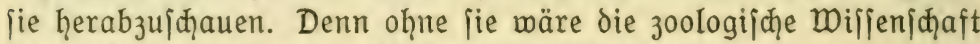
fiđz̧erliđ bei weitem niđ̆t auf dem Standpunkte, den fie heute einnimmt.

Auch iđ ḩabe miđ dem eigenartigen Rei३, den die Terrarien= liebhaberei auf jeden Katurfreund ausübt, niđ̧̨t entzieḩen können. Die woenigen einheimif̧̧en Dertreter aus der bunten welt der Kried)=

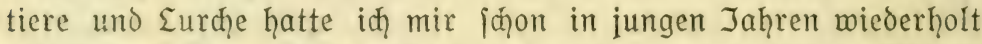

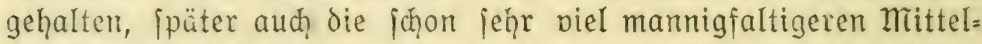
meerformen. Aber zur Galtung von Tropentieren, unter denen wir doç die vollendetiten, jđ̈̈njten und interefjantejten $\mathbb{E} r$. ¡đ̧einungen aus dicjen wärmeliebenden đierklajien zu juçen ḩaben,

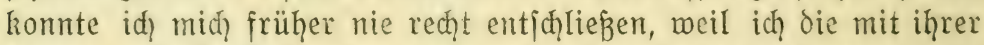

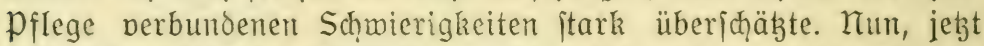
habe id endid den Derfư gemađ̧t und damit cinen alten đraum aus meiner Kindheit perwirkliḑt, und waḩrliđ - id habe es nid̨t zu bereuen gehabt. Wie viei Keues, ungeaḩnt Köjtliḑes gab es doch da zu beobaḑten, und wie gering eriḑien im Dergleiđg dazu die aufgemendete müḩe! zu bejonderen Eieblingen aber find mir dabei die in den wärmeren Striḑen der Keuen Welt heimilḑen und dort in jđjier zaḩllojen Arten allenthalben ḩäufigen Anolis geworden, deren Faltung id jedem Eicrfreund idjon wegen ihrer Anipruḑslopigkeit fehr empfeḩen kann, fobalo er nur überḩaupt in der Eage ijt, ïber cin heizbares Terrarium zu ver= fügen. Es find gar muntere, ulkige und poffierlidje Dinger, diefe

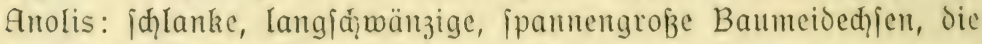
aber vermöge ihrer haftzehen im (万ezweig herumppringen und an den fenkreḑten, glatten (万lasmänden figen wie dic Eaubfröfḑe. Dabei bewegen fie die mit viel zu großzen sidern veriebenen, red)t ¡đ̧arffid̨tigen Augen unab̧̧ängig voneinanter wie cin đhamäleon, mit dem fie aud ein ganz grobartiges, ourdy die Sdynelligkeit des Dorgangs oft geradezu verblüffendes farbwedjiclvermögen ge= meinfam haben. Ihr ganzes (bebahren hat etwas unverkembar Dogelartiges, aber ber fladze, breite, langgejtredite kopf mit den

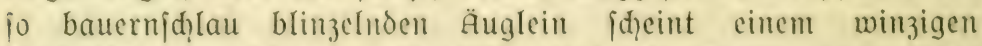
krokodil anzugehören. Jedenfalls find die Anolis trołz ihrer 


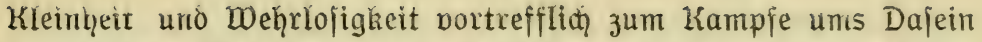
ausgerüptet. Mit dem einen Auge beobahten ie die am Boden krieḑende Raupe, mit dem anderen die an der wand pazierende fliege, und eines bon beiden erḩajhen fie finger, denn kein Sprung ijt iḩnen zu weit, keine fläđ̧e zu glatt. Denigitens bei einigen Arten ¡đ̧eint beim Injektenfang aud die 3unge als Eeimrute, an ber das Opfertier kleben bleibt, eine Rolle zu \{pielen, obmohl fie mur wenige Millimeter weit aus dem rofenroten, breitmäuligen Raḑen hernorgejọleubert werden kann. Aljo aud in diejer Be=

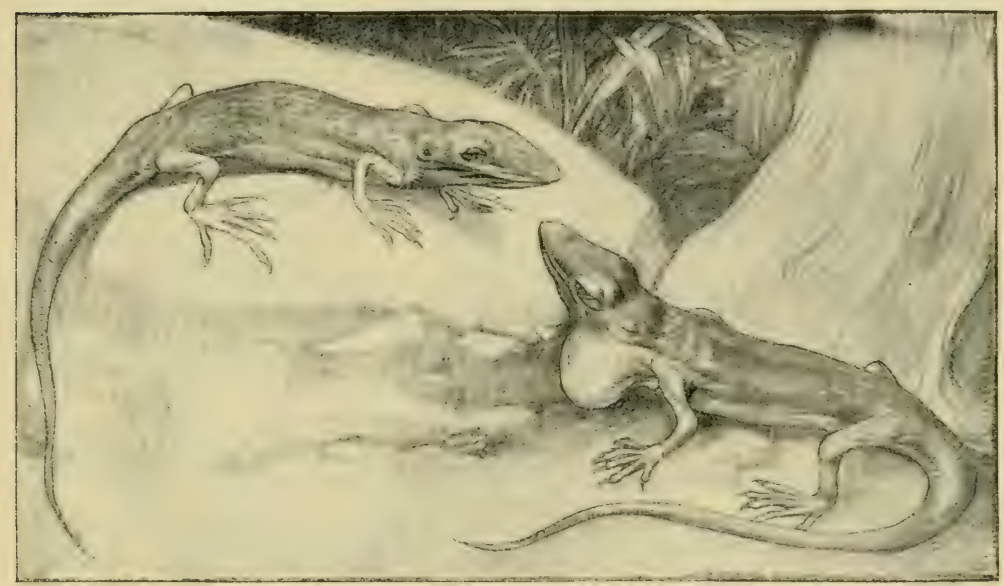

$a b b$ 1. Anolis, cine für Amerika ḑarakterijtifḩe Eḑiengattung mit verblïffendem faro: medfielvermögen, Gaftzehen uno aufipreizbarem Kehliack.

zieḩung wieder eine auffallende übereinjtimmung der jierliḑen Anolis mit den grotesken đḩamäleons. Unter jiđ̆ gejellig, find die Anolis doch gleidyzeitig arge Raufbolde, uno namentlich die männḑen jagen jiø̆ fortwähreno gegenjeitig herum. Kach zaḩ $=$

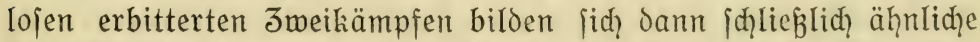

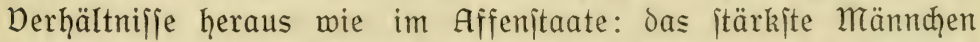
führt eine geitrenge Enrannis, betrad?tet die fetteiten Biffen und die ¡đ̈̈njten weiber als jein jelbjtweritändiches Eigentum und

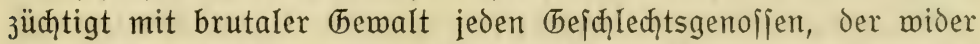
den Staçel zu lecken magt. Kamentliḑ zur paarungsjeit, wo die weibḑen ledigliđ ruhige 3uf̧̧auer abgeben, ift's oft grimmiger 
Ernjt mit diejen Kämpfen, und die eiferjüळ̧tigen Männđ̧en Iaufen dann mit blutig gebifjenen Sł̧nauzen auseinander oder fie ftürzen, zu einem wirren Knäuel geballt, bom Gezweig auf den Boden. Den Sđlwanz, der nur unvollkommen wieder nađ̧wäđjt, brechen fie

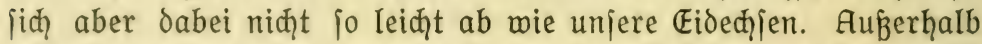
der paarungszeit tun fie fich trob aller jheinbaren wut gegen= jeitig niळ̧t gar viel zuleide, und dieje Duelle wirken desḩalb

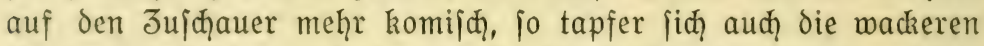
Kämpen gebärden und fo gut jie die Geldenpofitur anzunełmen wiffen. nit einem drohenden Abplatten des Eeibes, grimmigem Kopfnidaen und dem Aufblajen der Kehlwamme wird das Duell eingeleitet. Um ein eigentliđes Aufblajen des Kehliadres, wie es bei fo vielen anderen Reptilien vorkommt, handelt es fich dabei allerdings nid̨t; er wird vielmehr durd) das aufipreizbare Jungen= bein fächerartig in ganz eritaunlichem Maßze flad ausgedehnt und nimmt dabei zugleid eine wunderbolle färbung an - blutrot oder himmelblau, oder moosgrün, je nad der Artzugehörigkeit des kampflujtigen Tieres. Aber aud am übrigen Körper ift deffen farbe auß̧erordentlichen Deränderungen unterworfen. In den kühlen 2Torgen = oder Abenditunden drücken fich meine Anolis, die über= haupt nur bei freundrigem Sonnenjhein die ganze Munterkeit iḩres anziehenden Wejens entfalten, diḑ̧t an einen \{ḑräglaufenden Ajt an und erjđeinen dann rotbraun, ja bismeilen (bejonders ment fie fiđ̆ nid̨)t wohl fühlen) miß̧farbig graubraun. Wird es aber heller und wärmer im Terrarium, fo hellt fid ihre farbe auf, erjąeint bismeilen mie mit bläuliḑem Reif überḩauḑ und wiro (d) lieflid) herrlid) blattgrün oder gar leuḑtend gelbgrün, fajt

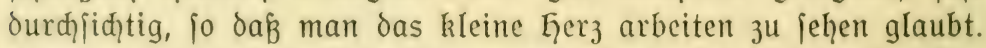
Dazu die blutrote Keḩlmamme des Männd)ens! Bei manḑen Arten gefellt fiç zu der (brundfarbe nod mannigfaltige Bänderung und एüpfelung, bei anderen tritt wenigitens cin türkisblauer fledi in ber Adffelgegend auf, und nody andere find an der Sdywanz= wurzel mit einem anfrid)tbaren, alleroings niḑt fonderlid hohen Gqutramm gefḑmüdit. Wenigitens zum Teil ift all diejer farben. wedjel fidęerlid) ein unwillfürrlider, aljo niḑt dem Belieben des Tieres anheimgegeben. Es geht dies idqon daraus hervor, dak die beim Sḑlafen auf Blättern nađ)ts grünen Anolis unweigerlid) braun werden, fobald man mit der Sampe hinzutritt, aud dann, 
menn fie den Beobađ̧ter gar niđ̧t bemerken, aljo niđ̧̧t aufwađ̧en,

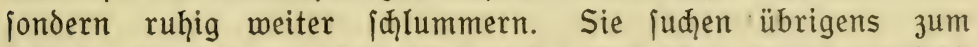

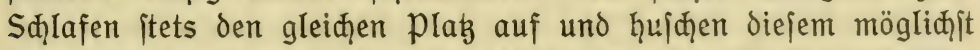
unvermerkt mit der gleiđgen Eautlojigkeit $3 u$, die alle ił̧re behenden Bewegungen au历̆ am 『age auszeiđ̧̧net. Wäḩrend 3. B. Der im Süden der Dereinigten Staaten und auf Kuba ungemein häufige

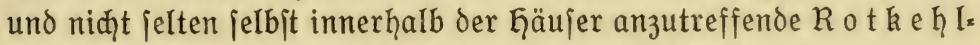
anolis (Anólis carolinénsis) zwei Eier legt, die er ohne alle Dorkeḩrungen fajt an jedem beliebigen Drte abjebt, haben एerrarienbeobađ̧tungen gezeigt, onß̧ andere Anolisarten lebende Junge gebären. So wurbe Schmiot ourd feine Anólis cristatéllus mit ganz entzüđkenden Kinderḑen erfrcut, die glänzend hellbraun waren mit weißem Rülienjtreif und nadeldünnem

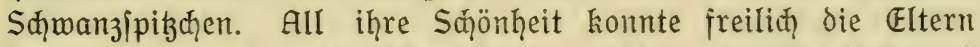
dod niḑ̧t von kannibalifḑen Gelüiten abḩalten. Blattläuje und fliegen winzigiter Art bildeten bie Kaḩrung der nieóliđhen Kleinen.

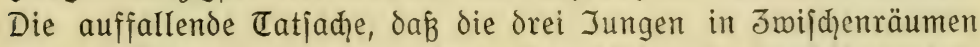

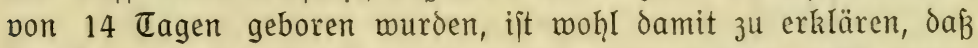
die bei der Begattung eindringenden Samenkërper niḑt gleid)= zeitig zu ocn Eiern gelangen, fondern die hinten liegenden erit ipäter befruđ̆ten.

Bekannter als bei den Anolis ift der farbenmedjel bei den C ḩ a mäleons, diejen vielleid)t abenteuerlidjiten aller Reptilien, die ja eben wegen diejer Eigeniđ̧aft geradezu ipriđ̧wörtliḑe Bedeutung erlangt haben. Die "Krone der Reptilien" haben begeifterte Krieḑtierfreunde fie genannt, und in der Tat haben wir in diejer etwa 90 Arten umfaffenden familie moḩ die jeltjamiten und intereffantejten, aber aud die unbeholfeniten und nervöleiten Krieḑtiere vor uns. Die "faultiere des Reptilien= reiđ̧̧es" könnte man jie mit gleiđḩem Reç̧te nennen, denn wie bei jenen übel beleumundeten Säugern ift auđ̆ ił̧r ganzer Drganismus in der einjeitigiten weife dem bejđ̧auliđgen Eeben im grünen Blättermeer angepaß̉t. Kur daß̉ iņnen die Kaḩrung niđ̧̧t ins Maul ḩineinwäđjit, fondern aus einiger Entfernung erjagt werden muß̧, wož į̧nen die Katur die bewegliḑen Augen und den treff= jiß̨̧eren Jungenlafjo verlieḩen hat. Aber mit Derteioigungsmitteln

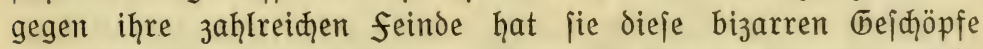

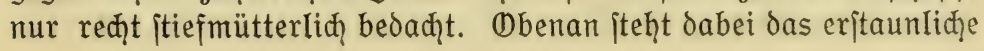




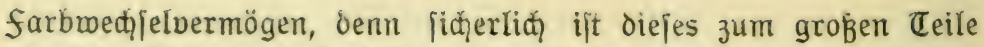
als Schubfärbung aufzufaffen, womit keineswegs gejagt werden

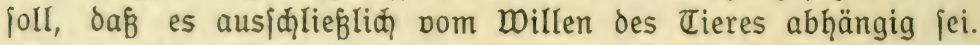
"Ein gefehenes Chamäleon iit ein perlorenes Thamäleon", fagt ganz riđ̧tig ein altes ipanifđ̧es Spriđ̧wort. Es geḩöt in der

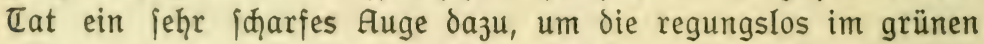
Eaubwerk fighenden und gleiđgfalls meḩr oder minder grün ges färbten Tiere zu entoecken. Und eine gemilfe fähigkeit, fiđ einigermaß̧en bewuß̧t der färbung der Unterlage und Ümgebung anzupaffen, fđ̧einen fie doch, ebenjo wie die Anolis, зu bejigen. Daneben fpielen aber auch wärme und Sonnenbejtraḩlung eine großße Rolle, und die Umfärbung ift desḩalb teilmeife aud als Wärmeregulator aufzufaffen. So werden einige zeit ḩindurd grö̈erer hige ausgejegte Thamälcons unmeigerlid hcllgelb, wie ja überhaupt viele efdifen in der wärme liđhter werden, indem Grunsfarbe und zeiđģnung gleiđzeitig jiđ aufhellen, jo bei Euméces, Taréntola, Uromástix, Phrynosóma u. a. Auffalleno wird der farbwechjel jedoch erjt dann, wenn jiđh (brundfärbung und Jeiḑnung dabei veriḑieden verḩalten, wie es 3. B. bei Anólis

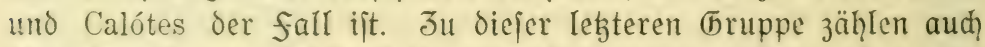
die Cḩamäleons. Diefe biloen jedod in iḩr gewiffermaß̧en eine klaffe für fid, wegen der auß̧erordentliá) groß̧en zahl und Mannigfaltigkeit der mögliḑen Limfärbungen, wenn dieje aud] eine gewiffe Regelmäß̧gkeit erkemmen laffen, da fie nađ̧ den forgfältigen Beobaḑtungen de Grijs in einer bejtimmten Reihenfolge immer

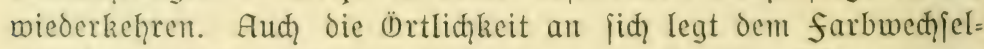
vermögen eine gewiffe Bejđ̧ränkung auf. So können aus vegetationsarmen (begenden itammende Thamäleons niemals ¡đ̆̈̈n blaugrün merden. Merkmïroig ift es aud, daßj bei kühter Temperatur von ber Sonne getroffene Stellen fajt vöIlig fdịwarz werden. Als britter faktor kommt mun nody die gerabe bei den

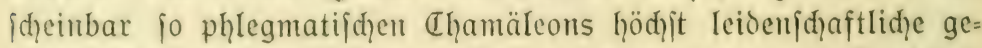
iḑleḑtliḑe Erregung hinzu, die zur Bildung der brillantejten Sd̦̣mudifarben bei den brünftigen Männḑen füḩrt. Dieje find an

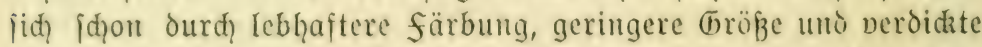
Sd̨̧anzwurzel volt den Weibḑen verjđ̧ieden, wie ja überḩaupt

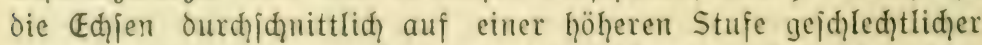
Differenzierung ftehen, als etma bie Sḩlangen. Allerdings be. 


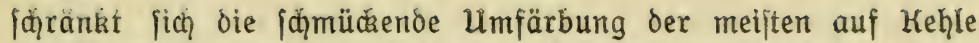
und Baud, weil eine zu lebhafte färbung der Dberjeite in uns liebjamer weije die Aufmerkjamkeit der in der Euft jhmebenden Raubvögel erregen müp̂te. Im engiten Jujammenḩange damit

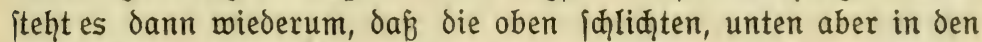
lebhajtejten farben erjtraḩlenden männchen durch eigenartig nickende oder wippende Bewegungen die Aufmerkjamkeit der weibđhen auf iḩre ḩalb verborgenen Reize zu lenken juchen.

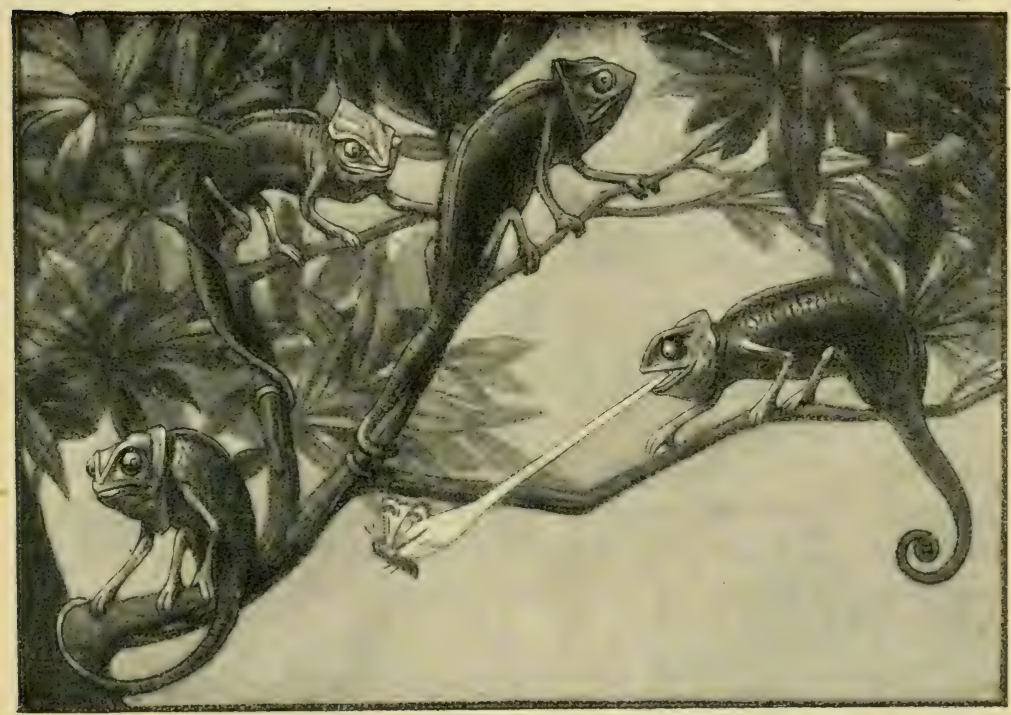

Abb. 2. Chamtäleon, faul und bequem, mechjelt die farben in allen Tönen von weí̉ bis ¡đ̆warz und fängt mit weit ḩervorį̧nellender 3unge die Beute.

Wir brauchen audh in diejer Bezieḩung nur wieder an die Anolis zu denken oder etwa an Agáma inérmis mit iḩrer praḑ̧t: voll blauen Kehle. Bei dem den jüßlid̨en mittelmeerländern angehörigen Chamáéleon vulgáris vertiefen fiđ bei ge=

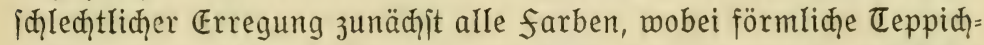

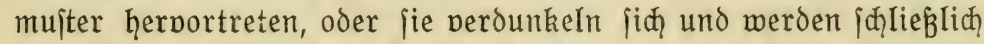

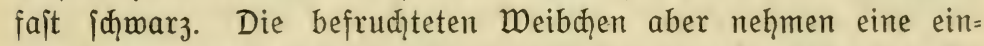
tönig iđ̆warzgrüne färbung an und beḩalten dieje bis zur $\mathbb{E} i=$ ablage fajt unverändert bei. Durch viel leudhtendere Kontrajte 
und einen in ber Erregung geradezu rapiden farbenmectiel

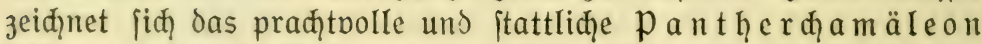
(Ch. pardális) Madagaskars aus, auf meldẹer zoologifø fo merkmüroigen Injel diefe eigenartige Edjenfamilie überhaupt zur üppigiten Entfaltung gediehen ijt. Das äußzerit nervöje und leid)t erregbare Tier crjheint bald einfarbig grasgrün, bald ebenjo mit gelben Punkten oder braunen fledien oder id̨warzen Queritreifen, bald \{apwarz mit leuditend hellgelben oder weifen oder himmel= blauen Binden, bald wieder jitronengelb. Ein ebenjo wundervolles farbenpiel hat das großze (etma $60 \mathrm{~cm}$ lange) Ch. méller i auf= zumeifen. Sdjlafend erf̧̧eint es rejedagrün mit dunkelgrünen ¿uberkeln und nur (đె) ad angedeuteten gelben Binden. Im wadien werben dieje nah den Aufzeid̨nungen Bergs beiler und ausgedehnter, die Grunofärbung ounkler, und gleichzeitig treten helle Nesfledze und fdiwarze Tupfen auf. In der Erregung ourd)= läuft die Grundjarbe alle Abtönungen bis zu fajt völligem Săbar\}, die Tupfen und Keţfledie verfđ̧winden, aber die Tuberkelfledie bleiben und werden weib, die Binden treten jđärfer hervor und leuditen in grellem Gelb. Dieje färbung ijt bei Angit und Ärger vorherrjąend, während das liebestolle Mämnchen fait weib aus= fieht mit grofen jąmarzen đupfen und jojarf abgejesten gelben Binden. So gefärbt, gemährt es einen geradezu jagenḩaften An= blidz, wenn es fid nun zu ciner riefigen ovalen Sḑeibe aufbläht, die Ginterhauptslappen wie ein wütender Elefant [enkred)t jum Kopfe ftellt, fid mit weit aufgeiperrım Radjen faudiend und zijḑend auf delt itrammen Ginterbeinen erhebt, die Dorderbeine aber wie bittende Gände dem Beobađ̆ter entgegenitredit.

Aud) das fonjtige phlegma der chamäleons exiḑeint mähreno der paarungszeit völlig perfđ̧wunden. fajt wiejelartig flink remen

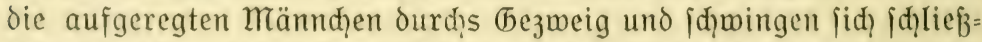
(id) mit eritaunlicher (bemandtheit auf den Rüdien der auserkorenen, anfangs heftig mideritrebenden Weibdyen, an denen fie fid) nur mit i̧̧ren kräftigen (breiffüßen feitḩalten, niḑt aber nad Art anderer Edjpen mit dem Maule in Madzen fejtbeifen. Matürlid] gibt es unter den Männḑen aud Eiferfuḑtskämpfe, und fie zeigen dabei ebenfalls eine ganz ungewohnte Ģurtigkeit. Es wiro bann tïđ)̧tig geknurrt, gefaud)t, gelirałt und gebiffen, hauptfäd)lid aber gebort, indem fid\} die (5egner mit wuḑtigen Kopfitößen traktieren, deren 


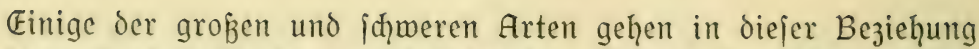
fo meit, daß̧ fie den zu bejteigenden Aft erjt forgfältig mit der

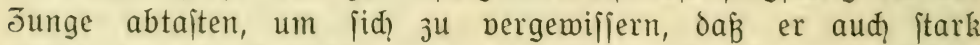

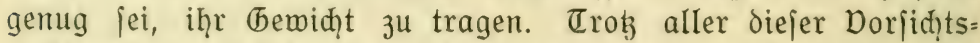
maß̧regeln verfieht's aber bisweilen jogar ein chamäleon und jaujt dann aus luftiger Göhe zum Boden herab. Das jąadet iḩm freilid niđ̧t viel, denn bas fonjt ziemlid empfindiḑ̧e एier kann in biejer Beziehung iđłon einen guten puff pertragen. (beifen= henner erlebte es, daßj eines feiner auf offenem Balkon gehaltenen Chamäleons $5 \frac{1}{2} \mathrm{~m}$ tief abjtürzte, aber nađh ađ̧t एagen woḩ genährt im angrenzenden Bohnengarten zum großßen Sd̨redien der Kaḑbarin aufgefunden wurbe. Jum Sąlafe pflegen jiđ die Thamäleons mit gejenktem Kopfe, jeitliđh zujammengedrücktem Körper und hod gemölbtem Kagenbudkel auf einem Aite nieder. zukauern, wobei der breite Sđ̧wanz feitlid ḩerabḩängt, aber in peiner Endhälfte jtramm zu der üblichen Spirale aufgerollt ijt. So erpiđ̧t die एiere aud auf die fliegenjagd jind, fo menig find iie ood aud hiierbei freunde überflüffiger Kletterbewegungen. Eieber vollfüḩren fie mit dem Körper die unglaublidjten Der.

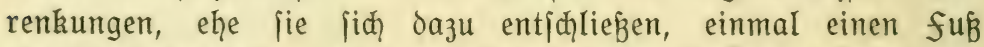
vorwärts zu jegen. Ihre Jagomethode iịt der Anjtand, und fie entwickeln dabei die ganze Ђeduld des geiđulten Jägers, der

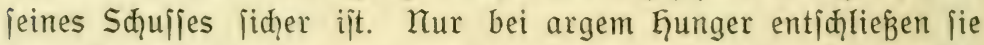
jich, aud mal ein menig auf die pirjळ zu gehen. Thre flinte ift die merkmüroige, weit hervoriḑnellbare Junge (Ch. mélle ri

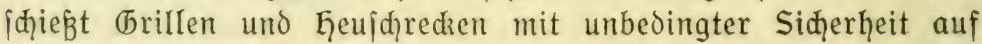
$30 \mathrm{~cm}$ Entfernung!) Diejes (Drgan arbeitet in der एat mit der Sḑ̧nelligkeit uno Juberläjfigkeit eines präzifionsgemehres. Die bisḩer unab̧̧ängig poneinander nađ̆ veriđ̧iedenen Seiten bliđaenden Augen werden jeל̧t beide auf das eripähte Beutetier eingejterlt und rollen in freudiger Gier immer rajḑer, bis die Entfernung genau abgejđägt ift. Dann fliegt wie ein unbermutet ge= iḑleuderter Eaffo die 3unge heraus, und mur felten verfehlt fie ił̧r Jiel. Das futtertier wird an dem kolbig verdiditen und eigentümlid klebrigen Jungenende angeleimt und daun bie Junge jo fabelhaft rajd wieder ins Maul zurüdrgezogen, daß̧ man den ganzen bliţiḑnellen Dorgang kaum mit dem Auge zu verfolgen vermag. Der Sđ̣uß̧ erfolgt mit großger thewalt, ift mit einem 


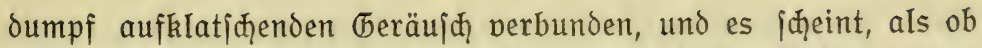

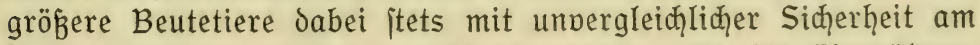
Kopf getroffen und fofort betäubt würden. Da die Chamäleons aud in freier Matur ziemlid gejellig leben, kommt es niđąt felten vor, daß̧ zwei fajt gleidzzeitig iḩren Jungenlaffo nađ berjelben

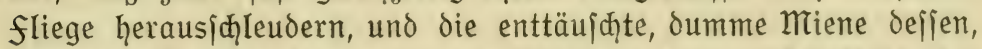
dem jein Kađb̧ar den erję̧nten Bifjen gerade nor der Kaje oder vielmeḩr vor dem Jungenende megidjoß, wirkt dann waḩrhaft tragiḱmilø. Im allgemeinen beborzugen die Tḩamäleons kleinere,

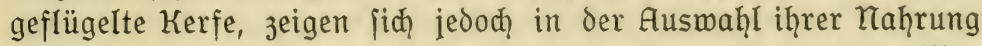
ziemlid) Iaunenḩaft und find jeoenfalls freunde einer gewiffen Abredjilung im täglichen Speijezettel. So Kam es den Chamääleons

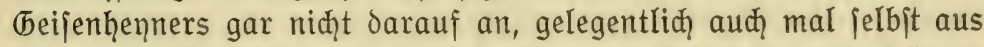

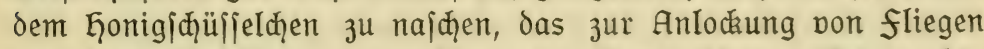
in ił̧rem Beḩälter aufgejtellt war. Die größeren Arten aber

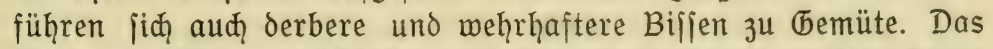

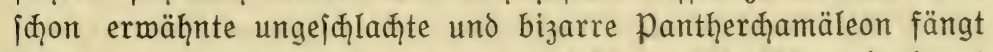

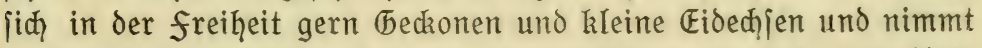
in der (befangenichaft audj mit jungen Mäujen vorlieb. Im Kote tunejifher chamäleons ḩat man jogar Rejte von Skorpionen ges funden, denen aljo dem fajt unfehlbaren Jungenlafio gegenüber

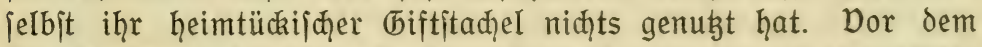
Deriḑluden wird die Beute erit zerkaut, etwa widerwärtig Sḑmekendes aber mit allen Anzeidyen des Abiḑeus wieder auss geipien und io leidht nidjt wieder aufs Korn genommen. Dies gilt bejonders von den Eaufkäfern, wie überḩaupt ḩartflügelige

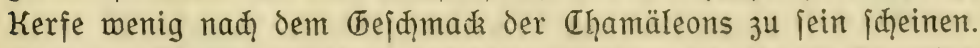
Gud ins wajfer gefallene Injekten veriteḩen fie, die im Gegenjag

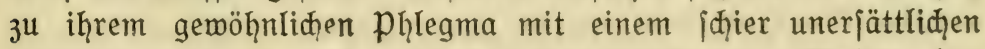

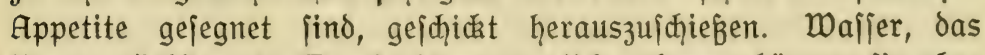
fie am liebjten in Tropfenform zu fiø neḩmen, können fie aber nod weniger entbeḩren als futter. Tamentlidy von dem jüb= afrikanifhen $\mathrm{Ch}$. basilissus, deffen Männđ̧en der Befib von ferjeniporen auszeiđanet, ijt es bekannt, daßj er ourch förmliḑes

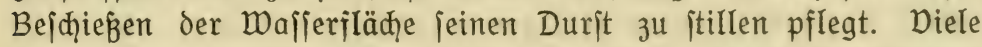
Thamäleons trinken aber unter pumpenden 3ungenbemegungen

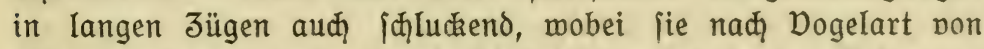
3eit zu 3eit den Kopf in die Ģ̈̆he ḩeber. Da bei der Maḩrungs. 


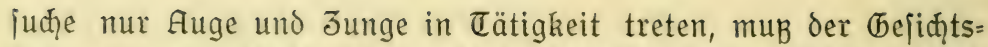
firn gut entwidelt fein, und in der Tat hat v. fijher ourch Derjuche fejtgejtellt, daß̧ eine fliege auf etwa $90 \mathrm{~cm}$ Ents fermung mahrgenommen wird, freilid) nur bei Somnenjhein, da wegen der winzigen siofpalte nur hell beleuđhtete (begenitände

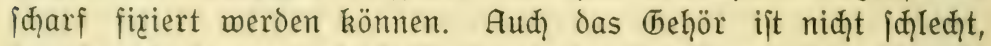

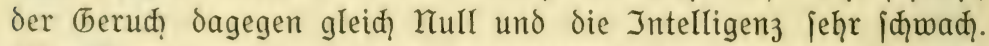
Alle chamäleons find echte Sonnentiere, die wärmenden Somnen= jąein fajt ebenjo nötig haben wie die suft zum Atmen und ohne ił̧n in kürzejter frift elend verkümımern. Das für das woh̨l=

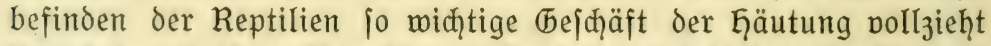
(iic) bei gejunden Chamäleons ebenjo wie bei den Anolis mit

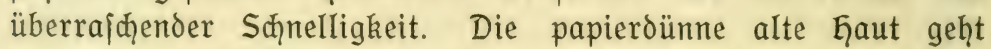
in groß̧en fegen $a b$, mobei nötigenfalls nod mit dem Ginterfuke nađ̆geholfen wird, und die frifhen Gautitellen jđimmern dann prađ̧tnol! wie köptlicher Samt. Die Chamäleons find niđ̨t nur völlig harmloje, fondern jogar re⿻̧一t nügliđ̧e Tiere. In manđen

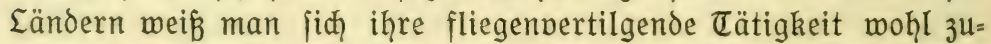
nuge zu mađ̧en. So $\{a h$ id in den mit Bäumen und 3ier= iträuđ̧ern ausgejtatteten Innenḩöfen der arabijd̨en Giäujer Süd. marokkos häufig Chamäleons, die dort als lebende flicgenfänger gute Dienjte leifteten. Solange das daneben aufgeitellte Gonig= ¡đäldhen nur fliegen in genügender 3ah̆l herbeilockte, fiel es iḩnen gar niđ̆t ein, den iḩnen zum Aufentḩalt angemiejenen Straud zu perlaffen, und mit der 3eit werden fold\}e Tiere fogar bis zu einem gewiffen Grade zahm.

Derweilen wir gleiđ, nod ein wenig länger bei den bizarriten und merkmürdigiten Erjßgeinungen aus der Edjiengruppe, und menden wir zu diejem 3wedke unjern Blida in நedanken nom Sđ̧warzen Eroteil weg und zum fünften, der ja überhaupt jo reid, ift an abjonderlidien Tiergeitalten! Dder kann es etwas Auffallenderes geben als eine grobe (Fidedje, die mit fabel= hafter Sdynelligkeit aufreḑt auf den Ginterfüßen einḩerläuft, fo die uralte Dermandjąaft zwijđen Reptil uno Dogel nod heute verkündigend und vielleid)t gar ein fidheres Sid)t werfend auf die ber Wiffenjđ̧aft nod) rätjelhafte Bewegungsart manđher aus= geitorbenen Dinofaurier, insbejondere ber zierliđ gebauten Compsognáthus. und Stenopélix-Sormen? Saville=Kent hat diejen 
von früheren foriḑern ftark bezmeifelten vogelartigen Gang

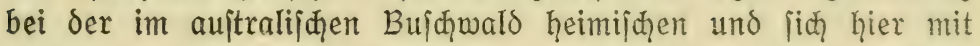
Dorliebs zwijd̨en dem Wurzelwerk groß̧er Bäume herumtreiben= den Kragenedife (Chlamydosáúrus kingi) jiđher fejtgeftelit und

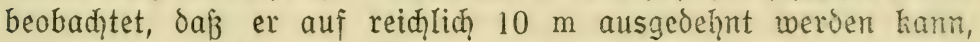
und dá̉ das Tier jeinen langen Sđ̧wanz dabei niđ̧t etroa als Stügorgan benügt, fondern iḩn im begenteil நod̦trägt, wie

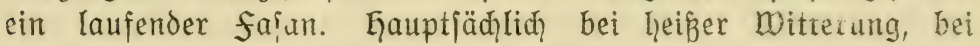
zorniger Erregung oder eiliger fluḑt maạt es von diejer jef̧r

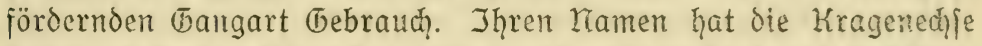

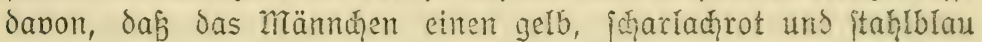
gefärbten Stuartkragen befist, der gewöhnlid in anmutigen faiten an Gals und Schultern anliegt, in der Kamplftellung aber woie

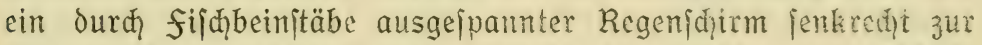
Körperadje ausgejpreijt wird. So dient er niât nur als Sąils, jondern audh als Sd\}reckmittel, indem aus jeiner mitte bas orohgnd geöfnete maul heransfhrout. Das kleine Shenjal zeigt

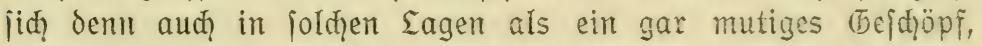
nimmt fo leiḑt niḑt Reibaus, geht vieimeḩr einem furbittjamen begner fofort angrifissoeife $z^{u}$ Eeibe.

Äḩnliđ treibt's die Bartagame (Amphibolúrus barbátus), bei der der fluḑtinitintit geradezu auffällig gering ausgeprägt ift. Das etwa halbmeterlange, auf trodkenes und fteiniges Geläitoe bejdiränkte Tier befigt einen enornt entwideiten, durd cinen eigenartigen Meḑanismus des Jungenbeins gewaltig aufblähbaren Kehliack, mit dormenartig ausgezogenen Sçuppen bejegt. Auigeblälit erinnert er ftark alt einen red) jtruppigen Dolibart und hat dahiger dem intereffanten 区iere bei den auftralifhen Anfiedfern zu dem Tamen "Iudeneidedjie" verḩolfen. Es fieḩt mirklion rent cin=

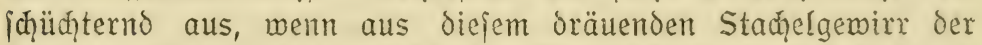

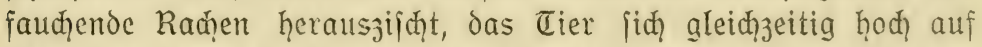
alle vier Beine ftellt und den Körper derart zu einer flaḑen Sḑeibe abflađ̧t, daß̧ man meint, er jei überfahren over platt

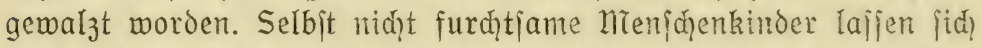

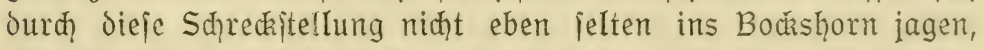
obmohll fie eigentfich nidits als eine leere Droḩung ift, oa das

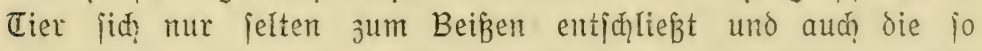

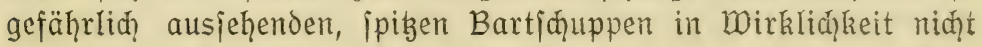

floeriđa, krieđ̧tiere und Eurđ̧e frember Eänder. 
hart, fondern weiḑ und elaftifh find. (bewöḩnlid läuft die Bartagame, die Klingelhäffer mir brieflid als eine der intelli=

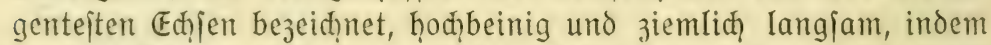

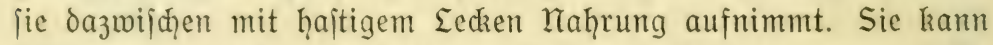
aber auch kurze, frojđ̧artige Sprünge vollführen, worauf fie

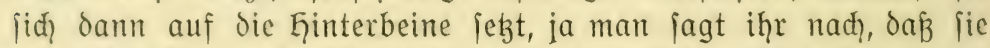
wie die Känguruhs if̧rer heimat nur auf ocn Ģinterbeinen zu hüpfen verjteḩe. Indes ift das nod niąt genügend fiḑer fejt= geftellt. fait nod) abenteuerliḑer als bie beiden geiḑilderten Arten mutet der wejentliø kleinere, von dräuenden Staḩeln itarrende Molody (Nóloch hórridus) an, der "Dornteufel" der aujtralif̧en Anjicoler, wohl eine ber bizarriten Erjdyeinungen aus der Tierwelt überḩaupt. Über und über ift der odkergelb und ¡đ̨̧warzbraun gezeid̨nete, übrigens reḑt träge und langmeiligs Buridge mit zwar harten, aber niḑt völlig fteifen Staḑeln bededit, jogar an ben Beinen. Aber fḑon jeine unab̧̨ängig voneinander bemegliḑen, gutmütigen Äuglein jtrafen biejes furḑ̧termedienoc Ausfehen Eügen, und in Wirkliḑreit vermag er megen feincs kleinen Maules niḑt cinmal in den finger 3 beifen.

Da ift dic ftattlidje, fajt meterlange, regiante wafler=

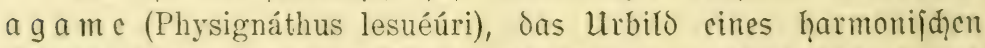

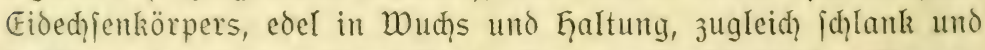
Iräftig, cin gantz anderer Kerl. Jhren wiffenfhaftlidęen Kamen, der foviel als "Kraftriefer" bedeutet, füḩrt fie niḑ̧t umionit, denn ein Stüdz Radiergummi beißst fie ohne weiteres durdy. Der hod) getragene kantige Kopf mit den mäđţtigen Kiefern und den Klug, lebensfroh und rampfesmutig dreinblickenden Augen gibt iḩo ein imponierendes Ausjeḩen. "Wenn fie mit aufgeriḑteten Dorberbeinen", fo iq̧reibt mir klingelhöffer, "auf cinem Ait

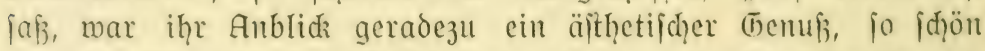

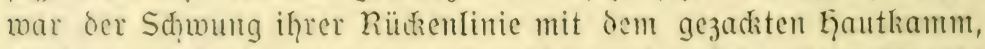
jo harmonifक die im lang herabhängenden Sd\}meife endigende (5)ejtalt." Dabei ijt namentlid) das Mämnḑen, defjen Baudjeite

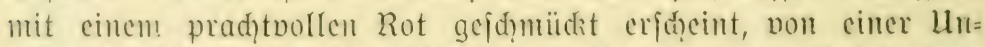
ruhe, Rajtlofigkeit und Eebhaftigkeit, die fid) mur mit der eines Dogels vergleidgen läp̧t. Im Jorn bliz̧en jeine Augen wie die cincs AdTers, und das ganze eier erimnert damm fo jehre an die fabelgejtalt der jagenumwobenen Draḑ̧en und Eindmürmer, wie 


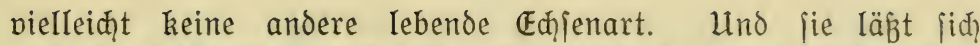

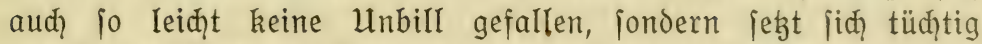

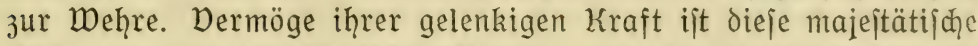

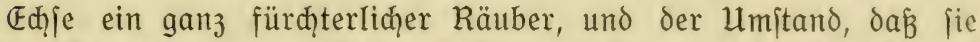
im Terrarium gern Eier und Iungvögel veripeift, läß̧ darauf

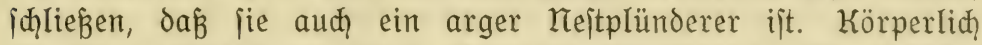
iit fie vorzüglid зu iņrem (bemerbe ausgejtattet. Die mäđ̧tig entwickelten Ginterbeine ermögliç̨en ih̨r gewaltige Säze, wobei

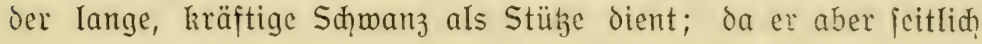

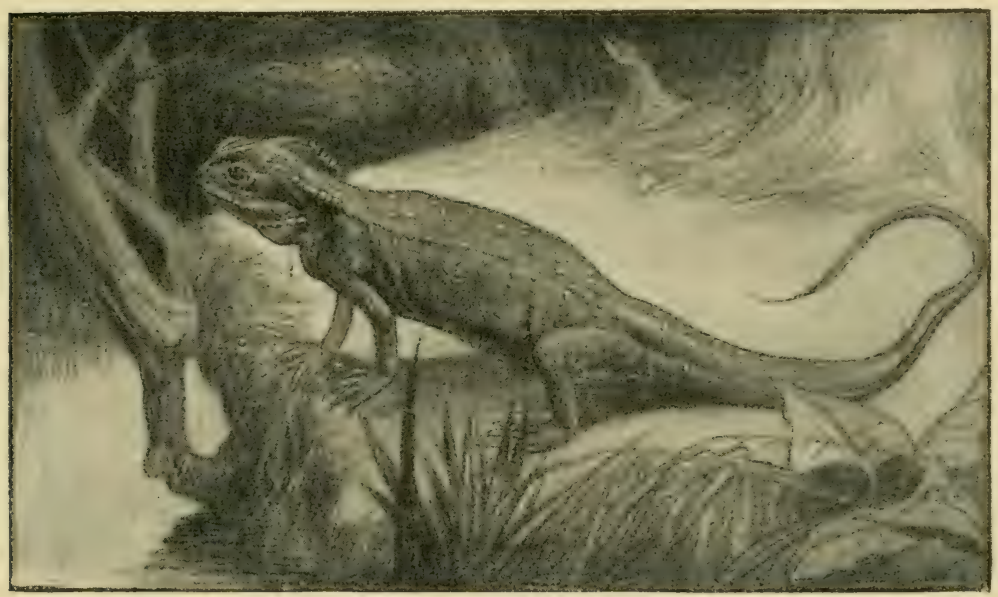

Ab৮. 5. Wafferagame, fajt meterlang, hat ein kräftiges (bebíb, lebt auf Bäumen und int waffer.

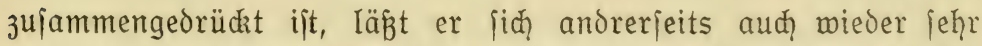
gut als Steuerruder im Waffer vermenden. Ebenjo veritę̧t fid? die Wafferagame gut aufs Klettern. (நemöḩntiđ̧ läuft fic hod)=

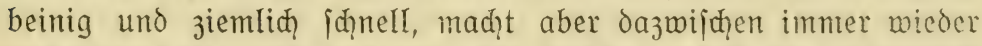

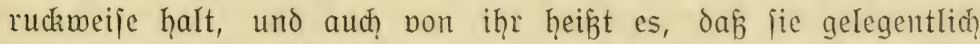
aufreçt auf den Ȩinterbeinen gehen oder fpringen köme. J J hr an und für fiø wildes und ungeitümes Temperament wird durd? cine gewiffe Intelligenz gejügelt. Eigentliḑ ein Baumtier, flünţtet die Wafferagame bei (befaḩr doch mit Dorliebe in das feuhte

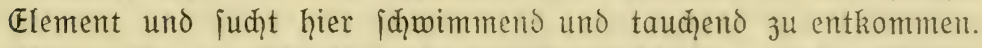
Aber aud zum Gbḩalten iḩrer Siejta fuḑt fie gern das waffer 
auf und liegt hier ganze Stunden fajt regungslos mit unter. getauḑtem Kopfe, ohne daß̧ man bisher reḑt weiß, woher fie eigentlid! wäḩrendoem den zum Atmen nötigen Saueritoff bezieht. So ftellt fid die "Waterlizard" gewiffermaßen als das Amphibium in der grogen Eruppe der Agamen dar.

Eine weitere feltiame Edjie Gujtraliens ift die $1 / 3 \mathrm{~m}$ lange,

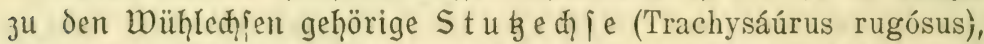
cin träges Tier von Tannenzapfengeitalt mit äuß̧erft didkem und

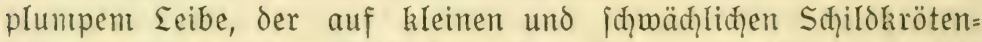
beinen ruḩt, mit auffallend großen Sḩuppen und einem wie abgehadat ausieḩenden Sdzwanze, der namentliđ bei den weibd̨en iehre didz und kurz ijt. Die fortbewegung ift nur ein idjwer= fälliges Krieđien, wobei ocr feifte Bauth fajt auf der Erde jळhleppt

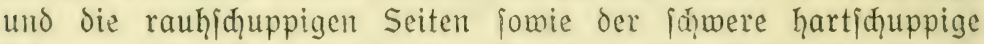

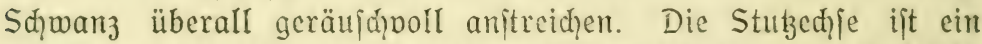
ausgejprodgener Allesfreffer mit einer gewiffen Dorliebe für jüße

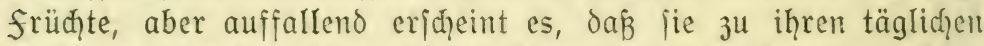
Maḅlzeiten audh erbjen= bis bohnengroßge Steindyen in foldyer

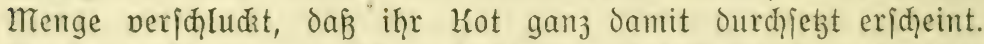
Es kann bies unmöglid auf blöem jufall beruhen, fondern

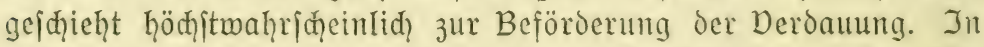
geringerem ntaß̧e finden wir ja die gleiḑe Erfḑeinung bei zahl= reiḑen anderen Edjien jowic bei viclen Dögeln, und aud] ḩier haben wir wieder ein wertnolles Seitenitüdz zu den ausgejtorbenen Riejenedgen bor uns. fano man bod\} bei einem prefiofaurus niḑt weniger als 20 siter apfelgroß̧er Steine! Selbjt beim frejien, das dod jonjt die ftumpffinnigiten Tiere in Erregung

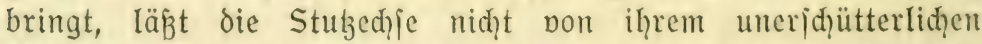
phlegma. Thur wie widerwillig öffnet uno iđ̧ließt fie langjam das Maul, und es paffiert iḩr desḩalb gar niđ̧t jelten, daß̧ gewandtere Beutetiere ihge nodh im Iegten Augenblidie entrommen.

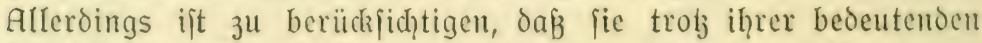
Kieferkraft glatte Biffen mit ił̧en ftumpfen Kegelzäh̆nen mur

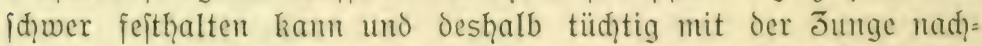
helfen muß̧. Die einzige Derteioigungswaffe des harmlofen (h)e=

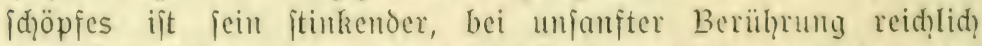

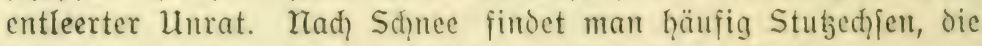

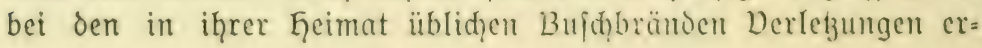




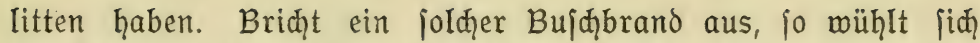
das Cier nur fo meit in die Erde ein, daßj die kleinen Beine und das (bejiḑt gejdüubt find, und läß̧t nun das feuer ruhig über jich hinwegrajen: die ungemein didken Ģornplatten der Dberjeite

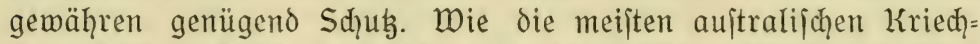

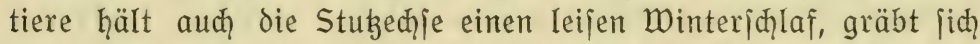
bazu aber niḑt in die Erde ein, fondern in den vermodernden mulm abgejtorbener Baumjtämme, da namentlid, das weiđge

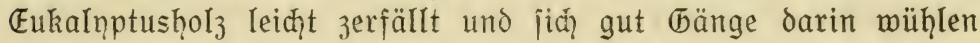
lafien. Thre Epidermis ftreift die Stugeḑje bei der Ģäutung niđ̧t in feken, fondern in theitalt eines ganzen hembes $a b$, wie die Shllangen. Sie ijt in höherem Grabe vivipar als andere Edijen, da die zwei bis orei Jungen oḩne Eizahnn und ohne jekundäre Eiḩaut zur welt kommen - Ein in jeiner Art ebenjo inter=

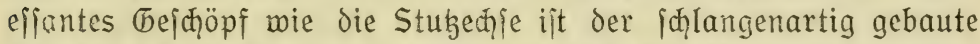
floffenfúb (Pygópus lepidópus), dem die Dorderbeine pöllig feḩlen, währeend die zu beiden Seiten der Afteripalte befindriđ̧en Ęinterfüpe zu $1 \mathrm{~cm}$ langen, flađjen, flofjenartigen (bebilsen ver= kümmert find. Jum beḩen kömen dieje flofjenfüße natürlid, nid̨̧t verwendet werden uno werden desḩalb gewöhnnlid glatt angelegt, ipielen aber waḩriḑeinlid bei der Copula eine Rolle. Sonft pereinigt der aud in Keuguinea vorkommende floffenfup in feinem Körperbau Charaktere der Geckonen, Warane und

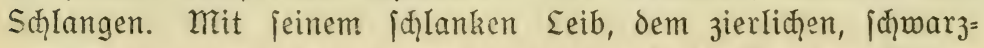
äugigen Kopf und der glänzend hellgelben Kehlle ijt er ein fđjönes

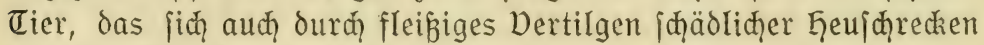
um ben Menjąen verdient maḑt.

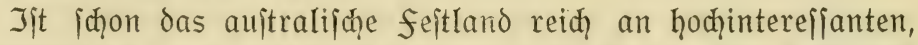
vorjintflutlid, anmutenden 区ierformen, jo finden mir bod nod, merkwürdigeres Tetier auf der großjen Doppelinfel reufeeland, und hier wäre in eriter Einie unter den Reptilien ein merk würdiges Relikt aus grauer Dorzeit, ein lebendes foffil gewiffer=

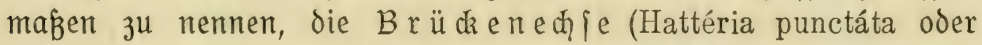
Sphénodon punctátum), die ił̧ren wenig bezeiđhnenden Kamen nađ̆

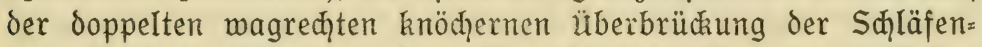
gegend führt. Was uns diejes Tier fo intereffant maḑt, ift der

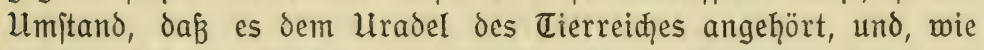
Breḩm jiđ̆ ausorüdat, "eine Aḩnenreiḩe aufzumeifen ḩat, wie 
Eein zweites Wirbeltier auf Erden". Wir haben es hier mit cinem "lesten Mohikaner" aus längit entichwundenen Erdepod)en ju tun, defien nädhite Dermandte òie Paláéohattéria des fäḑiif̧̧en Rotriegenden ijt. Thre unmittelbaren Dorfahren reiø̧en zurück bis zur Trias = und permzeit, jie jelbit ijt der lezte Rejt der Sțnabelköpfe oder Rhnnndiokephalen und vermittelt als jolḑer den übergang pon den Krieditieren zu den Eurdien. Ihre un= mittelbaren Dorfahren itanden der gemeinfamen Stammform der Sţirokröten, Eidedpen und plefiofaurier nahe und bejaken aud?

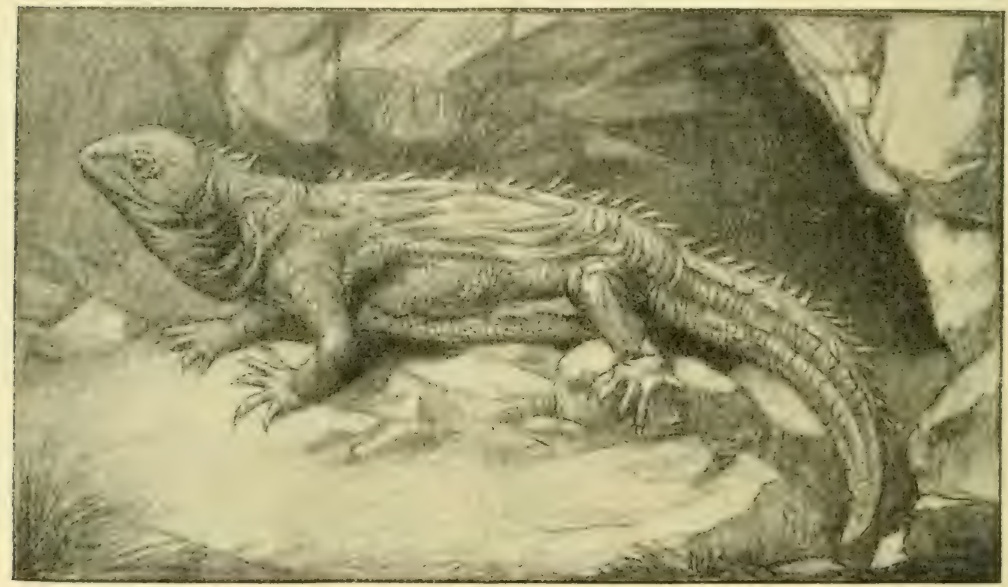

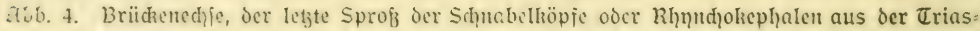

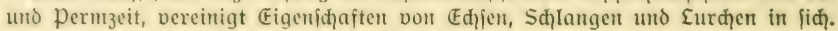

Beriiḩrungspunkte mit den Krokodilen und der ausgejtorbenen Amphibiengruppe der Stegokephalen. Das eier ijt ein joger. "Sammeltup", der Eigeniḑaften von (Ed) fen, Sḑlangen uno Eurd)en in fide vereinigt. In Europa find feine Dertreter fdyou in oer Inrazeil ausgejtorben, aber auf dem meltentlegenen Ireufecland hat (id) das abjonderlidie (bejđzöpf nod) bis heute erhalten. freilid) jind auđ dort jeine एage gezählt. früher kam es allenthalben bäufig vor, aber heute ijt es bereits auf cinige cinfame Sanozungen ber lTordinfel und anf die diejer vorgelagerten kileinen Eilande befdirünkt. Menfden (die Eingeborenen leujeclands verfolgen die "बuatera" teils ihreer angeblidien (biftigkeit, teils ihres als Eecker= 
biffen gejd̆ägten fleijhes wegen), von diejen eingeführte und wieder verwilderte Ģaustiere (Sđ̧weine, Ģunde, Kagen) und WaId= brände ḩaben zujammengewirkt, um die Ausrottung der Brüđien=

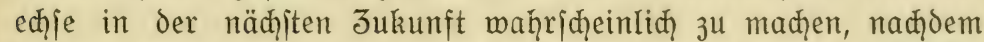

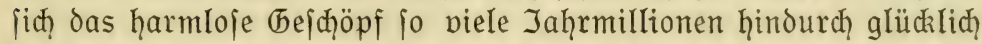
im Kampf ums Dajein beḩauptet hatte. Jwar hat neuerdings die neujeeländijhe Regierung itrenge $I a g \delta=$ und fangverbote erIafjen. Db́ fie aber nod) etwas helfen werden? Bei flüdţtiger Betradtung fieḩt die Brückenedyje eigentliđ gar niđ̧t fo übermäßig abenteuer= lidh aus, [d]eint vielmeḩ in allem wejentliḑen mit dem uns wohllbertrauten Eidechjentn̨p übereinzujtimmen, aber bei näherem

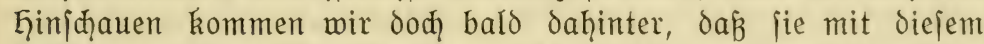

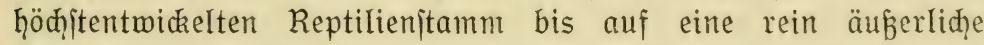
äḩnliḑ̧eit herzlid menig gemeinjam hat und jedenfalls auf einer wejentlid niedrigeren Stufe iteḩt. So find die unter= kieferäjte niḑt wie bei den Eḑjen miteinander veriđ̧molzen, jondern, wie bei den Sdylangen, nur durch ein jehnniges Band verbunden, eine Erif̧einung, die übrigens für die Biologie des Tieres oḩne merklid̨en Einflub geblieben iit. Der Körperbau ijt plump und gedrungen, der Kopf dick, krokodiljđ̨nauzig und auffallend groß̈äugig, die Beine find jtramm und maffin, die zehen kräftig und mit j̧̧arfen Krallen beweḩrt. EFin Rückenkamm, deffen zäḩne beim Männḑen tiefer gezadat find und in der $\mathbb{E} r=$ regung willkürliđ aufgeriđgtet werden können, erinnert an bie Eeguane. Die weiḑ̧e, ¡đ̧wammige und voluminöje Junge vermag als Tajtorgan idjon desḩalb keine Rolle zu fpielen, weil jie bis fajt zur Spize fejtgewadjen ift. Trobsem bejorgt jie das Auf= lejen der Maḩrung, da fie mit groß̈er heftigkeit und meiter Wölbung vorgejtülpt werden kann, jo daß́ mit der vorgewölbten flädhe kleines Gewürm aufgenommen werden kann. Die von der Körperḩaut überdedzten Dhren haben kein Trommelfell. Die Gqaut jelbjt ift [eḩr kileiniø̧uppig, lederartig, runzelig und von olinengrüner farbe mit gelbliḑer punktierung. Der platt gedrückte Sdjwanz des etwa $2 / 3$ m langen एieres äḩnelt dem der Krokooile und dient im Waffer als Steuerruder. Wie đđ̧on die Kleinen Sđ̧wimmদ̧äute

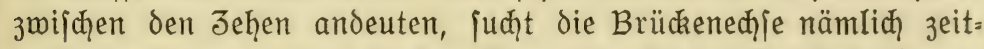
weife reḑt gern das feudyte Element auf, wo fie fin als ge=

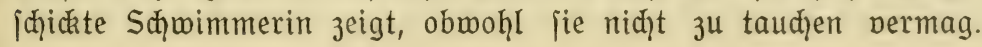


Aud des Klettems ift fie niḑt völlig unkundig. Auf dem Erd= boden bewegt fie jiđ ungejtüm, hajtig und ruckweife mit jüḩ̨en, edigen und unbeholfenen Bewegungen. Es ift ein tappiendes

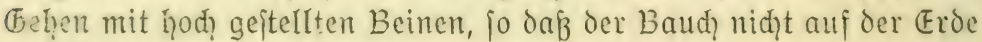
auffiegt, linterbroḑen ourd zientidy iḑnelles, ftopmeipes Dor=

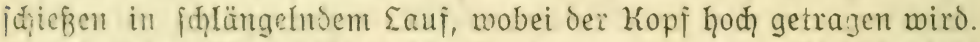

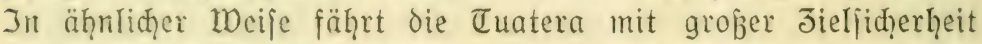
aud) mit aufgefperrtem Raden auf inre Beute los, als weldye Infekten, würmer, Sd?nediri, aber aud kleine Nager und würmer anzufehen find. Erwijdit fie das (Dppertier gleid beim eriten Jujd)napper am ḱopfe, jo mird diejer mit dem zwar itumpfen, aber Kräftigen thebiß in bet Regel fofort zeimalmt. Anòmfalls aber beginnt eine entjebliţe Quälerei; dani bie Tuatera zermalmt bas arme Beatetier lebens und ganz al!mählid zu Brei, wobei der

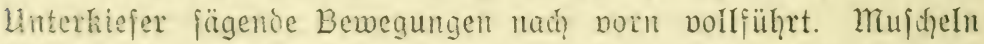

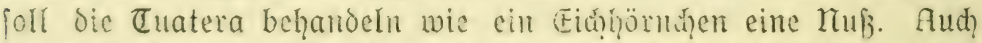
die Aufnaḩme von Wajjer gejđjicht nidist ledend, fondern unter

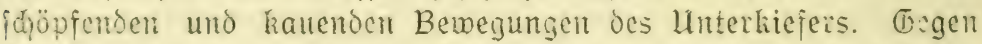

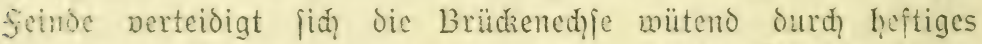
Kragen uno Beifen. Obwohi fie nie nad Ant eer Eideñfen hinter ihren Iagotieren oreini̧aftet, jondern ruhig oen jum Jufaḩren ge= eigneteri Rugenblidi abwartet, oft aud itundentang mit iḩren gropen Augcn wie weltvergeffen in bie feme finausträumt, kann man fic body niḑt eigentlidy träge nemnen. Am lebhafteften pflegt fie in ber Dänmerung zu jein, Jenn fie ift ein ausgejproḑenes Redittier und verbringt den gröpten Teil des Tages in auffaltend feftem Sḑlafe in Erobhöhinungen. Dieje werden entweder von Der Tuatera jelbjt gegraben, ober fie bittet fiđ in den oft meḩere Mreter langen Bruthöhlon der Sturmtauḑer zu (hajte: aljo cine hodintereffante Snmbiofe zwijden Sḑmimmoogel und Urreptil.

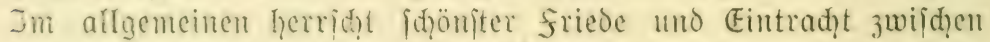

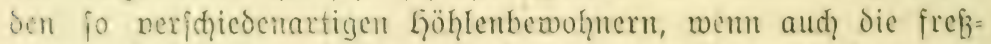
gierige Edjpe hier uno da mal einen jungen Sturmtaudjer weg:

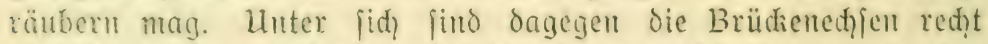

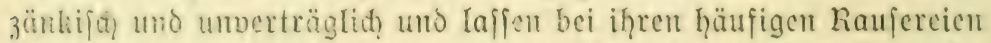
ciaentümlid quakende Eaute hörent. Ihre cigenen Eicr Iegen fie

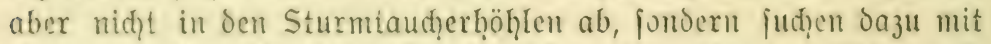
einer gewifien Umfiđ̧̧t oft ziem!ión weit entfernte plätze auf, 


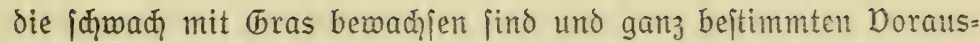
jegungen hinfiçtlid Sonnenbejtrahlung und feuđțtigkeitsyehalt entiprechen. Gaben hier im Kovember Regengüife den Boden

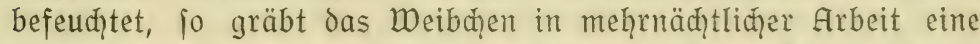
Grube von 5-8 cm Durđimeffer und $15-18 \mathrm{~cm}$ Tiefe aus und padat in dieje mit dem Maule feine (meijt 12) meibjớligen, läng= liḑen Fier in mehreren Lagen diḑt nebeneinander, jo dak der ganze Raum mit ihnen ausgefüllt ijt. $D a$ die Fier während ihrer Entwidklung nod an Umfang zunehmen, kann niđt jedes ein Junges liefern. Die Grube jelbjt wird mit Erde, Gras, Moos und

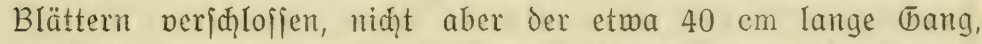
der ḩäufig nađ̆ auß̉en führt. Jum Dorfhein kommen oie Jungen erjt nađ 12-14 Mronaten, weil die Embryonen uad Thilentus den neujeeländiḑen Winter (unferen Sommer) im Jujtande eines

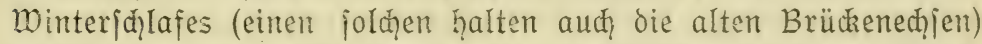
verbringen, vor deffen Beginn ihre lajenlöhţer durh ein zelliges (5ewebe veritopft werden. Obwohl die Brüdrenedye nur ein jąlen̆tes Unterjđeioungsvermögen für Entfernangen befight, fieḩt fie dođ fonit ganz gut und hört aud leidiç, wäfirend iḩr der Tajtinn völlig zu fehlen f̧̧eint.

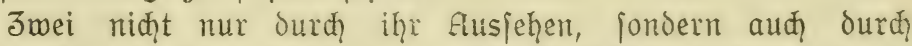
andere Eigenjąaften höajt ausgezeidnnete Enjen finden wir in Jentralamerika. Die eine ijt die Kröteneđle (Phrynosóma cornútum), anzujeḩen wie ein kleines Teufelchen mit ihrem kurzen, oreieckigen, mit Dornen bewehrten und mit Görnern gejđmü̈đten Kopf, mit ihrem kreistunden, abgeflađ̧ten, itaḑeltragenden Rumpf, der in ein kurzes Sđ̧wänzḩen endigt. Aber fđ̧on die gutmütig oreinblidienden äuglein zeigen, daß̧ wir hier kein bos= haftes Ђejळöpf vor uns haben. Die Kaum handlange Krötenechje hat genug mit jidj jelbjt zu tun, denn die Katur hat jie zwar mit einem jehr gejegneten Appetit begabt, und iḩr auffalleno breites Mäulçen vermag aự verhältnismäßig groß̉e Bifjen ipielend zu bewältigen, aber jie zum fang diejer Biffen niđ̧t gerade glänzend ausgejtattet. Der tief zwifden den Schultern jigende, nur jehr menig bemegliḑe Kopf und der Mangel einer Shleuderzunge machen die Injektenjagd für die Kröteneçje zu

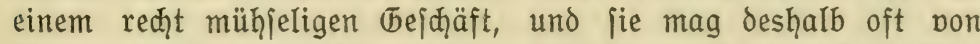
Nahrungsjorgen gequält werden. Allerdings ift es nicht riळhtig, 


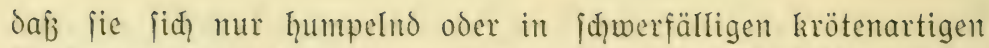
Sprüngen fortzubewegen vermöge, denn in Wirktiđ̨̧eit kann jie menigitens rudimeife und auf kürzere entfermungen aud reḍt

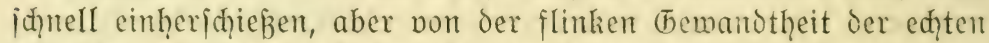

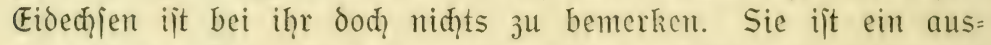
geiprochenes Tag=, Sonnen= und Sandtier. Sowie die wärmende Sonne zur Rüjte geh̆t, gräbt fiḑ die Krötenedjje unter heftigen jeitliđ̧en Sçüttelbewegungen flach in den Sand ein, wie eine flun= der auf dem Meeresgrund. Das auf oer ganzen (Dberjeite wie ein Igel mit GornjtaḑeIn bejegte एier ijt ohnedies auf jandigen Boden

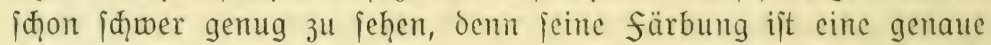
Wiedergabe diejes Bodens mit all jeinen Abtönungen, Unebenheiten, Steinđ̧en und Sḑattenitreifen. Ein hädjit eigenartiges Der=

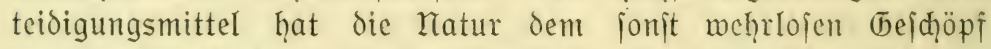
aber dod verliehen. In der Angit ipright es nämlich aus feinen Augen einen dünnen Strah̨l einer blutartigen flüfiligkeit, die

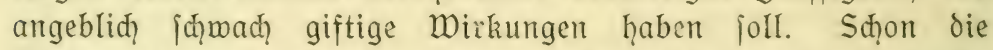
ältejten Erforjher mercikos haben von siejer einzig dajtehenden एatjaḑe beriđ̧tet, in wiffenfḑaftliden kreifen hat man fie aber immer wieder in Jweifel gezogen oder gar frifhtweg non vorn= herein als eine Unmögliḑkeit erklärt. Etwas Dahres muß̧ aber dody daran jein. Fier eine fidjece Beobadytung aus neuejter Jeit (1907): Als Ditmars im zoologifđ̧en (Jarten von LTeunork

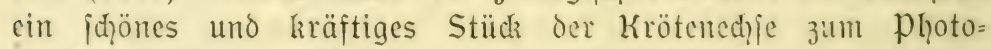
graphieren herausgriff, bemterkte er, daß̧ die Augen aus iḩren

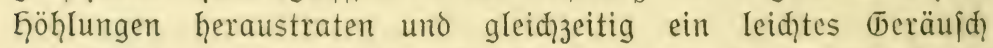
vernehmbar wurde. Gernorgebraḑ̧t murde es durd einen haar: oünner Blutitrahl, der eine vier fuf entfernte Wand traf; auf diejer konnten dann 103 kleine Blutströpfden gezählt merden. Das Blut fdien aus dem Augenlid zu kommen, das fiḑ als itark angeiḑwollen erwies; aud blieb bas Auge nad? dem Sprizen eine Weile gefdhlofien. Da der Angapfel unverändert blieb, konnte der Blutjtrahl niḑt gut aus ihnm hergekommen jein, aber ungemiß blicb es, ob er aus dem sio jelbjt herriihterte oder der Tränenorïje entjtammte. Äl̨nliḑ wie mit dem Blut= iprizen der krötened)je ift es aud) mit ber viel umitrittenen (biftigheit der $k x$ uftenedfie (Inelolérma suspéetum) ergangen. jwar die mexifkaner jụworen von jeher Stein und Bein auf die 
müffen, *) daß̧ die alte überlieferung der Merikaner dod! nur allzujehr auf Wahrheit beruḩe. Das (bift jelbit bejight einen niḑt unangenehmen, ¡đwad) aromatijđen (berud, reagiert nad Rein= hardt alkalifel (Sollangengift meift jauer) und wirkt als Gerzgift.

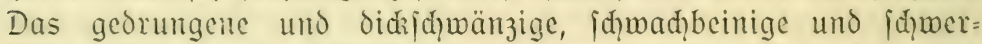
fällige, träge und nädhtlid) lebende, nur in öden (begenden vor: rommende cier fdpeint fith feiner furd?tbaren waffe aud wohl bewubt zu fein und tut keineswegs ängitlid). Seine lebhafte und auffallende färbung dürfte ähnlid wie bei unferem feuer= falamanocr als Warnfärbung aufzuf̂ffen fein.

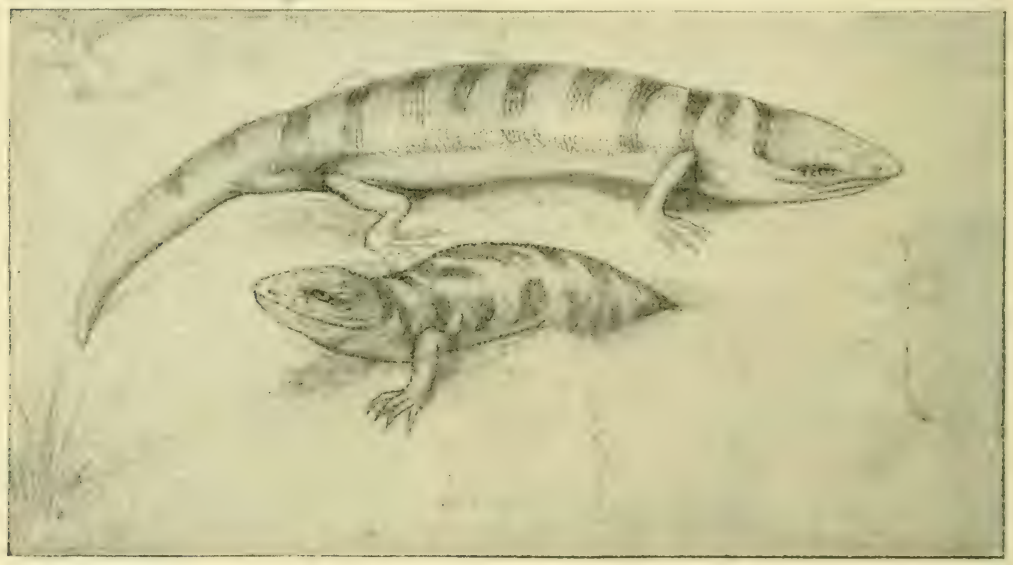

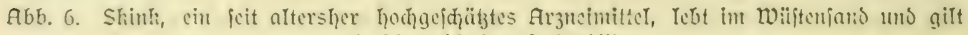
als iđmađhhafter Eederbiffen.

Im Stiparzen Eroteil finden wir namentlid) cine lange Reifie von Wüftenreptilien, dic in meļr oder minder intercifanter und bollkommener weife der liargen Katur ifrer leimat angepafst find. Ein gutes Beifpiel dafür bildet der icit altersher als hod)= acidäğtes Arzncimittel bei den Quadijalbern aller Eänder be= rühme Skink (Scíncus officinális), den v. fifdęer fo treffent als den "Maulwurf unter den Eided)fen" bezeiḑnet hat. Wie unfer Maulmurf ift auç cr auf cine gröftenteils unteriroifd) Ecbensmeife angewiejen, aber fo meifterhaft find feine $\mathrm{Be}=$

*) Oberit クeanger wurde 1889 von einer gekïfigten Krujtened) in in den Daument gebiffent und war naक wenigen Stunden eine Eeiḑe. Фanz ähntid) erging es 1890 aud) cinem Wärter im 3oologijd̨en (barten 3u Eondon. 


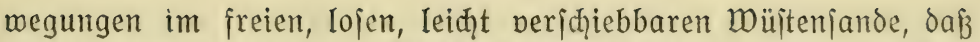
man das nid̨̧t meḩr ein "Wühlen" nenten Kann, fondern in Der= juđ̆ung kommt, es als ein "Sđ̧wimmen im Sande" zu bezeiđ̧nen.

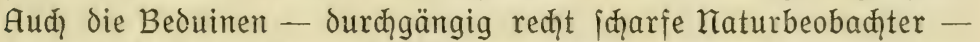
haben jiø̆ diejes Eindrudks offenbar niđ̧t erwehren können, denn der arabijche Kame des Tieres bedeutet niđts anderes als "Sand= fifd]". Das abjonderliđ̧e Tier erfreut fid aum heute noch bei ihnten großzen Enjehens und wird eifrig gejagt, denn es gilt nidjt

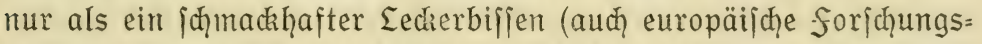
reifende haben jiø zu diejer Anjiḑt bekehrt), fondern aud als ein ganz untrügliḑes Stärkungsmittel im Dienite der Aphrodíte sáharae. Mit feiner glatten, porzellaniđhimnternoen Dberfläche, der gologelben Grundfarbe, der opalifierend milḑweiß̈en Unter= feite und den 8 bis 10 breiten, violetten Queritreifen ift ber

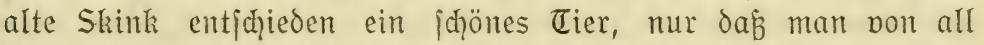
der Gerrlid\}keit niđ̧t oft etwas zu jehen bekommt, oa er fein Dajein fajt völlig im rotgelben, jonnendurḑglïḩten wüjtenjande verbringt. Und die braungetben windhundköpfçen, sie im blendenoen Sonnenjđ̧ein hier und da mit kiteinen, aber jđ̧arfen äuglein neugierig aus dem wüjtenfande herborlugen, find felbjt

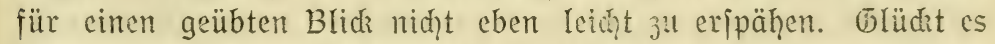

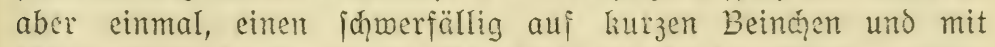

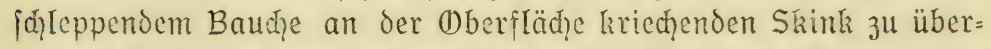

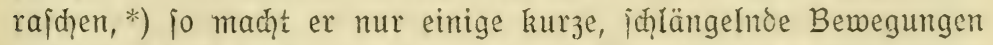
und ift fofort wieder in dem rotgelben Sandmeere verifiwunden, deffen winzige Körnchen fiđ fajt ebenjo leiđạt veriđ̧̧ieben wie die Moleküle des waffers und das er desḩalb mit ausgefprochen ruder=

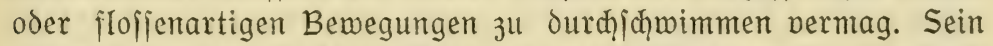

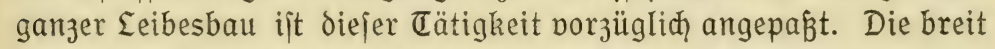
beiđ̧uppten Jeḩen ermögliđ̧en die rudernde Sđ̧wimmbewegung, indem fie jiø zu einer vollkommenen Sđ̧aufel zujammenlegen, der breitið̧nauzige, keilförmige Kopf wirkt als Erobohrer, der derbe Gals entfaltet feine Muskelkraft, und, der glatte Walzenleib gleitet ohne jede Mühḩ und Anjtrengung einher. Der weit über sen Unterkiefer voripringende Dberkiefer ift diejem derart aufgejebt, dáb ein Eindringen von Sand ins Maul ein Ding der Unmöglid)=

*) Er vermag aber auđ mit eigentümliç 3udrenden Bewegungen reç̧ rajă 3u Iaufen. 


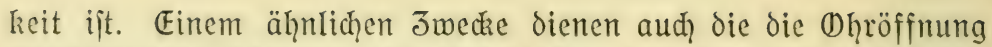
überlagernden Sḑuppen, die Kajenlöđ̧er find jeḩr eng und ppalt= förmig, und das Auge iit ourch die winzige sidöffnung gut gejđü̈bt. So gleitet der Skink auf der Jago nad, im Sande lebenden Kerfen wie eine glatte porzellanipindel mit unglaub= liđ̧̧er Sḑnelligkeit meite Strekken unter dent Sande daḩin, den die meikelförmige Sḑnauze wie eine Pflugiçar zur Seite iđjiebt. So fremo alio aud dem munteren Eidedjientn̨p an jid eine unterirdijđ̧e Eebensweife zu fein jheint, hier ijt fie bis zur hödfiften Dollendung ausgebildet. Einige der damit verbundenen Ampaffungserfdecimungen find allerdings bei gewifien anderen wüifterteden nody meiter getrieben. So find bei $O p h i$ óps zum Sdzuge gegen den riejelnden flugiand die ourdjpidztigen Augen= liber zu einer art Uḩrglasdediel miteinander verwad)jen, äḩn=

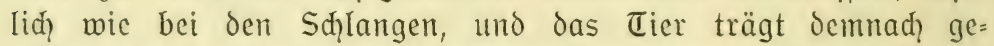
wiffermaßjen bejtändig eine Sḑubbrille, gerade wic unjere iteine= klopfenden Chauffecarbeiter. Dic Krötenkäpfe (Phrynocéphalus) der transkajpifđen Wüijten, die id) fo ojt mit immer crneutem Dergnïgen in ihrem freileben beobaḑtet habe, bejighen nođ̆ ganz bcjondere Sápuţoorriḑtungen gegen die dort fo ḩäufigen und fo furç̧tbaren Sanditürme. An iḩrem unförmlid großen, ciner breitgedrüdsten Jwwicber vergleiḑbaren Kopfe jtehen sic Augen unter dünnen, aber ftark voripringenden Augenbrauen= iḑildern und werden von ungemein kräftig entwidkelten Sidern völlig bededit. Dieje fint jo cingeriḑtet, daß̧ beim Sdylięen des Auges ihree umgebogenen freien Ränder cine mehrere Milli= meter breite fläḩe daritellen und beim Aneinanderpreffen cinen äuperit feiten Deriḑlußs bilden, deffen Staubfidgerḩeit die unferer beiten und teucriten mujeumsfd\}ränke nod\} weitaus übertrifft. כu allem überfluffe find aber aud? nod\} auf ihree Außenfeite aufred)titehende, dreiedige Schuppen angebrad̨̧t, die wie Wimpern zum Abhalten der feinften friegenden Staubpartikel dienen. Fine äupere (1)ḩröfinung bejiģen dieje fo raffiniert gebauten kröten= köpfe iiberhaupt niḑt mehr, und die (i)ffnung der feinen, fpaltförmigen Kajenlöd)er meijt praktifḑerweife naḑ rïđkwärts. Dom

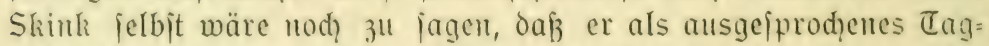

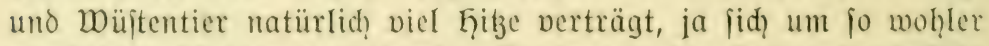
3u füḩlen fogent, je meḩr der Sand von der Somme durḑglüḩt 


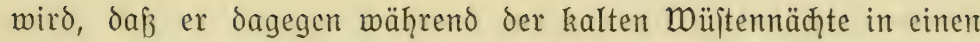
tiefen, Ietḩargijø̨en Sḑlaf verfinkt. Seine Bedürfnislojigkeit ift groß̧, aber cinige Tautropfen zum Trunke kann er niḑt entbehren, io jehre er aud fonjt alle feuchtigkeit verabiđ̧eut. Auf Erjdütterungen des Eroreichs durđ fußtritte oder Pferdeḩufe aú, tet er jofort, fonjt aber iḑeint mir, foweit meine eigenen, jowohl im freieli wie in Terrarium gemaḑten Beobađ̧tungen reid̨en, jeine Intelligenz ję̧r gering zu jein.

Der Riefenfliink (Macroscíncus coctáéi) der Kap Derden iit ganz im (Tegeniage zu dem maulwurfsartigen एreiben feines Detters eingefleifdyter Degatarier und obenorein Baumtier, obwohl er durchaus kein hervorragender Tumer iitt, vielmehr mur reht langiam und behäbig klettert, ohn: den Sḑwanz dabei zu Gilfc zu neל̧men. mit feinen feiften Ģängcbacken ijt der dicke, plumpc und ungejhlaḑte (bejell (ein Eremplar Tofoḩrs mog bei nur $59 \mathrm{~cm}$ Körperlänge niọt meniger als 570 (Tramm!) das Urbilo cines gutmütigen phlegmatikers. Don überflüffiger Bewegung ift er durḑaus ricin freund, troģem aber niḑ̧t etwa ein ber= [d] lafener (bejclle, aditet viclmehr mit ben klugen äuglein auf= merkjam auf alle Dorgänge in feiner Umgebung. Fine gute

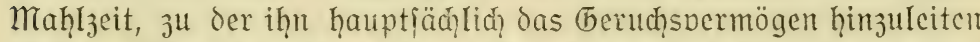

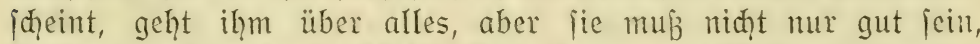

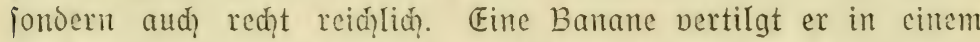
Juge mit Stumpf und Sticl und läß̧ aud von der Schale niḑts vertiommen. Es ijt daher begreiflid, daj der didie frebladi unter Umitänden in den Bananenkulturen erḩeblichen Sḑaden anrif̧̨ten Kann, und die pilanzer verfolgen iḩı desḩalb unerbitt= Iidy, wo immer er jiḑ blidzen läß̧t. Dazu krommt, dá̧ jein fleiph infolge des reiđ̧lid̦en Bananengenuffes einen jeḩr feinen und aromatifhen (bejdmad annimmt, demgenäß aud als biel= begehreter Eeckerbiffen teuer bezaḩıt woiro. Die völlige Ausrottung des \{dyon ziemlid\} felten gemordenen und in feiner Derbreitung jo bejđịänkten Tieres ift daher leider wohl nur nod cine frage der Jeit. Da der Riejenjkink aber dic tocfangenjhaft gut ver=

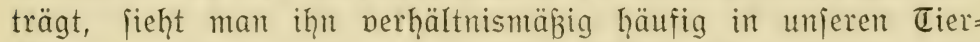
gärten, uno hier wiro er, wic Klingelhöffer fid ausorückt, balo der Eiebling aller äIteren herren, denn es jieḩt gar zu gemütlid aus, wenn er den Kopf mit den didien Ģängebadien zu feiner 
Gähle herausitredat, alles mit feiner blauvioletten Junge betajtet

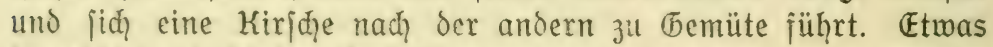
¡đ)redzhaft bleibt der Riejenfkink aber fojt immer, und wenn er dann flüd̨̧tet, fo gefọieḩt es mit überrajăcnder Sdinnelligkeit und unwideriteḩliḑer woumt, daß̧ alles nur fo krađ̧̨t.

Jit der Skink die Charakteredyje der afrikanifden Sandmüfte, fo der now viel abenteuerliḑer ausjehende Dornidqwanz (Uromástix acanthinúrus) biejentige der oft viel furç̨tbareren Kies=

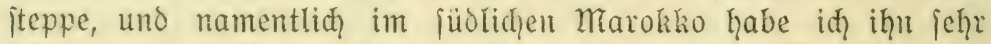
häufig angetroffen. Die intereffante Gruppe der Dorniḑwänze, die mant als die Bären unter den Reptilien bezciḑnen könnte, zeigt wieder eimmal fo reḑt die geradezu phantajtifhe Dielpeitigkeit, vie die Edjfen im Gegenjag zu dem uniformen Geer der Sçlangen befigen, und zwar niđ̧t nur in bezug auf Körperform und $B e=$

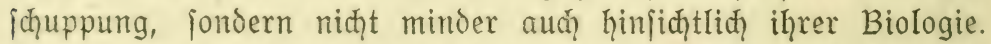
Der kleine, kurze, vorn fdgildkrötenartig fteil abfallende Diďkopf mit den hellen, lebḩaften und ausdrudisvollen, kedi und offen= ḩerzig, aber gutmütig in die Welt iđ̧auenden Augen, der beḩäbig breite, abgeplattete und nicoergedrildite $\Sigma$ cib poller Runzeln und falten in den flanken und der kurze, wirteiförmig mit Staḑel=

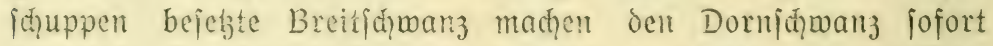

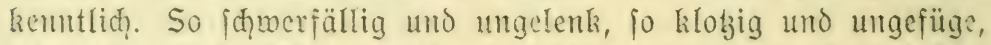

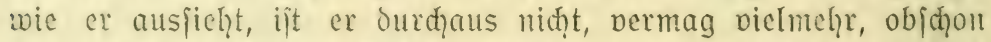
iḩm cine gute portion pḩlegma eigen ift, im Rotfall verbliffeno rajó ju laufen. Dabei riḑ̧tet er jiḑ hođ auf den Beinen auf

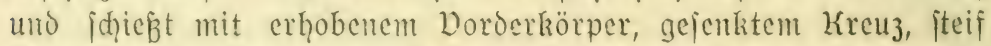
gehaltenem und mit dem Enoe etwas nadijid? leppentom Stzwanze und mit jeitwärts weit abitehenden Ȩinterbeinen rudameije daḩin, intom

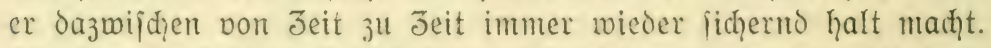
Jit das furḑtiame (5ejhöpf in Sdyredien acjagt, fo artet bicje fluçt niḑ̧t felten in cin wüjtes und kopflojes Dahinjtürzen aus. So lange aber der Dormf(̧)

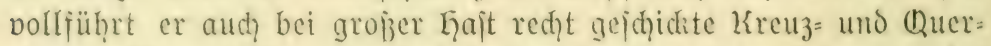
wendungen, wobei der majpine, zadienftarrende Sḑwanz dic Riḑtung bejtinment, indem er mit Wud\}t jeweils nad der entgegen=

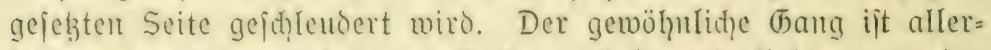
oings nur ein unbeholfentes Eintherwadieln uno fieht megen oer zrürze des plumpen Rumpfes und der Steifheit des Stadyalidgwanzes 
wunderlid genug aus. Sogar ein wenig klettern kann das Tier und nimmt dabei den itarken und harten Sḑwanz als Stüje zu Gilfe. für das Graben aber zeigt es geradezu eine Eeiden=

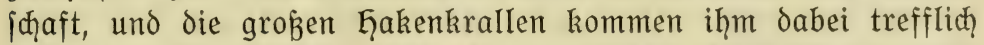

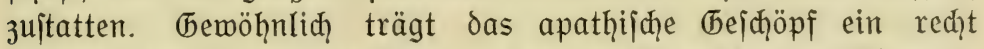
langmeiliges bejen zur Sḩau, aber es ift entið̧ieden jähzornig und zur paarungszeit überḩaupt jeḩr erregbar. So furchtiam

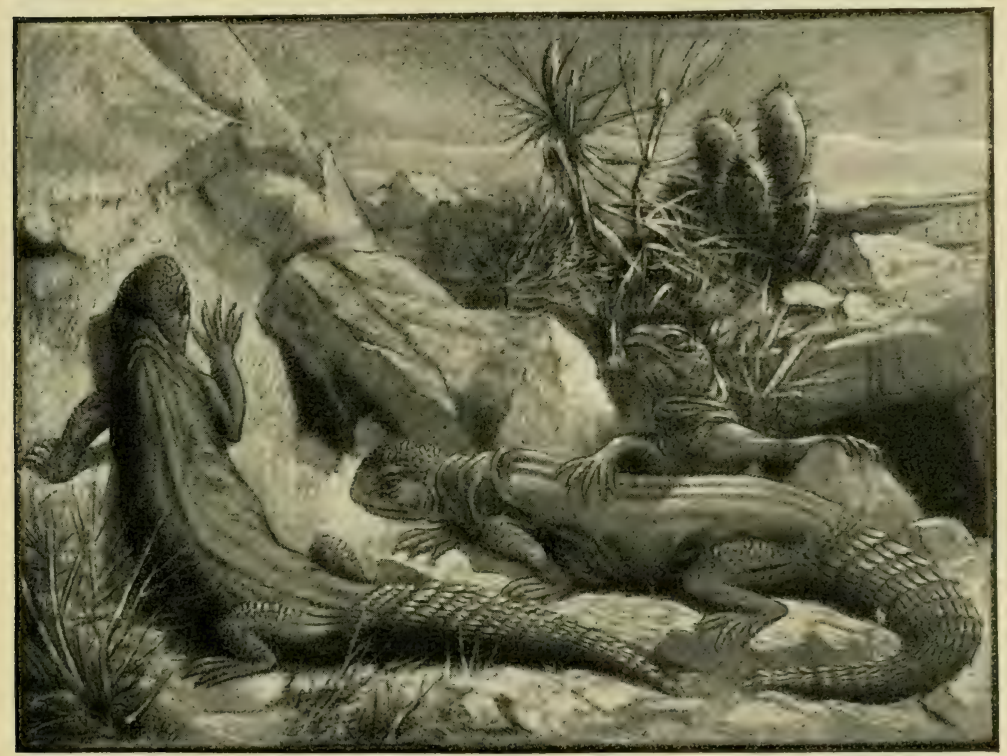

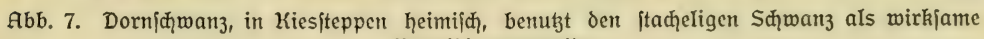
Derteidigungswaffe.

es jonjt jeden überlegenen (begner flieht, fo mutig jegt es jich dod zu: Wehre, wenn es in die Enge getrieben und iḩm der

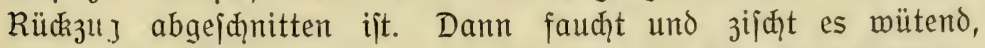
plattet den Eeib nod meḩr $a b$ und teilt mit dem Stadeliḑmanz

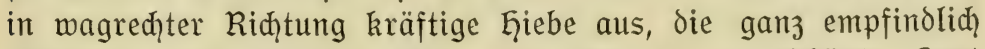

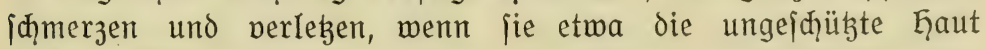
trafen. Mit diejer Dermendung des Sđ̧wanzes als Waffe mag

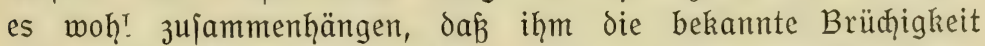
des Eicechjenjđ̨manzes völlig fehlt. Weit feltener mađ̆t der Dorn=

flocrickc, Krieđ̧tiere und surḩe frember Eänder. 


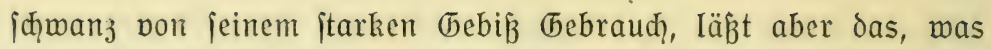
er einmal gepadit ḩat, jo leiđht niḑ̨t mieder los. Jur paarungs= zett kennt die Eeidenfđhaftliḑkeit oer Männḑen Keine Grenzen.

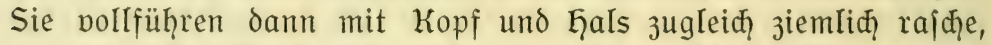
eigentümlid) nidkende, aber plumpe und ungeiḑidate Bewegungen und bemüḩen fiḑ, mit den ftumpfen zäḩnen ein vorüber kommendes meibḑen an jeinen Ģautfalten feitzuḩalten. Die Iungen find überaus niedliḑe ए̦ierḑen, viel flinker und munterer

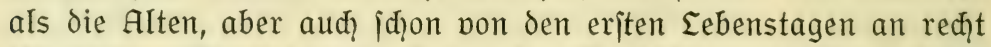
jähzornig. Die rofenrote Junge des Dornifiwanzes ift zu kurz, als daß̧ fie eine Rolle als Tajtorgan ipielen könnte, woh̨l aber eignet jie jiđ wegen iḩrer klebrigen und fleifḑigen Beiḑaffen= heit zur Aufnaḩme der Kaḩrung. Dieje ift gemiiß̨̧ter Art. Db=

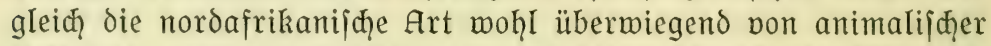
Kojt lebt, werden dod jeḩr gern aud bitter iḑmeckende pflanzen= itoffe berzeḩrt, namentlid jolḑe mit kleejäuregeḩalt, und gewiffe Blüten find begehrte Eeckerbifien. Da jolḑe pflanzen 83 bis 90

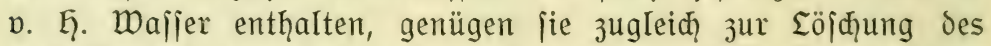
Durites. Wo fie aber dem Dornjđ̧wanz niḑ̧ zur Derfügung itehen, kann er das wajfer niḑ̧ entbehren, und zwar trinkt er ¡đlürfend unter Juḩilfenaḩme der Junge. Als eḑte Steppen=

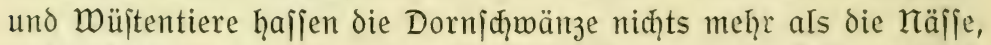
und gierig juđhen fie überall siột, sonne und poärme auf.

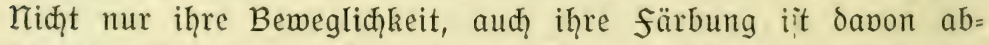
ḩängig. Im Somnenjđein braungelb mit eifengrauer Marmo=

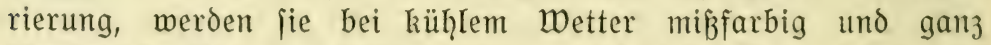

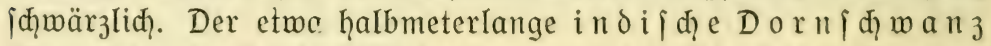
(Uromástix hardwíekei) ift dagegen auf der (Dberjeite cifengrau,

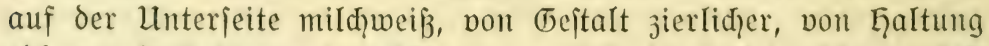

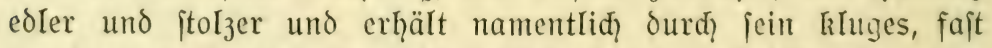
vogelartiges Auge etwas jehre summpathifd̨es. In ber eat ift er niđ̧̨t fo jähzornig wie fein Detter, vielmeḩr janfteren (Demüts, wird daher auḑ in der (befangenjd\}aft lciḑter und vollitändiger zahm, ja bis zu einem gewiffen (5rade anţänglid) und bekuitoet gar niđ̧t geringe Spuren pon Intelligenz und (5edäḑ̧tnis. Fr

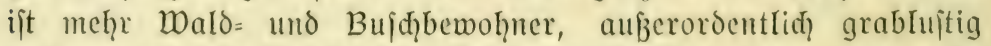

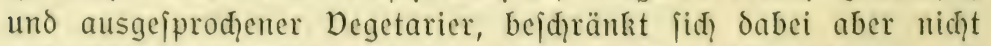

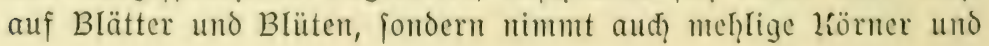


zermalmi fogar fteinharte Maiskörner mit erjiḑtlichem Wohl= beḩagen und groß̧er Kraft zwijhen feinen jtarken liiefern.

Wahre Könige des Edjengeidiled)ts find die $\mathfrak{W}$ arane, die зugleid zu den phnjilich hödjititehenden aller Reptilien gehören und über den ganzen Süben der Alten Welt verbreitet find. Es

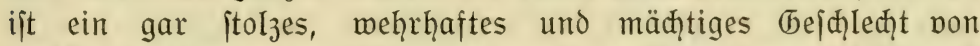
mohlproportioniertem Körperbau und im Beutefangen fait nod?

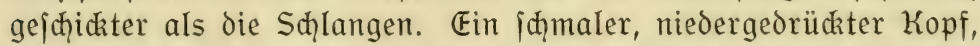
ein ausneḩmend langer Ģals, überaus kräftige Shenkel, waḩre Raubtiertagen mit mäḩtigen Krallen, ein muskulöjer, feitlid) $3 u=$ jammengedrüđater Sđ̧wanz, ein wohlgeformter, objhion ctwas deprimierter $\Sigma$ eib, eine geipaltene Sţlangenzunge, helle, leb=

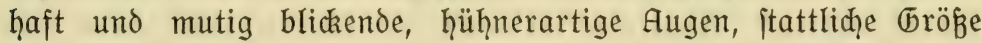
(einzelne Arten melien mehr als $2 \mathrm{~m}$ ), würdevolle Ģaltung, un= bändigz Raubjuळ̧t und vermegener Mut dharakterijieren den maran. Der wö̈ it enwaran (Varánus gríseus) ift woh̨l die bekanntejte Art und eine der tollkühnniten zugleiḑ. Im 3orn riđhtet er jich gänjeartig auf, bläh̨t den Kehlliaç und itürz̧t vermegen auf die Kamele oder Pferde der Karamane los, über deren Dorüberziehen er fid) ärgert, beiß̧t fiđh ihnen in Kehle

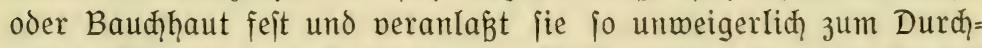
gehen. Werner beobaditete, wie ein Wüjtenmaran jogar im Kampf mit einer biffigen, dänifđ̧en Dogge glänzend Sieger blieb. Will man ;id ein fold intereffantes đeufelsvieh für jein Terrarium julegen (und man tut gut daran, denn die geiḑeiten Warane können auक jeḩr liebenswürdig jein, wenn jie nur wollen), fo mird man beim Auspadien jđ̄on hübiळ vorfid̨tig verfaḩren müffen, fonit kann es einem gehen wie meinem alten Studien= genoffen Klingelḩöffer, der mir iḑreibt: "Als iđh den heftig zijhenden Buntwaran (V. várius) beim Auspadken greifen wollte, maḑte iḑ in hö ḩit unangeneḩmer Weije Bekanntiḑaft mit den drei Waffen des meḩrḩaften Recken. Tief gruben fid̄ die ipigen Krallen in meinen Arm, die jugarfen Jähne ergriffen meinen reçten Daumen, dẩ das Blut nur fo ftrömte, und $3 u$ guter Lest hääte mir fait nođ der lange, muskelkräftige peitjhen=

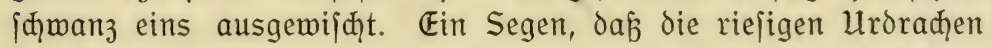
der Dorzeit niđ̨t meḩr auf uns gekommen jind!" Ein bosḩaftes Erḩeben des Kopfes und ein unruhiges Aufblähen und Jujammen= 
ziehen der Kehle perkündigt, wie de (brijs an gefangenen Exem= plaren beobaditet hat, den nahenden Jorn beim erregten waran. Dann atmet er tief cin, bläht fiç tommenartig auf, bläit unter lautem zifdien Euft aus, maḑt jid Jurch Ausipannen der Rippen ganz breit und flach, legt den Kopf iḑief, den Sḑwanz auf dic dem Angreifer abgemendete Seite, zieht den Gals S=förmig ein und führt nun urplöglich und mit verblüffender Treffiḑerheit feine kraftwollen Sḑwanzhiebe. So ungeitüm der Waran aber aud im Angriff ift, fo rüdifichtslos or bann aud? jedem weit größ̈eren (begner zu Eeibe geht, mit fo ftoijder Ruhe fügt er fid dod in das Unvermeidiḑe, fobald er unter= legen ijt. Die arabijđ̧en fänger nähen dem übermältigten, um ihmm weiteres Beipen zu verleiden, cinfach das Maul zu, mas er ohne weitere (begenmehr über fid, ergehen läßst. Diel zu j̧aden jđeint dem Wüjtenmaran dieje graujame prozedur gerade nid̨̧t, wic er überḩaupt eine ganz eritaunliđ̧e Eebenszähigkeit befigt. Sonit aber ift jeine Erregbarkeit eine fo großze, daßz er bisweilen nor lauter wut heftig erkrementiert und dabei leicht einen Darmborfall bekommt. So jeḩr der waran einerjeits den vollendeten Eidedjentnp darjtellt, fo hat er andrerjeits dod? aud, etwas unverkennbar Sdlangenartiges an ;id, fich megen feines bejtändigen züngelns und desḩalb, weil er vermöge feines jehr ausdehnungsfähigen Galjes die Beutetiere ganz und un= zerkleinert veriḑlingt, jumal feine ipigen und dünnen zähne ledigliđ̣ zum feithalten, niđ̧t aber zum Jerkleinern des Dpfers geeignet erfheinen. Er ift cin unheimlid) gefräbiger bejelle, der alles lebende (betier, das inm nod verjd̨lingbar erjąeint, oḥne meiteres mörderifक anfällt und jiđ danı ganz nađ Sđ̨langen= art gewiffermaßzen darüber hinmegitülpt. Ein von Klingelḩöfer eben der Derjandrifte entnommener, nod) nid̨̧t meterlanger $T$. be ngaléns is beförderte fofort zmei Mäuje und fünf grofe wafjerfröpde in das Dunkel peines unerjättlichen Magens une

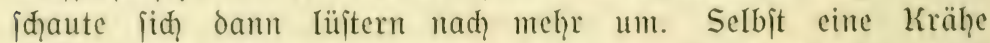
ift dem ermadjfenen Wüjtenmaran kein zu grofer Biffen. Dem Junggeflügel ijt er ein gefährrlideer feind, und aud Eier führt er fid\} gern zu (bemüte, indem er fie zierlid) mit den kicfern fafzt und erhobenen hauptes zerorïdst, fo dab iḩr jd̨madihafter Inhalt dic Gurgel hinabrinnt. Ebenjo merden Sḑlangen ohne 
Umitände veripeift, gleiḑviel ob fie giftig find oder niđ̧t, und angeblid audh Skorpione. Ein Koitberäḑter ijt der Waran

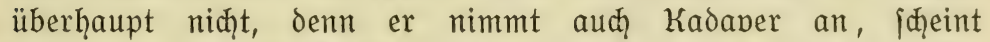
jogar eine gemiffe Dorliebe für etwas Ģautgout zu ḩaben. Die taitende Junge allein entidgeidet, ob etwas veridhlungen werden

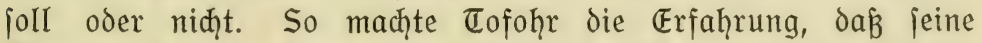
Warane, die bis daḩin rohes fleifd von Gqustieren hartnädzig veriḑmäht hatten, diejes fofort gierig annaḩmen, naḑoem er es mit Mäujeurin beträufelt ḩatte. Mauswitterung war ił̧nen eben etwas Dertrautes. Am liebiten bejđ̨leiḑt der Waran jeine

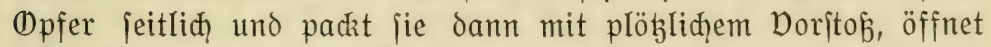
beim Jujd̨nappen das Maul jeḩr menig, jo daßj er jie oft nur an einer Ģautfalte crwijh̨t und nun arg quälen muß̧, bis er jie mundgeređht hat. Ijt das Tier erit einmal im Rađhen, jo wird es durch heftiges und ruckmeifes Doritopen des Kopfes weiter befördert, allo niḑt ourḑ Kieferveriḑiebungen wie bei den Sḑlangen, und der ganze Körper vollführt dabei windende und

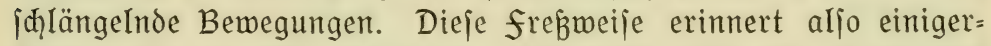
mak̉en an die der Krokodile, doch wird dabei der Kopf niḑ̧t wie bei diefen nad oben gehalten, fondern wagreḑt oder gar nady unten. Mit kleineren Biffen, einer Maus etwa, werden freiliç nid̨̧t fo viel Umitände gemađ̧̣t. Sie veriđ̧winden einfad mit einem eleganten "Wuppdid" auf Kimmerwiederjehen. Der gemöḩnliḑe Б̄ang des Warans erinnert fajt an das Tappien eines Igels, ift io hoḑbeinig, daßß der Baud, niđ̨t dem Boden

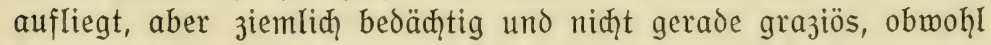

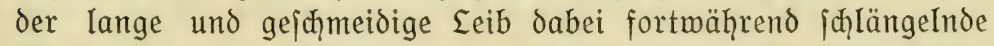
Windungen und Krümmungen bejḑreibt, indem die Wirbeljäule

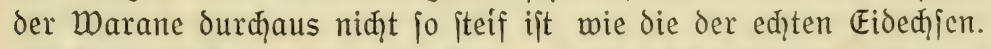
Im Notfalle kann er aber aud 3 u rajender Sdynelligkeit gejteigert werden, und ebenjo vermag der Waran beträđḩtliđ̧e Sprünge zu vollfüḩren. Dagegen ift feine Kletterfäḩigkeit megen der menig gekrümmten fajt wagređ̧t iteḩenden Krallen bejđ̧ränkt, obgleiđ̆ das Tier dabei aud den Sţmanz als Stühe zu Eillfe nimmt. $\mathcal{U m}$ jo beffer veriteḩt es jich aufs (braben, dem es mit einer gemiffen Eeidenjdaft und groß̈er Kraft obliegt, daß̧ die Kiejel nur fo itieben und ein mäđḩtiges bepolter entiteḩt. Wäḩ̨rend die Eideḑien in der Regel iḩre ganz bejtimmten Sd̨lupfwinkel 
und fomit fejte Wohnniige haben, ift der Waran ein nomadifierender Jigeuner. Wo's genug zu frefien gibt, da ift er zu Gauje. All= täglidh durḑmiß̧t er beutejuchend bei Sonnenichein meite Strecken

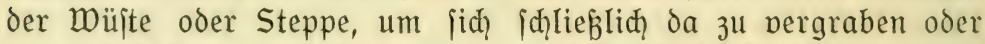
zu verkriecţen, wo ih̨n gerade der. Einbruđ der Dämmerung

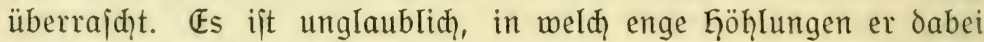
jeinen muskulöjen Eeib hineinzuprefien vermag, ja er jheint [id] in einer fold fürḑterlich engen Jmangsjacke gerade am allerwoḩliten zu fühllen. Bei der gewöhn̨liḑen Sd̨lafftellung

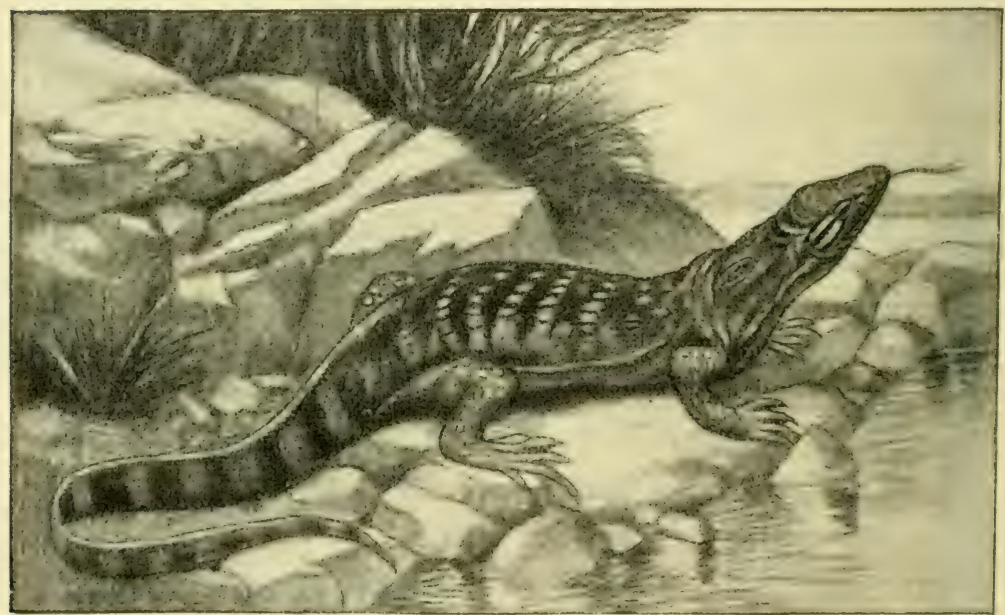

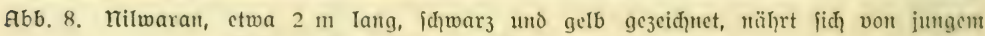
Waffergeflügel, Kröten, fröjđ̨en unঠ Krokodileiern.

werden die Beine nađ̆ hinten geriđ̧tet und an den Körper an= gelegt, der Kopf aber etwas geneigt. Dem ausgefprodienen Erodkentier Düftenmaran gegenüber muß der etwa $2 \mathrm{~m}$ lange,

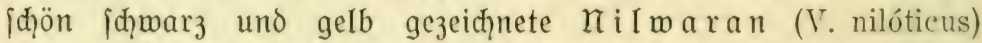
als ein halbes Amphibium bezeidnet werden. Dermag er dod? jogar auf dem (5runde des waffers entlang zu laufen. Scinen feuḑten Aufentḩaltsorten entipreḑend, bejteht feine Kaahrung ḩauptjäḑ̧lid) aus jungem Waffergeflügel, Kröten uno fröfđ̧en, aber er foll audy mit viel Eifer und Erfolg den Krokodileien nadjitellen.

Was die Warane für die heiken Eänder der Alten Welt fint, 
das bedeuten die Eeguane für die tropijकెen Gegenden der ITeuen.

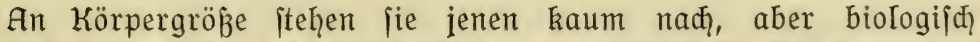

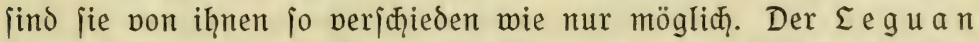
(Iguána tuberculáta) ijt nämliđ̄ Baumtier und Pflanzenfrefier,

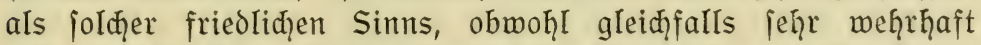
und uneridyrockenen Mutes. Jmergḩafte Derwandte von iந̨m দ̧aben wir ja jđ̧on in den niedliḑen Anolis kennen gelernt, und in der Tat hat die Eebensweije beider reçt viel gemeinjame Jüge aufzumeijen. Stol3, fajt majejtätijch ijt die Galtung diejes rönig= lichen Reptils, wenn es mit jđ̧arfen Krallen am dicken Baumajte ¡id] fejthält, auf den itrammen Dorderbeinen ruḩend, den Kopf aufgeriळhtet, und aus großzen, runden Augen ruḩig, wie aus Era

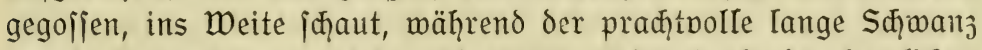
nervös ḩin und her pendelt. Blattgrün ijt die farbe des lierrliç̨n

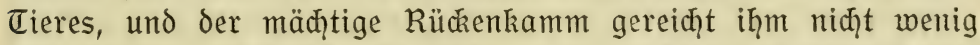

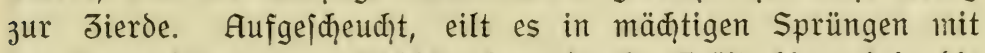

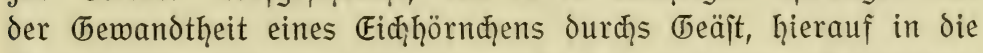
Baumkrone, oder es läß̧t jich aud bei gegebener (belegenţeit plöglid ins wajier ḩerabfallen, um hier j̧̧wimmend fein Geil zu verjudien, wobei der kraftbolle Sdimanz als Steuerruder dienen muß. In die Enge getrieben, jest fiक aber auđ ber Eeguan

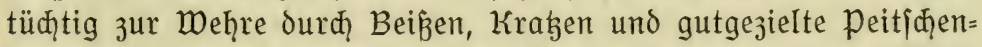

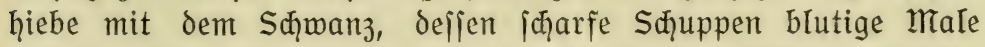
auf der Ģaut zurücklajfen. Ein dumpfes, kurzes, fajt brummendes zijd̨en ijt jein Kampfruf. Auf dem Boden krieḑt diejes Baumtier

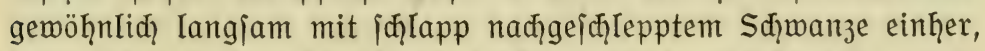

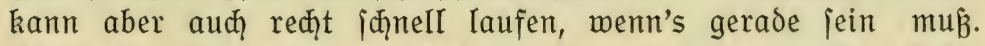

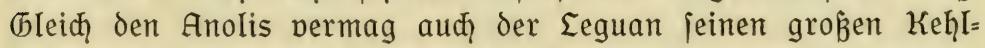
jadi durd, Spreizen des Jungenbeins permittels eines bejonderen Muskelmeḑ̧anismus $3 \mathfrak{u}$ entfalten, und er nickt $\delta a z u$ eifrig und

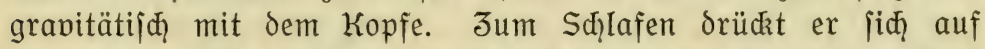
einen hohen Ait, jenkt den Kopf und fpreizt die Ginterbeine meit aus. rur in der feuchtwarmen $\mathfrak{L}$ uft der tropijçen Urwälder fühlt fidc der Eeguan wohl; bei Erodkenheit verblaß̧t fofort

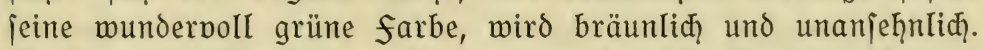
In feiner Dollkraft aber ijt er eines der jööniten Reptile und vielleicht das intelligenteite pon allen. Als Jukojt 3 u jeinen Blättern, Blüten uno früđten verzeḩrt er aud kleinere Kerfe, 
namentlid) nadite grüne Raupen, die aber fofort voll Abjđ̧eu wieder ausgefpudit merden (nad) Tofohr), falls fie fid etwa von Kajturtien (Brunnenkreffe) genährt hatten. Der Eeguan j̧̧eint aljo über einen im Reptilienreiḑe jelten hod entwidrelten (5efđ̧madzsfinn zu verfügen. Auch wird jeder Biffen vorher niḑ̧t nur mit der Junge, die aud zum Ergreifen der Kahrung dient, abgetajtet, fondern überdies nod) forgfältig bejđnüffelt; jtark oder eigenartig rieçende Blumen zum Beifpiel verjđ̧mäht er. Das

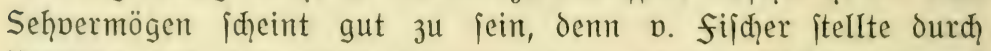
Deriuçe fejt, dabj jeine Eeguane einen kleinen Mehlwurm auf $3 \frac{1}{2} \mathrm{~m}$ Entfernung wahrz̧uneḩmen permod̨ten. Alle Eiebhaber, die dic märmebedürftige groß̧e Eaje im Cerrarium hiclter, find iḩres sobes boll, denn der Eeguan wird im Eaufe der 3eit fo zahm, wie es ein Reptil überḩaupt nur zu werden vermag, und gewöhnt jiđ an die verjạiedenartigite Kojt, jelbjt an jüße Mehlipeifen. Sein fleifd gilt für jehr jđ̆maḑhaft, und er wird desḩalb in Sübamerika eifrig gejagt. Impojanter, Kloghiger, mürde= voller, monumentaler nođ als der gemeine Eeguan itellt fid der düiter blaugraue, im felfigen (belände der Injel Ģaiti lebende nashornleguan (Metopócerus cornútus) dar mit feinem maffigen Kopf, den fhönen, Klugen Augen, den itark entwidielten Stirn= und Badzenwürjten, dem mäđ̧tigen Rüdrenkamm aus itarren

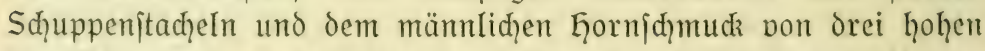
Kegeliduppen auf der Mitte der Sdnauze. freilid ift jein Körper= bau plumper, auđ fein Sđ̧wanz kürzer, aber dafür werden deffen

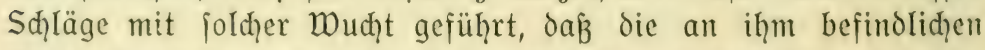
Wirteliḑuppen ganz bösartige Wunden verurfaḑen kömmen. Müller erzählt, daß̧ fein Exemplar eine (நieß̧kanne mit menigen Sd?waņhieben vollitändig zerbeulte! Das Tier begnügt fid oft niḑ̨t mit der bloßsen Derteidigung, fondern geht aud zum Angriff über, ipringt den (hegner ingrimmig an uno beiß̧st tïd)̨tig 3 . Es ijt neu= gierig und menidenideu, brutal uno manierlid) zugleid, kann nid) fo gut klettern wie fein Detter nom fübamerikanifden fejtlande, aber dafür beffer graben und fḑarren. Süßze früd)te bilocn feine Eicblingsmahrung. Beim Kopfnidien bleiben die Dorderbeine nadh den Beobad)tungen Müllers iteif, während fie bei den Agamen mit= wippen. In dex (befangenjobaft gewöhnt aud der Mashornleguan fich an die verfḑiedeniten Kahrungsitoffe und wird meḩr und 
meḩr zum Allesfreffer. So bekundete Klingelhöffers Eremplar eine Dorliebe für fifđhe, die es dod̆ auf den fonnendurdiglühten feljen Gqaitis unmöglid kennen gelernt ḩaben kann. Der bejte Springer unter den Eeguanen ijt vermöge jeiner ungeheuer langen und ftark bekrallten Ģinterbeine Crotaphytus colláris, eine jđ̧on im jüdliđ̧en Kordamerika vorkommende 3wergform

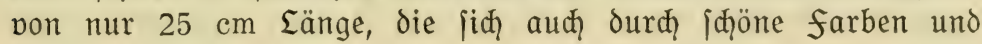

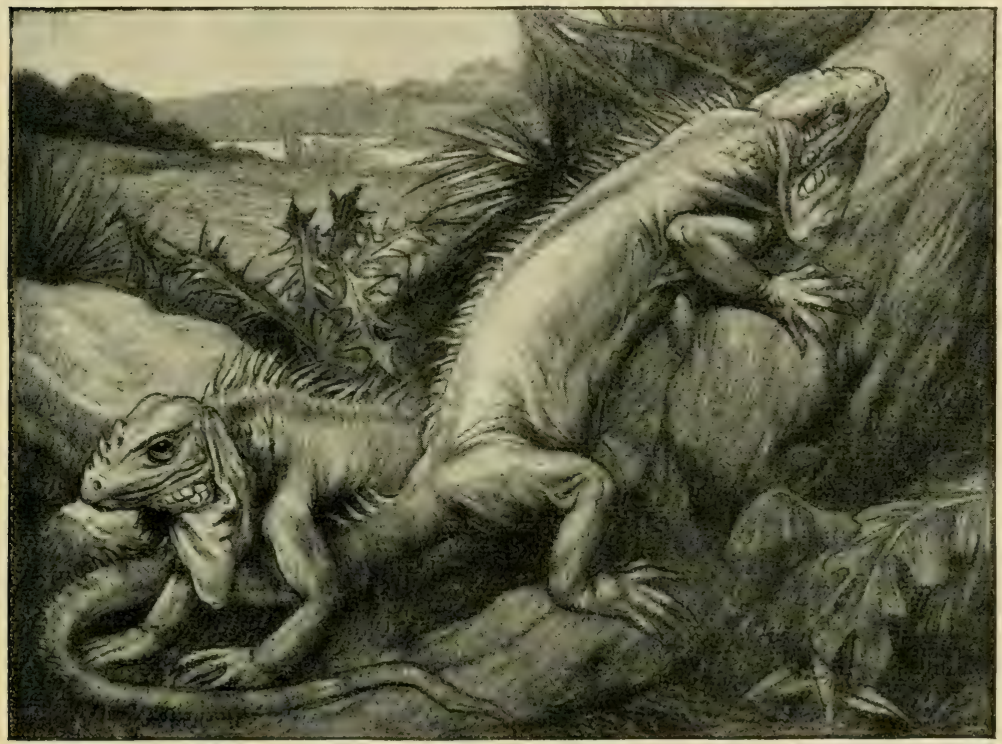

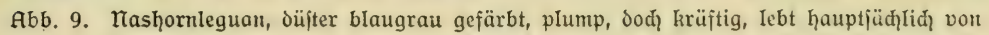
jüßen früđ̧̧ter.

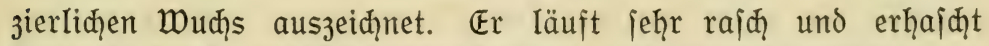

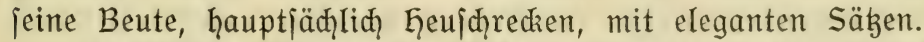

Im öjtliḑen Südamerika ijt der fajt meterlange, ziemliọ bunt gezeiḑ̧nete, dicke und faule, aber jeḩr langiđ̧̧wänzige đeju (Tupinámbis teguíxin)zuḩau\{e, und namentliḑ in den Juckerroḥr= pflanzungen eine ganz gewöḩnliche Erjø̨einung, geḩört auđ jeiner Anjpruđ̧̧slojigkeit megen $z$ den in unjeren Tiergärten regelmäßig vertretenen Reptilien. Der gemütlich ausjeḩende Burjąe ift in Wirkliḑ̧eit ein ređ̧̨t gemalttätiger patron und ein arger Räuber.

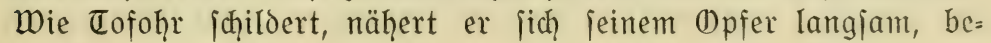


trađ̧̧tet es mit erḩobenem Kopfe, fäḩrt dann plöglid) [đ̧räg von oben zu, jąleudert das im Tadien gefaß̧te Tier wütend auf dem

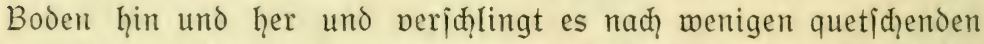
und fiđ̧̧er tötenden Kaubewegungen. Wäḩrend der Sđ̧̧wanz des armell (Tejdjöpfes langlam in jeinem Radhen verjḑwindet, windet [id] der Teju, um den Biffen herunterzubringen, unter den fürḑter= lidjiten Körperberrenkungen, als ob er die gräbliç̧iten $\mathfrak{E} e \mathrm{ib}=$

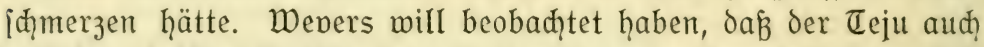

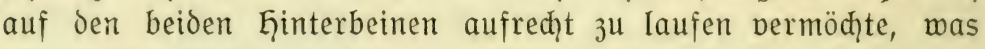
aber meines Wiffens bisher von anderer Seite nod) Keine Beitätigung gefunden ḩat. Klingt ¡đjon der एeju in jeinem Äuß̧eren erheblid?

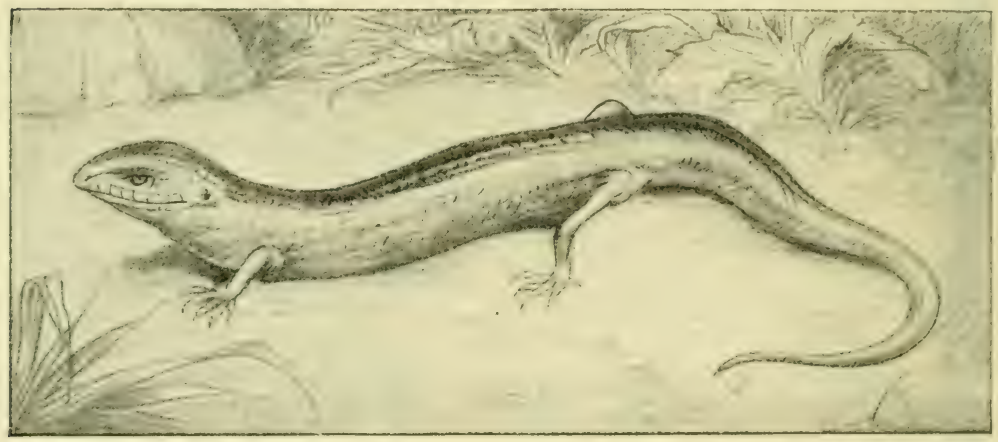

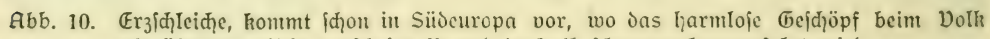
als überaus giftig veriđ̧rien ift und deshalb jđ̆omungslos perfolgt wiro.

meḩr als Warane und Eeguane an den gewöḩnliḑen Eided)ientųp an, fo gilt dies in nođ̆ ḩöherem Maß̧e von den iḩm vermanten und iḩm aud im tharakter ähnnliḑen, gleiḑ̧alls jübamerikanijhen Ameiven, die allerdings nur halb fo großj find. Eine ber fdiöniten und bekannteiten Arten ift A méíva chrysoléma von St. Domingo, die in vielfaḑer Ģinfiḑt an die Smaragdeioed) fe er= innert, jedody nod zierliḑer und eleganter gebaut ijt unt an den Dorderbeinen riḑtige Grabfübe bejight. Dieje bemugt das jehr wärmebedürftige (bejđj̈pf, um fid ill etwas feuḑtem Eroreiđ?

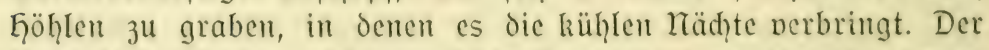
Kopf diejer farbenpräḑtigen Ed\}je ijt vogelartig jpił uno erimnert

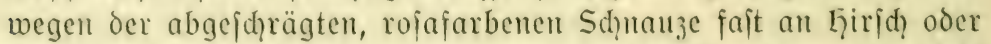
Antilope. Eroz diejes gutmuitigen Ausfehens find aber diefe 
Ameinen aud unter fich arge Raufbolde und traktieren fiđ

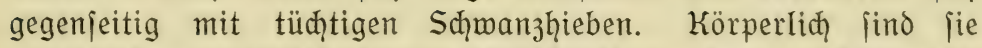
vorzüglich ausgerüjtet, laufen pfeiliđ̧nell in etwas geichlängelter Dangart, klettern und ipringen vorzüglid, find aber bei alledem

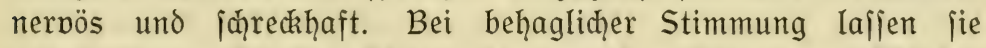
ein jeltiames Quieken hären, das wie das piepen von Mäujen Elingt. Durd mę̧r oder minder ftark reduzierte бbliedmaß̧en

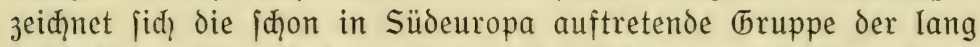
gejtreckten, glänzend bronzebraun oder jilbergrau gefärbten $\mathbb{E}_{3} 3=$

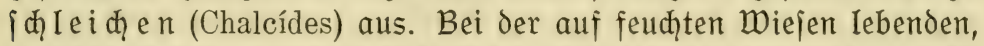
nur orei Jeḩen an jedem fuß̉e bejigenden Ch. tridáctylus z. B. find die füke noḑ weit meḩr verkümmert als bei der $a b=$ gebildeten Art (Ch. ocellátus), jo dá̉ das Tier jtark an unjere Blindiçleiđge erinnert, der es aud̆ in der Eebensweije äḩnelt.

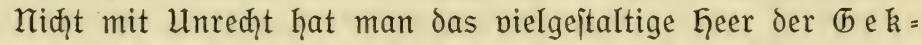

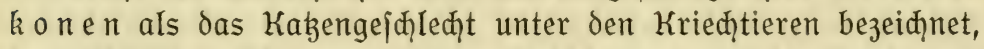

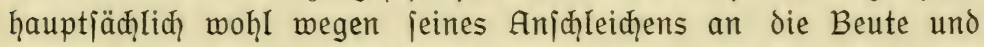
wegen feiner jtreng näđ̆tlichen Eebensweife. Ausnaḩmen bejtätigen jedod aud hier die Regel. Es gibt aud $\mathbb{E}$ a g geckos, und gerade zu iḩnen zäḩlen die iąönjten und intereffantejten formen, fo der Taggecko von Madagaskar, Phels úma madagas car iénse. Krefft hat von iḩrem rajtlojen एun und Treiben eine jo lebendige und liebevolle Sđjilderung gegeben, daß̧ woḩ in jedem Eiebḩaber

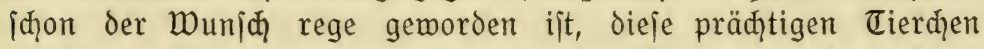
ielbjt zu bejigen und in̨r anziehendes weien zu beobaḑten. Dberjeits find dieje etwa $20 \mathrm{~cm}$ langen Baumbewoḩner un=

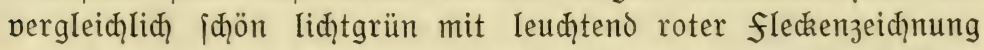
auf dem ḩinterrüdken, und dieje effektbolle (begenüberitellung zweier Komplementärfarben wirkt bei einem Reptil fo verblüffend, daß̉ man meint, es jei gar niḑt Katur, fondern irgendein Spaß̉= vogel habe die Tierchen mit Eachiarben fo angeitriḑen. Dazu

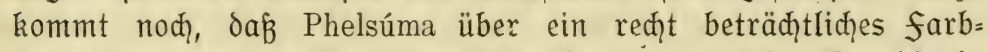
weđ̧felpermögen verfügt, das fiø alleroings auf die (brundfarbe

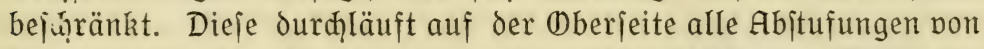
papageigrün bis Graubraun, auf der Unterieite von Weíß bis finjtergrauj̧̧warz, und bisweilen tritt aud nođ eine bläuliche

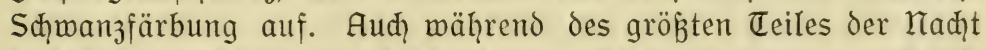
find dieje quedsitbernen theiçöpfe in rajtlojer Bemegung, und fajt 
idheint es, als nahe überhaupt kein Sd?laf iḩren nimmermüben

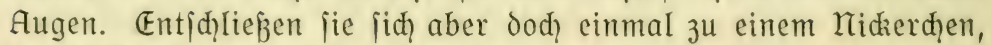
fo neל̧men fie eine Mimikrn=Stellung ein, indem fie lang aus= gejtredit mit allen Dieren einen ienkreḑt emporjtrebenden 3weig umlklammern, und den Kopf nad unten, die Sḑwanzipige aber nad oben riđ̧̧ten. Thre Ģaft= und Sprungfäḩigkeit ift phänomenal und übertrifft nod die der Anolis und Eaubfröiḑe. "Wie von einer Sehne geid̨nellt," jagt Krefft, "iđ̧ieß̧en die rotgeperlten Smarago= leiber in meiten Sprüngen kreuz und quer durḑeinander. Bei den

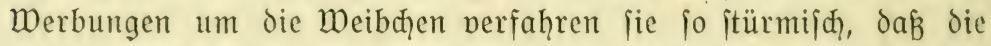
vielbegeḩrte Sḑöne im (heoränge niđ̨t jelten iḩre Sḑ̧wanzeszier verliert, die dann von dem aud mitten im Eiebesraujø für materielle Grenüffe jtets empfängliḑen Männdhen als gute prife betrađ̧tet und mit Behagen aufgeknabbert wird. Katürliđ feḩIt

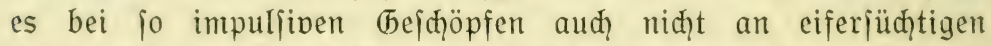
Raufereien unter den Männḑen jelbjt, und der Stärkere \{đ̧üttelt

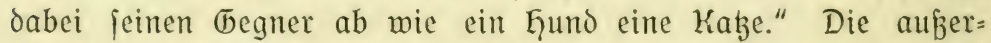

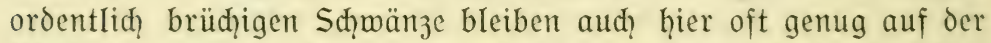
Walitatt, und fo kommt es, daß̉ man eigentlid) hödjit felten cinmal einen Taggedio mit niđ̨t regeneriertem Sd̨wanze antrifft, und bei den gleiḑfalls reḑt zankiüühtigen Kaḑtgedros ift es ja aud) niđ̧̧ niel beffer. Bei diejen paarungskämpfen jtö̈t Phelsúma in der hödj̧ten Erregung einen wilden und dumpfen Sḑrei aus, völlig verjḑieden von den gewöḩnlichen piep= und Medierlauten enderer (beckos, und dabei blähen jid) die Sḑallblajen zu beiden Seiten des offeniteḩenden Sdylundes mäḑtig auf. Las Endergebnis

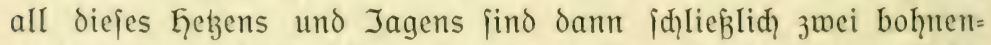

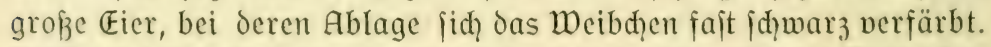
Sold bielerlei Aufregungen maḑen aber duritig, und die Taggedios

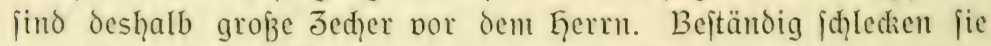
mit ihrer gelenkigen Junge köjtlidge एau= oder erfrifdenende Regen= tropfen aus dem grünen (Бelaub, faḩren fiḑ auḑ ab und zu mit der benegten Junge über bie Augen, um bieje zu reinigen, da die Sider verkümmert und unbeweglid, find. Selbjt dem unan=

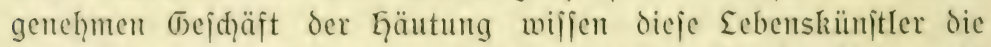
bejte Seite abzugewinnen, indem fie mit bem Miaule eifrig nad)= helfen, den alten Adam ausjuziehen und dann das abgelegte ந̧emo prafitifḑerweife - veripeifen. 
Ganz anders ipielt iid nun freilid das Eeben der Tacḩt= geckos $a b$, diejer in Anpajfung an felswände oder Baumrinde

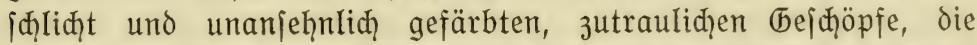
mir fo mançe lange abenditunde auf afrikanifhem Boden ver=

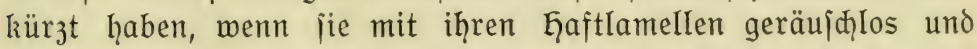
jiḑer an den ungetünđ̧ten wänden des arabijđ̧en Ģaujes auf

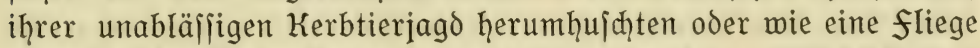
oben an der Decke herumipazierten, bis es dann iḑließ̧lidy dodn mal einer veriah und herunterplumpite, meḩr als einmal mitten hinein in die dampfende Abendjuppe. Die Unterjeite der finger und 3eḩen trägt aljo vielfađ Gaftlamellen, die aber bei den ein= zelnen Arten in jeḩr periđ̧iedener Weife ausgebildet und modifi= ziert find. एagsüber unerträgliđ̆ veriळ̧lafene und langmeilige

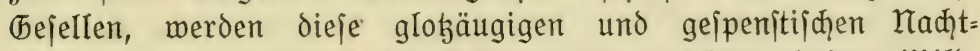

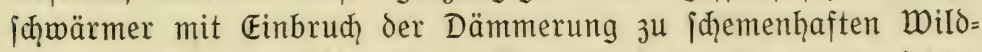
lingen und flinken Kobolden. Das ift dann ein unausgejegtes Iautlojes দquiḑen, ein jtoßjweijes Jagen, ein erbittertes Kämpfen, ein itürmifđ̆es siebeln die ganze Kaḑ̧t hinourdy unter dem munteren, ränkejüđḩtigen Dölkđ̧en, bis es dann der anbrechende

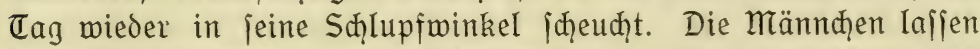
dabei fleiß̧ig iḩren piependen oder medkernden Kampfruf ḩören, und über eine bejonders laute Stimme verfügt Ptenópus gárrulus aus unjerer jübmejtafrikanif̧̧en Kolonie. Teratoscíncus scíncus aus Turkejtan vermag nad? Werner aud zirpende Töne hervorzubringen, indem er die groß̧en Sđ̧ilder der Sđ̧wanzober= leite aneinander reibt. Am allerlebhaftejten find die bedkos wäḩrend der Abendoämmerung, und auch iḩre Seḩ⿸kraft iđ̧eint

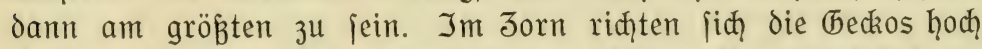
auf den Beinen auf, maḑen einen riđ̧̧tigen Kaģenbuckel dazu, und nun kann das Knurren oder Gludken, Piepen oder Quieken losgehen. Bei Gymnodáctylus kótschyi erinnert die Stimme an das einjt zum நaudium aller Бbafienjungen und zum Entiegen aller ruheliebenden Staatsbürger aus frankreid ein= geiđlleppte Spielzeug "Krikri“, das Eeute mit empfindliđ̧en Kerven zur Derzweiflung bringen konnte. Bei den meiften beckonen klingt aber dic Stimme gar niđ̧t unangeneḩm. Der tierfreundliđ̧e Moḩammedaner tut dem luitigen Kaahtgejindel niđhts zu leide, ja

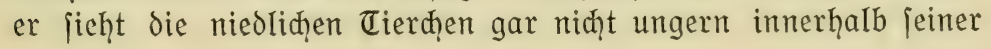




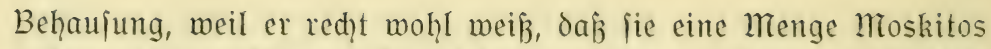
und anderes läjtiges Ungeziefer vertilgen. In den Eändern

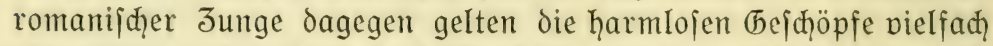
für giftig und merden desḩalb iḑonungslos verfolgt, fo nament= lid) in gemiffen Teilen Sübamerikas. Da fie audh zaḩlloje natür=

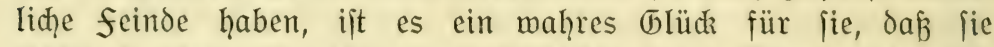
wäḩreno iḩres ftumpffinnigen Ginbrütens am Tage, wobei fie den Eeib ftark abflađ̧en und iḅn der Unterlage förmliç auf=

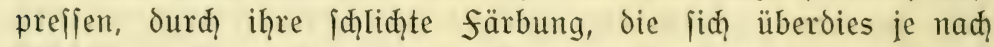
Bejđ̧affenḩeit der Unterlage nod etwas abzutönen vermag, fo gut

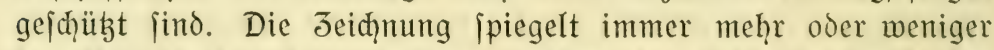
das Kolorit der Aufentḩaltsorte mider, das faḩle Sandgelb ber Wüjte, das unbejtimmte Grau der verjengten Steppe, die matten एöne des nađaten felsbodens, die zarte Marmorierung des Kies= gerölls. Im übrigen kennzeid̨nen ein abgeflaḑter Kopf mit

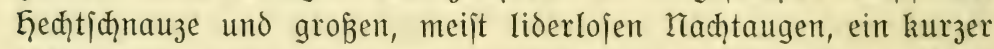
didker hals, ein georungener, platt georüdter Rumpf, ein dicker Sḑwanz und kleine Beine nit abjonderlid geitalteten Jehen die äuß̧ere Eriḑeinung der beckos. Die Ģautbekleioung bejteḩt aus jeḩr Kleinen, körnḑenartigen Sđ̧uppen. Die Weibḑen legen in der Regel nur zmei meißße, rundliḑe Eier, die bei den kileinjten Arten verḩältnismäß̨̊ am größten find.

Der knapp zugemeffene Raum dicjes Büḑ̧ leins verbietet es, auf die einzelnen (⿹勹ckionengruppen näher eirızugehen. Tur menige Worte jeien den miḑtigiten und intereffantejten Arten gewiomet. Der gewöḩnliḑ̧e mauergedio (Taréntola mauritánica) der Mittelmeerländer, deffen Eieblingsipeife Spinmen bilden, fteḩt zum Meniḑen etwa in einem äḩnliḑen Derḩältnis wie der Sper= ling; er läßst aljo bei aller iđeinbaren Jutrauliḑkeit die eigene Siḑerḩeit niemals völlig auß̧er aḑ̨t, wiro niđ̧t blinolings ver= trauensfelig, fondern bleibt itets bemüht, fid in einer gewiffen Entfernung von dem Gerrn der Sdyöpfung zu halten. Seine Der= trautheit beruḩt oft meḩr auf der iḩm wie fo vielen Exhjen cigenen Neugier. Das Ķaftnermögen ift großzartig ausgebildet. Selbjt auf jenkreḑten oder aud) überhängenden ipiegelglatten (blas= wänden eilt er mit derjelben দqurtigkeit und siḑ̧erheit daḩin, wie auf ebenem Boden, indem er die beim Berühren des (blajes nodh zufammentiegenden Jehenblättḑen ausjpreijt uno jo zwijd̨en 


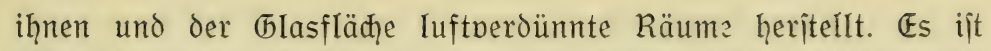
aljo allein der Euftoruck, der iḩn ḩaften läpt. Ie älter die Tiere werden, um fo meḩr wäd)ît iḩre Raufluit, um fo jeltener findet man dementipreḑend Stücke mit unverjeḩrtem Sđ̧̧wanz.

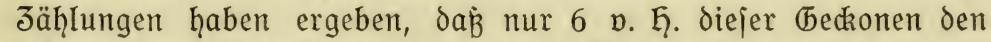

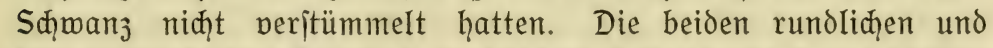

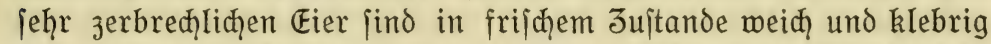
und bleiben desḩalb an den trockenen Plägen, wo jie abgejegt merden, haften. Ihre Entwidklung ijt eine jehr Iangjame, denn nadh den Unterfuchungen Tofoḩs pergehen volle jeḑs Monate, bis die Iungen zum Ausjఢ̧lüpfen gelangen. Beträđḩtliđ größ̈er ijt T. a nnuláris, aber ebenio unverträgliđ̧̄. Die ganze Tađ̆t hindurd balgen fiđ die märndhen unter quietichen= dem theichrei herum, das fie durç heftiges Aus|toßnen der suft herworbringen. Ihre Gaftfäḩigkeit ift jo groß̧, dá̉ fie 24 Stunden Iang an der Unterjeite einer (5Iasplatte 3 k kle= ben vermögen, ohne daß̧ man ihnnen die geringite Spur von Unbeḩagen an= merkt; aber fie wird durch

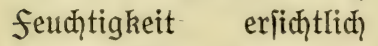
beeinträđ̆tigt, weshalb die ciere immer foldge Stellen auffuchen, die vor Regen gejđ̧übt find. Spapig fieht es aus, wenn fie bei der ந̧äu= tung die Epidermis der Beine mit dem Maule langjam und porjiḑtig abjtreifen wie einen Gand= ¡đuh und dabei die zehen gekrümmt halten. Der

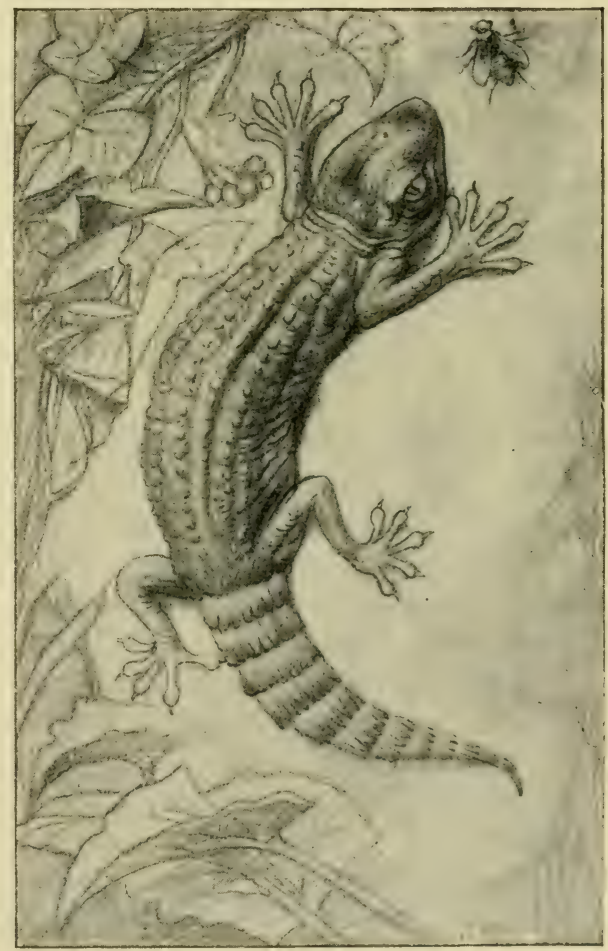

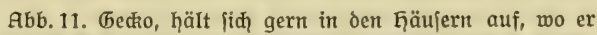
fich ourđ Dertilgung von allerlei llngeziefer nüblich mađ̧̨t. 
Eleine und zierliđ̧e S heibenfinger (Hemydáctylus túrcicus) rommt fđ̧on im jübliḑen Dalmatien (iđ) fand ihn 3. B. bei Budua und Spiza) vor, wo er mit Dorliebe in den Mauerrigen der

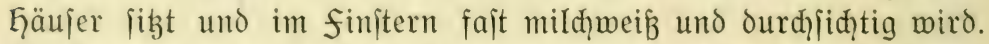
überhaupt ijt das farbmedifelvermögen bei ihm bedeutender als jonit bei đedkonen. So zart das merkmüroige Dingelḑen aud ausfieht, fo ppringt es doch in leidenjhaftliḑer (bier und mit geradezu gewaltigen Sägen nad friegen, die man dann nađ dem Derjąluditwerden blaugrau durch die dünne, fein gekörnte, fajt nadite Gaut ourdjidimmern jieht. Bemerkenswert ift im

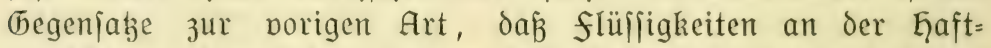
vorriḑtung der Jehen keinen Galt finden, jondern abgleiten. H. mabúia feḩlt in keiner wohnmung des uns jegt zuge= fallenen Kongogebiets, und das flinke, drollige (bejđ̧öpfđ̧en mađ̧̣t

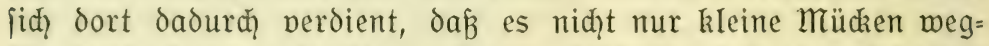
fängt, fondern aud die riefigen, ekelhaft riechenden Sđ̧aben. Der reizende und fabelhaft behende Phyllodáctylus e uropáéus itellt mit jeinem bunten fellḑen und den groken, funkeln= den Augen gewiffermaken den Eeoparden im Kajengejd]leḑte der

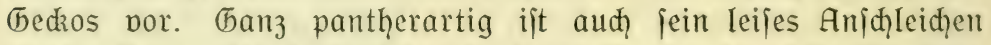
an die Beute, die dann folgende kurze Pauje, das fejte Insauge= fafjen, der plögliḑe Sprung, der felten fein Jiel verfehlt. Als Dertreter der Baumgedros jei hier zunäajit der indijđ̧e Gecko monárchus angefüḩrt, beffen rauhe, itark gekörnte Gqaut in ihrer 3eiḑnung bis auf die kleinjten Einzelheiten der alten Baum= rinde entipriḑt, jo daßj das cier jelbịt für ein jharfes Auge

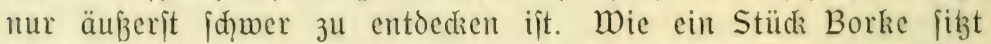
diejer Kad̨tjd̨̧ärmer in träumerifd̨er Ruḩe mit fajt völlig ge=

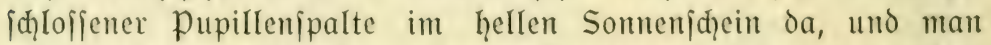
erjtaunt niḑt menig, wenn das permeintliḑe Stüdi Borke weiter aufwärts zu rutfhen beginnt, oa fid bas Tier entoedit glaubt. fait nod intereffanter ijt es, daßj Lygodáctylus picturátus aus dem Sudan nad) Werner in färbung und Derhalten pöllig mit dem gleiđ̧ iদ̨m auf alten Arazienjtämmen lebenden Weibḑen der Mantide Eláa márehali übereinjtimmt. Beide laufen bei Beumruhigung in Spiralen aufmärts um den Stamm uno orüdzen fid) dam wieder auf der d:m Beobaḑter abgekehrten Seite. I. lugubris von den Marihallingeln ijt ourdy feine 


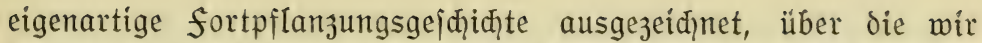
Sd̨nee nähere Mitteilungen verdanken. Die beiden erbjengroß̉en

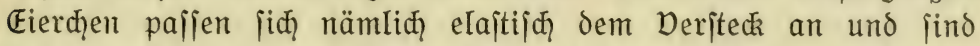

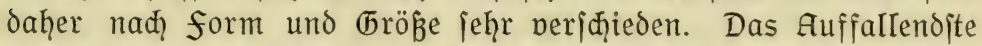

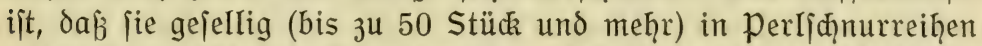
unter Baumrinde, in Termitengänge, bejonders aber in iđ̧aðhafte 『ür= und feniterraḩmen alter Ђ̨äujer abgelegt werden. Der

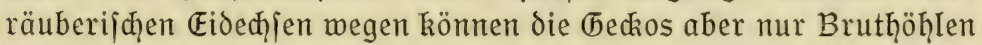
mit ganz engem Eingang benugen, uno man muß jich oft wundern, wie jid die eierbejţwerten weibđ̧en durḑ den winzigen Spalt überḩaupt ḩineinzuzwängen vermođ̧̨ten. Das Abplattungsvermögen diejer Tiere ijt eben ein ganz erjtaunliḑes. Die Iungen halten

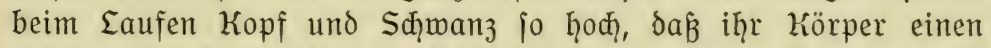
riḑtigen ḩalbkreis bildet. Kod in einer weiteren Bezieḩung ift diefer thecko merkwüroig. Er kneipt nämlid] gerne. Sein Wirts= ḩaus ift die duftende Blüte einer Amarnllibee, fein Trank deren ourch Regenwaffer veroünnter Kektar. So übermütig geḩt es

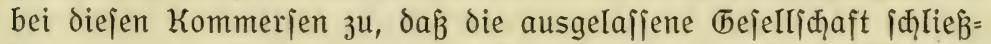
liḑ die ganze Blüte zerreiß̧t und zertrampelt und im morgen=

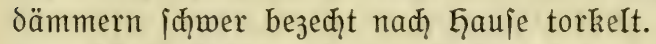

Eḑ̧te wüjptengectios jino die Acanthodáctylus $=$ formen, die deutid als $S t a d$ e $I=$, Dorn= und $f r a n j e n f i n g e r$ bezeiḑnet werden, und von denen namentliđ Acanthodáctylus syría c us ḩäufig in die দ̧ände der Terrarienfreunde gelangt. Es find

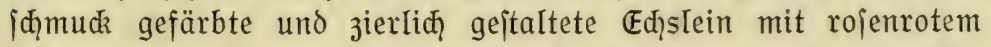
Sđ̧wanz und jägeartig bejđ̧uppten zeḩen, die es if̧nen ermög=

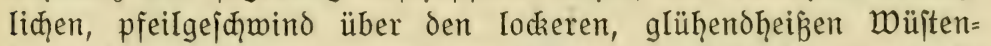
fand daḩinzurennen, oḩne einzufinken. Sie find aljo niḑ̨t Kletterer, wie die Baum= und feliengedios, fondern Sđ̧nelläufer. Schon die farbe des (bemandes verrät die Kinder der Wü̈jte. Wie bei

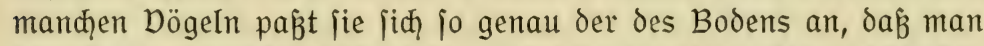

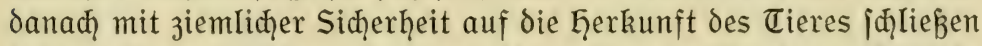
kann. Einige größ̧ere formen, die auf meḩr iteinigem (belände leben, find gefleckt und klettern aud an den felien. Don der pfeil=

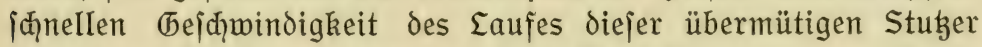
kann man fiđ kaum einen riđ̧̧tigen Begriff maḑen: es ift ein förmliḑes Daḩinfliegen über den Sand. Mitten im tolliten Rennen aber mađ̧en jie oft plöbliđ auf einer kleinen Erḩebung ḩalt,

floeridke, Krieçtiere und surđ̧e frember Eänder. 
ridḩten fid auf den Dorderbeinen empor und überiđ̧auen ppäḩend iḩ Jagogebiet. Don Tharakter find die fpigköpfigen, unjteten Eejellen einerjeits keck uno neugierig, anorerjeits aber jđzeu,

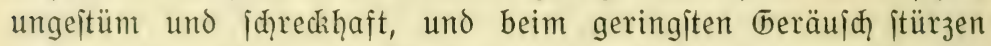
fie in verzmeifelter fluạt davon. Als Bodentiere veritehen fie natürliđ) aud, fiđ in den Sand einzugraben, wobei die paddeln= den Bewegungen ihree Dorderbeine fo flink vor fid gehen, daf man ihnen kaum mit den Augen zu folgen vermag, und wenn unfreundiḑ̧e witterung anḩält, bleiben fie tagelang darin ver=

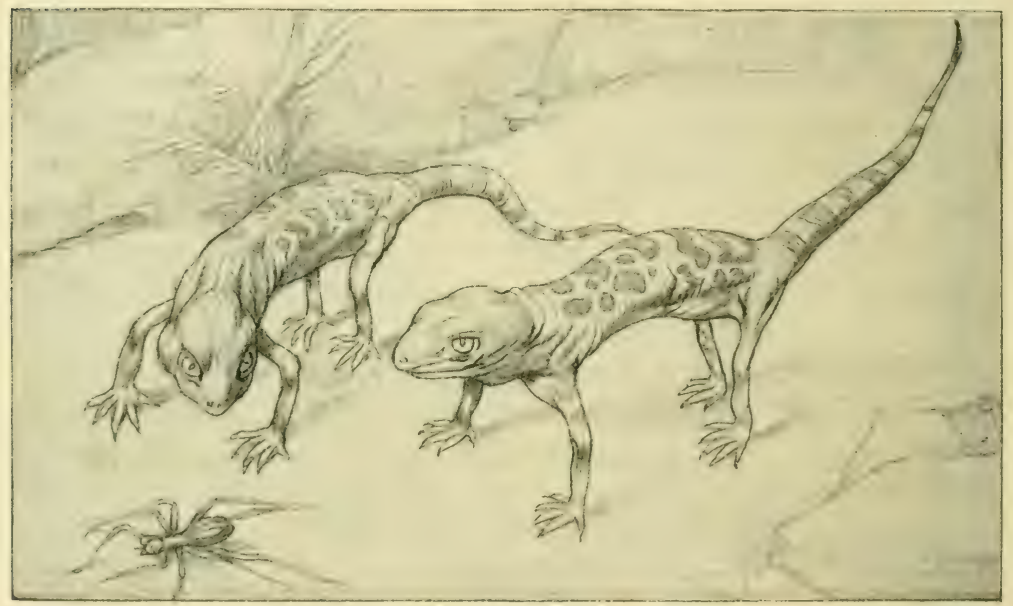

Abb. 12. Stenodactylus guttatus, cin Wüiftenticr, das dic Trägheit des faultiers mit der Drolligkeit des Dadkels und der fledrenzeiđ̧̧ung des Eeoparden vereinigt.

borgen. Ein ganż ausneḩmeno jđhnurriger (bejelle ijt nun aber ein weiterer Wüjtengedio, stenodáctylus guttátus, den idł in diejem Jaḩe felbit im Eerrarium geḩalten und liebgemonnen habe, obgleid) er eigentlid) cin hödjit langweiliger patron ift, das faultier jozufagen unter dem fonjt menigitens bei Kaḑt io beweglidyen Dolke der (bedros. Jede Bewegung wird nur gewiffer= maß̧en widerwillig vollfüḩrt, unt hat er mirklide einmal cin paar Sḑ̧rittḑen gemaḑ̧t, fo bleibt er urplöłzliḑ in der vertraditejten Stellung iteif wie eine (bliederpuppe mit unglaublid) verrenkiten (5liedern jtehen und döjt mun jtundenlang por fid, ḩin. $D$ ünn= 
finger heiß̧t das ppaß̧ige Kerlḑen offiziell, aber bejeiđgnender

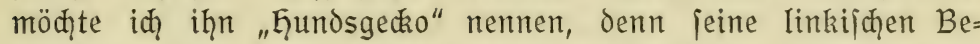
wegungen und feine köjtliđ oummen Stellungen haben etwas unverkennbar দ̧undeartiges, ḩaben mið insbejondere immer leb= haft an die bekannten Dackelbilder der "fliegenden Blätter" er= innert. Drollig genug jieḩt fđ̆on die Ruḩelage aus: der Kopf mit den gutmütigen blogaugen lang am Boden, die Dorderbeine nad, innen und unten eingejđ̧lagen, die Ginterbeine lang ausgejtreckt, das rojenrote zünglein bejtändig über die breite Sḩnauze faḩrend, der lange Rolliģwanz bei guter Stimmung freundlidg wedelnd - aljo eḑt ḩundeartig. Unjägliđ einfältig und dabei dođ wieder ganz bauerniçlau jieht der kleine Sḑelm aus, wenn er jiđ auf jeinen krummen Dackelbeinen jo hodh aufriḑtet, daß̉ das wüitenfarbige, leopardenartig gefleckte Körperçen förmlich in der suft zu

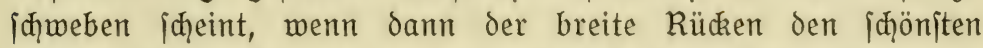

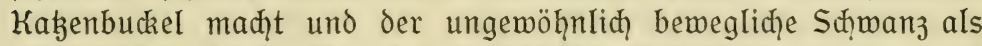
untrügliḑer bradmeffer der geheimiten Empfindungen ein = und aufgerollt oder hin und her gejḑwungen wird, die bis auf einen haarförmigen Spalt verengten, übrigens re⿻̧一 guten Augen aber mit der Madjoenkliḑkeit eines philojophen nady vorn itarren. In

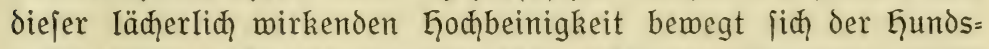
gedzo dann aud mit ausgejtreditem Sd̨̧wanze pormärts. Selbit

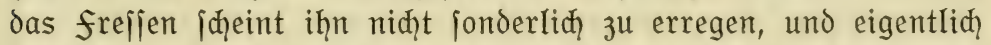
bekundet er nur für eins wärmeres Intereffe: fürs Graben im Sande, das er mit gründlid̨=behäbigen Bewegungen der \{đ̧einbar

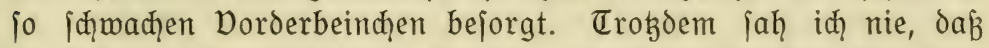
er fid jemals völlig im Sande vergrub; er fá̉ immer nur,

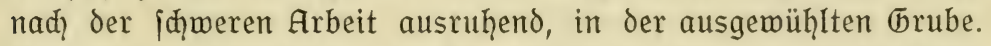
Dout meinen Streifzügen in den transkajpijḩen und bucharifąen wüjten her erinnere iđ mid nođ mit bejonderem Dergnügen der ¡đ̧̆on erwäḩnten Krötenköpfe (Phrynocéphalus), die mit Stenodáctylus die ḩundeartige Bemeglid̨)keit des einrollbaren Sđ̧̧manzes

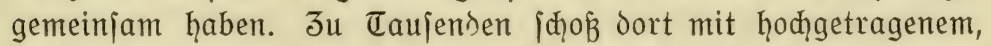
nađ̆ oben eingerolltem Sđ̧̧anze Phrynocéphalus interscapuláris im ärgiten Sonnenbrande über den flugiand, fo

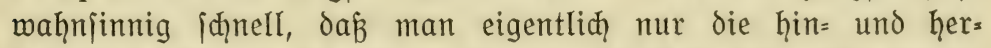
flighenden Sđ̧atten der unterḩaltenden Tierçen jah. Alle Augen= blicke wird ber itopmeife Lauf im Jidizackkurs geändert, dann 
qaujt das unfaß̧bare Ding in weitem Bogen über fteile Eänge und auf einmal veriḑwindet es mit ein paar jđüütelnden, welligen Bewegungen im Sande, wo es aber nid̨t weiter gräbt, jo daß̧ es nun unjh̨wer zu ergreifen ift. Die meijten Stüdie erhielt id aber dadurd, daß̧ die Kojaken mit großzen Bejen einfad) die ganz: (bejellichaft zujammenkehrten. An den gleichen örtliçkeiten lebt auch der größere uno derbere Ph. mystáceus. Sein Mops= gejiđt mit dem breiten Maul, den vieredzigen bligenden Augen, dem rojenfarbenen Raḑen und den ipigigen Jähnen maḑt einen hödjit originellen Einorudz, wenn er fid) in reizbollem Jorn tapfer zur Wehre jegt. Dann ift iḩm eine Sḑredsitellung eigen, die 3ander bejąrieben hat: Die Gautfalten an den Mundwinkeln fđ̧wellen zu einer halbmondförmigen Platte an, die vorn tief rojenrot gefärbt ijt, wodurd eine ideinbar ungeheuerliḑe Der= grögerung des Maules erzielt wird und das Tier mirklid reḑt

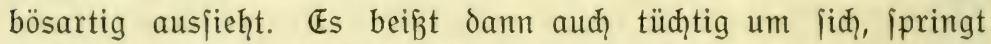
gegen die hand, läßst niḑt leiđht mieder los, was es einmal gepadit

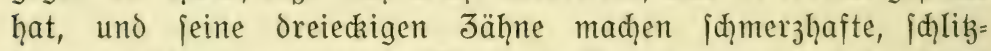
förmige, jđ̧wer verheilende Wunden. Daзu rommt, daßj der Kopf (id) auf dem langen Galle wie auf einem Stiele unter fabelhaft ¡đ̆nellem Augenblinzeln hin und her oreht, woourd das Abenteuer= liḑe des ganzen Anblidzs nod erheblid geiteigert wird. Beim Ausruhen foll diejer Krötenkopf eine ähnliḑe Stellung einnehmen, wie ein figender द̧und, und zwifḑendurd oudit er [id\} ein dugendmal und öfters [đ̧nell nieder, um (id) fofort wieder 3 u erheben. Jander meint jehr bezeiḑnend, die krötenköpfe jähen aus wie fragenhafte badende 3wergenkinder. Oder die Tiere wärmen (id) itundenlang mit behaglid) iḑief gehaltenem Kopfe, um dann plögliḑ blibłd̨nell mit den Dorderbeinen nach Gundeart im Sande zu paddeln und einen unglüdzlid̨en pillendreher ans Tageslid)t zu befördern. Dann wieder traben fie mit emporgereditem Kopfe hod)beinig wie Affen hinter einem folḑen orein, betrad)ten ihn ein Weildęen mit geöffnetem Munde und vorgejtrediter Junge wie

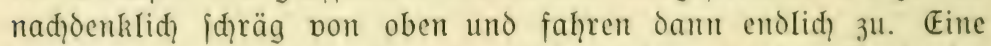
britte Art, Ph. helióscopus, Iebt niḑ̧t auf dem flugiande, fondern auf dem völlig vegetationslofen Eelpmboden, der für fo viele (begenden 3entralajiens dqarakteriftifd und fo hart und glatt wie Afphalt ift, und jagt hier fleißzig nady Affeln und mi= 
nierenden Ameijen, trägt aber im übrigen ein ganz äḩıliđjes $B e=$ neḩmen zur Sç̧au.

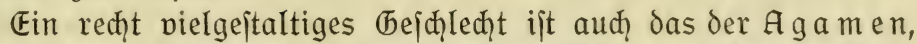

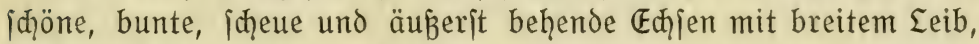
rauher Bejđ̧uppung und Iangem, dünnem Sđ̧wanł, gemandte Kletterer und vorzügliche Springer, die fid mit Dorliebe auf den jonnendurḑglühten feljen des Südens herumtummeln und bei Annäḩerung des Beobađ̧ters in eigenartiger weife mit dem oreiedrig abgeiegtem Kopfe nicken. Am bekanntejten ift die etwa $30 \mathrm{~cm}$ lange und in allen Kegerdörfern und faktoreien Afrikas vorkommende Siedleragame (Agáma colonórum), die fiđł bei (befaḩr auf Bäume mit rauher, riffiger Rinde zu flüd̨̧ten pflegt. Es find zügelloje Wildlinge und die Männḑen ausgemaḑte Rauf= bolde. Mit erḩobenem Kopf Iaufen fie hoḑbeinig auf den tbegner

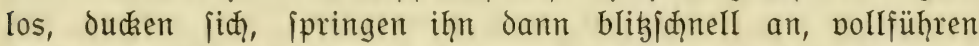

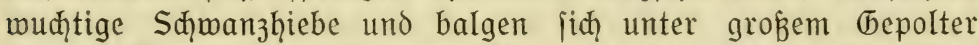
herum. Dabei zittern fie vor wut und zeigen den praḑtoolliten farbenmedyjel. Kopf = und Sţwanzende werden flammend rot, die Sd̨wanzmurzel gelb, die flanken jđ̧illernd grün. Sđhon das gemöh̨nliđ̧e prađ̨̧tkleio des Männđ̧ens, das übrigens von der paarungszeit unabhängig ijt und bei küḩler Witterung fofort

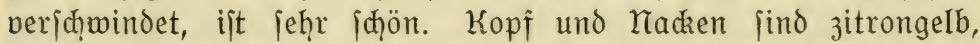

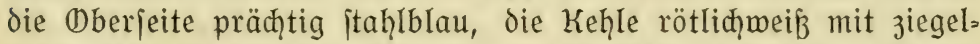
roten Eängslinien, der Sç̧wanz an der Wurzel ḩellblau, in der

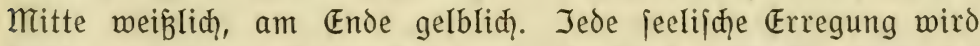

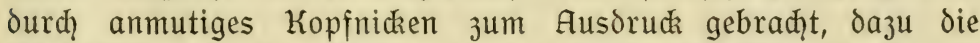
Dorderbeine breit geftellt und die Keḩle ausgejpreizt. Kqupt=

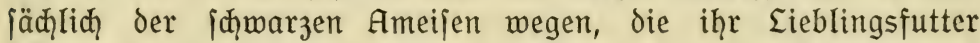
billen, ḩält fiđ die Siedleragame gern an und in দ̧äufern auf und legt hier audh in geeigneten winkeln iḩre 8 bis 10 perga=

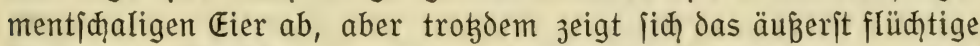
Tier dem Meniḑen gegenüber keineswegs bejonders zutraulich. Don geradezu unbändiger Sđ̧euheit und nervöjer Sđ̧reckhaftig= Keit aber ift der Ģardun (A. stéllio). Jeder jid̄ bewegende

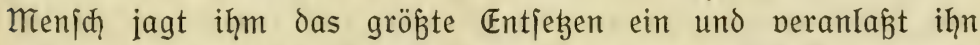
3u wilder, jinnlojer fluđht, wobei er zwar wie toll daḩinrajt, aber dod immer eine gewiffe Steifheit der Bewegung bekundet. Sein ganzes Beneḩmen in foldhen fällen ift redh̆t kopflos und 
[priḑ̧ niḑt gerade für feine Intelligenz, denn er treibt riḑtige Dogelitraußspolitik. Dermöge jeiner nadelipiłjigen, winklig abjtehen= den Krallen ift er ein vorzügliḑer Kletterer, und die ftark ent= widkelten Ģinterbeine ermögliđ̧̣en iḩm ein frojđ̧artiges Springen. Wie alle Agamen ergreift er feine Beutetiere mit ḩilfe ber klebrigen Junge und zermalmt fie dann vollitändig zwijhen den kräftigen Kiefern. Sonft iit er ein liebenswürdiger mildsling, gefelliger Natur und gegen jeinesgleidjen jelbjt am futternapfe verträgliḑ. Als ein ausgefproḑenes Tharaktertier ausgedeḩnter Ebenen muß̉ A. inérmis gelten. Dieje in iḩren Bewegungen etwas jteife und ungelenke Art ift jo jeḩr daran gewöhnt, endlos weite und völlig freie Stredken jđ̧nellen Saufes zu ourḑmeffen, dá̉ fie

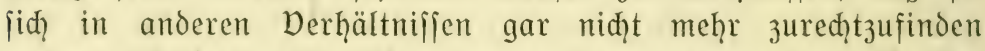
vermag, fondern tolpatichig gegen alles anrennt, was $i \not h r ~ i m$ mege iteḩt. Sie kennt eben Raumihranken ebenfowenig wie die

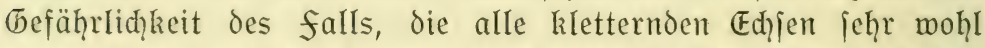
zu würdigen wiffen. Aus den jteinḩarten Eeḩmiteppen Turkejtans fteht mir A. sanguinolénta in guter Erinnerung, die dort auf der Ameijenjagd mit jehre iteif getragenem Schwanze fleiß̧ig an den Eehmmauern herumbletterte, bei (befahr aber fofort

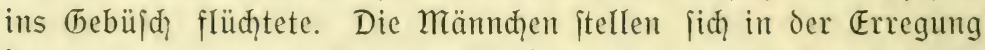
ftramm auf, jenken den Kopf, blajen den kantigen und dabei ultramarinblau werdenden Kehlfack itark auf, bekommen cinen bosḩaft ftarren Gusorudz in iḩre weit aufgeriffenen und fajt vier= edaig erfdecinenden Augen und fahren dann blinowütend auf

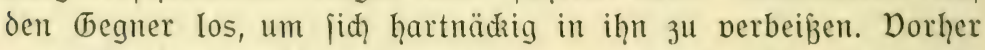
war iđ̧ f̧̧on im Kaukajus mit A. ca ucásica bekannt gemor.

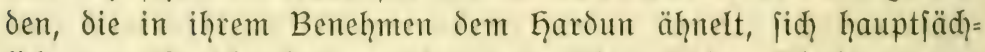

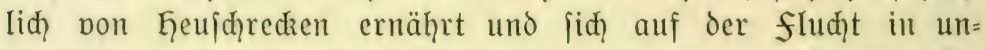
begreiflid\} \{đ̧malen felsipalten jo feitklemmt, daß̧ man fie kaumi herauszieḩen kann, ohne fie zu zerreifen. Die flinthe Ringelagame (Oplúrus torquátus) der brajilianifđ̧en wälder, deren weibḑen wie mit goldigem puder überitaubt eriḑeint, fight gewöhntid? regungslos wie ein ipähender Raubvogel an Stämmen oder Steinen, um aber naḑ kurzem Kopfnidien blindlings davon=

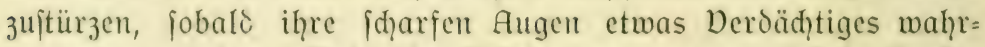
genommen haben. Daj̧ iḩr (befiḑtsfinn gut entwidielt ift, be= weifen audh die Unterfuḑungen v. fifdeers, der feititeflte, daßß 
dieje Agamen eine Steḑmüdie auf $83 \mathrm{~cm}$ Entfernung mit Siḑ̧er= heit erblickten.

Fine überaus graziöje und jđ̆lanke Baumagame ift die grün gefärbte $S$ ḑöned) fe (Calótes cristatéllus), die man in Ginter= indien überall forglos und ungeniert an den Thauffeebäumen

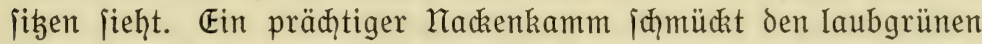
Rumpf, am Kopfe ift fie blau, am Sdywanze oben olin, unten gelb gefärbt. Bei Unbeḩagen verblafjen dieje fđ̧̈̈nen farben, aber im Jorn oder bei gejक̨leḑtliçer Erregung werden Kopf und Dorderkörper rot, wesḩalb die Singḩalejen das Tier "Blutjauger" nennen. Der kantige Kopf erinnert an das Chamäleon, und der riefige Sḑwanz maḑt fajt $4 / 5$ der etwa einen halben Meter be= tragenden Tejamtlänge des Tieres aus. Die fąlanken Beine be= fäḩigen es zu mäḑ̧tigen Sprüngen, aber troboem liebt es eine

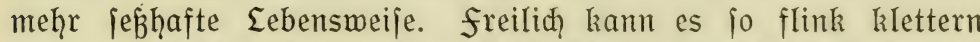

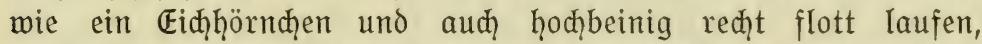
wenn's jein muß. Trob des ziemlidh entwidkelten farbwedjpel= vermögens ift dod keine Spur von farbenanpafiung an die Unterlage vorḩanden, und die lebḩaft grünen Tiere fehen desḩal: auf den Baumitämmen auffällig genug aus, zumal fie den langen Scḩanz gewöh̨nlid̄ iteif nom Stamme abjtehen lafien. In die Dermandtiçaft der Agamen gehört weiter nod eine der merk= würdigiten und interefiantejten Fided,jen, die zu bejigen der

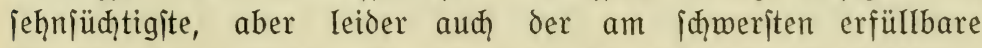
wuniḑ aller siebhaber ijt. Id meine den flugdrađ̧en (Dráco vólans), diejes jagenumwobene, ipannenlange wundertierchen der Sundainjeln, das dort in den hädj̧ten Baumkronen jein geheim= nisvolles, poefienerklärtes wejen treibt und kaum jemals frei= willig zum Eroboden herabkommt. In der Erregung ift das

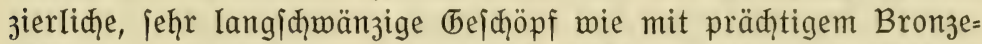
jø̧immer übergoffen, und zugleiđ̧ riḑtet es jeine auffallend lange und ipige Kehllwamme in jenkrenterer Ebene auf, fo daß̧ jie beim Ģerumklettern wie ein grellgelber Blig aus dem grünen

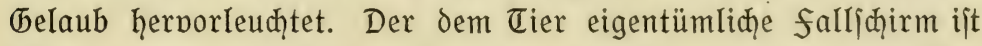
dabei zulammengefaltet und jo fejt angelegt, daß̧ man fein Dor= handenfein erit merkt, jobald fid der flugdrache zum Euftiprung

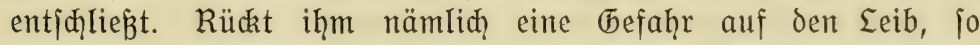

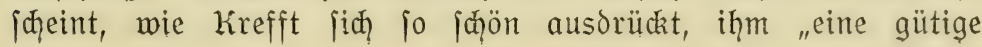


Jauberin plöglid weite, im Sonnenitrahl bunt (euą)tende Sdipingen zu verleihen". Die flugḩaut wiro halbkreisförmig ausgeppannt, und nun ¡đwebt der flieger mit perblüffender Sąnelligkeit und

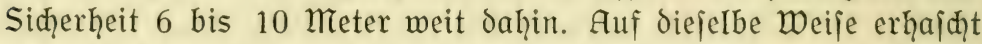
er auđ fliegende Injekten. Der flugoradie ift aljo ein riḑtiger fallidirirmoirtuos.

Mađ̧en wir nun gleid) den rüḩnen Sprung von der elegant fliegenden zu der träge auf dem Bauđ̧e Erieç̧enden und in der Erdjđolle wühlenden Edjic! Während meines Aujenthaltes im fiidliden Marokko wurden mir von den frabern wenige diere

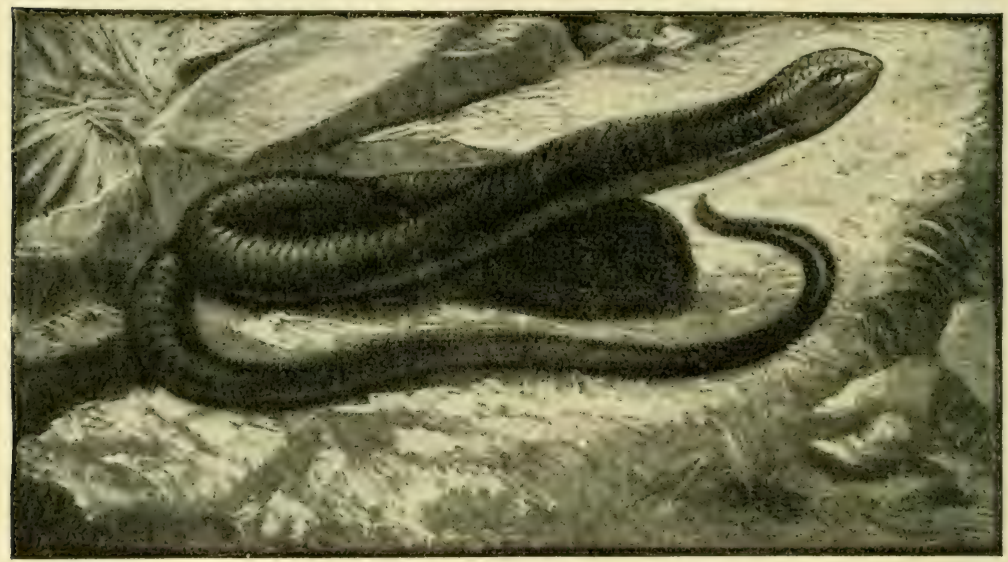

Abb. 13. Sheltopulik, in jïठcuropäijđen Steppen zu finden, ift ein fleifiger Sḑnedenvertilger uno Mäulejäger.

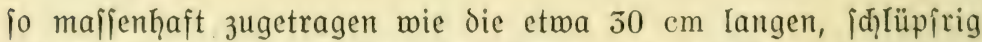
anzufaffenden und gemöhnlid) zu einem Kringel zufammen=

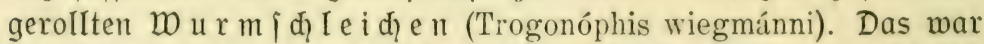

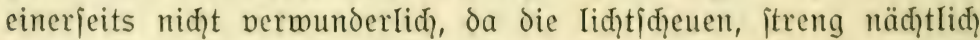
lebenden, nur verkümmerte Augen befigenden und den feud?ten দqumusboden mit ziemlid tiefen und vielfad) gewundenen (bängen ourḑwühlenden Tiere beim pflügen allenthalben zahlreid) ans Tageslid̨̧t befördert wurden, und andrerjeits dod, meil es in allen Bejđ̆reibungen heiß̧t, baß̧ sie Eingeborenen fie für giftig halten und deshalb in hohem Maß̧e fürđ̧ten forren. Aud bei

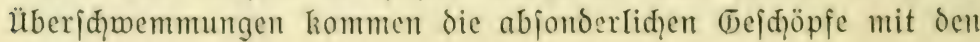




\section{$-57$}

winzigen Augen und der engen Tiundipalte träge züngelnd oft plösliḑ zu Taujenden zum Dorjđein, während man jonjt nur

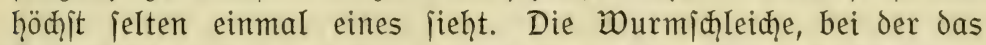

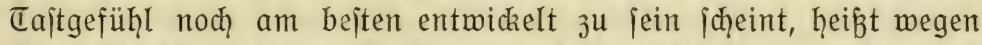

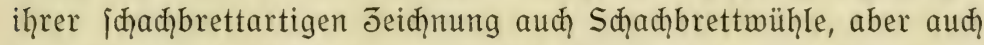
der erite Tame eriḑeint gut gewäh̆lt, oa man eḩer einen Wurm als ein Wirbeltier vor fid zu haben glaubt, indem der ganze Körper gleiđ̧mäß̈ig verläuft und der Kopf nirgends deutlid abgejeģt ijt. Auch in Südeuropa haben wir eine bedeutend größere fußlofe Edj]e, die aber in einen plattenpanzer geḩüllt ijt und niđąt einem Wurm, fondern einer Sđllange gleiđ̧t: den Sheltopulik (Pseudópus apus). Wegen der itarken panzerung kann er aber

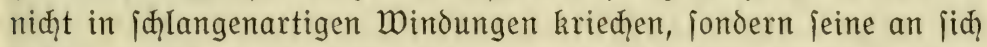
niđ̧t gerade langlamen Bewegungen beḩalten immer etwas Gölzernes. Als Steppentier ift der Sheltopujik (der Kame ijt dem Ruffiiḑen entnommen und bedeutet foviel wie (belbbaudy) troz

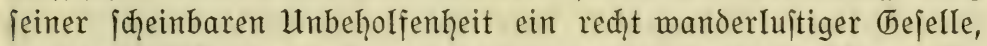
perkrieḑt fid aber aud gern in Steinḩaufen, unter itađ̧ligem the= büid oder in Ģöhllungen aller Art. Die jtark ausgeprägten Seiten= linien an feinem langgejtredaten Körper mögen woḩl die ourch sie panzerung gehemmte Atmung erleiḑ̧tern. Dem Charakter naḍ jind die Sheltopupiks indidiouell ieḩr veriđ̧̧ieden, was

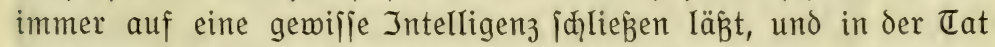
beneḩmeli jiø̆ im Terrarium gehaltene Stücke fo veritändig,

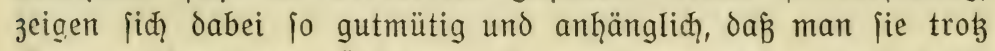

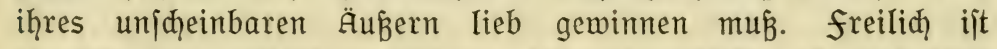
er ein gar gefräßiger patron, der gelegentliø, aud mal über Eideçjen herfällt. Auß̧erdem friß̧t er fröjh̨e, junge mäuje,

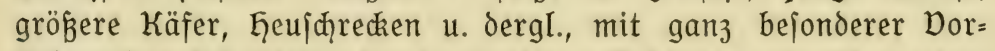
liebe aber Sçnecken, die jamt iந̨rem tbeḩäufe perjpeijt merden.

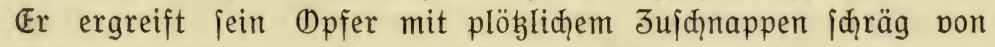
oben und drüđat es dann kräftig zu Boden, oder er oreḩt fich meḩrfaḑ um die eigene Aḑ̧e und iđ̧lägt es dabei wiederḩolt auf; in diejer weife merden aud zu grobe Biffen zerteilt.

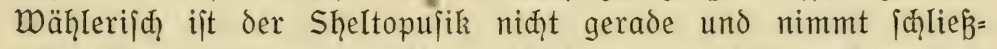
liđ̧̆ alles mögliḑ̧e. So pflegte iđ lange ein jđ̧önes Erremplar, defien Eieblingsipeije - bañrijhe Eeberknödel waren. Da der Sheltopujik zwar ein grober freund der Sonne, fonjt aber ourḑ= 


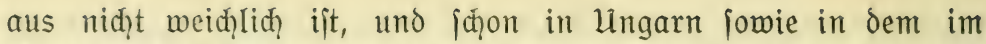
winter jehr kalten ruffijđ̨en Steppengebiet vorkommt, dürfte

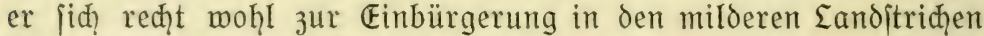

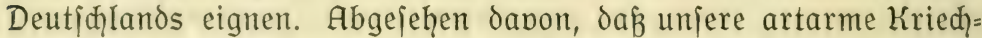
tierfauna dadurd einen fehr ermüniø̧ten Jumađ̧s bekäme, wären folḑe Derfuņe aud desḩalb mertooll, weil der Sheltopufik als fleiß̧iger Sd̨nedkenvertilger und eifriger Mäu[ejäger fid in unjeren (bärten jiđ̧̧erliḑ als jeḩr nüblid ermeijen würde.

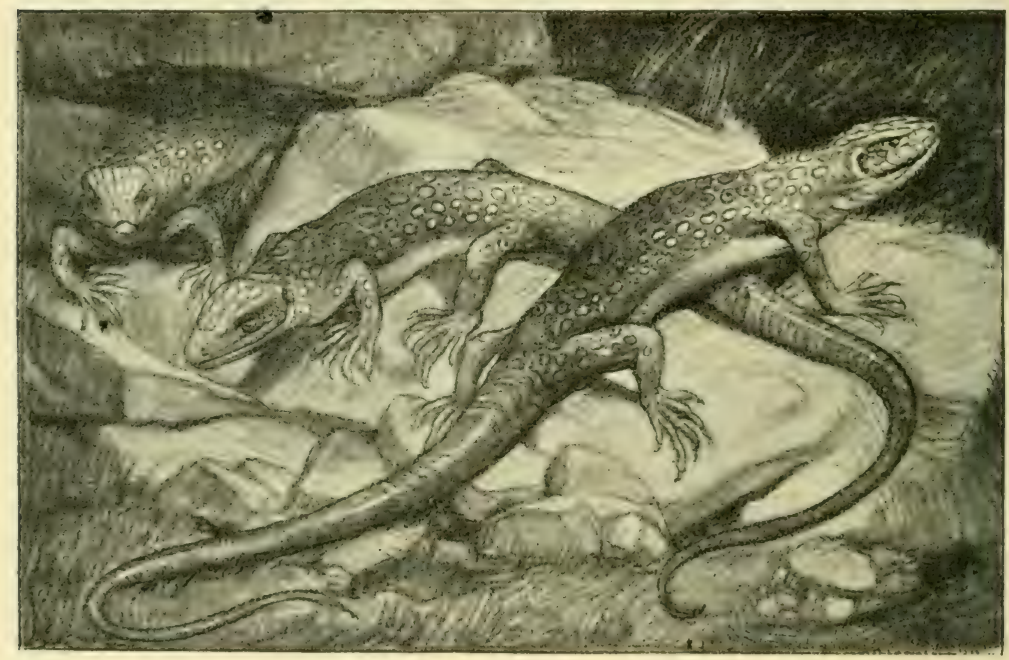

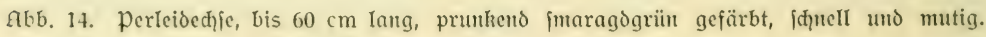

Als Dertreterin des eigenttiḑen Eided,jentnpus fei die kraft= volle, felbjtbemuß̧te, urbändige, iḑnelle und mutige perl= eide⿻̧一 (Lacérta ocelláta) angefüḩrt, das bekannte und beliebte prunkitüdz unjerer Eerrarien. Sie verdient dieje Bevorzugung in der Tat, da fie mit ihrer prunkend imaragogrünen Eeibes= farbe, dem praḑtoollen Teppiḑmuiter auf dem Rüdien uno den himmelblauen, erbjengropen fledien in den flanken in ber Tat

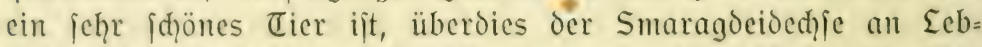
haftigkeit gar niḑ̧t, an Intelligenz mur wenig nadj̧teḩt. In Süb= wejteurope und Rordafrika bewohnt das ftattlidęe, bis $60 \mathrm{~cm}$

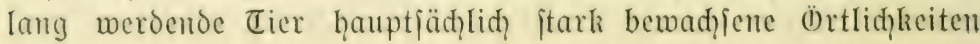


mit einer gemiffen Bodenfeuḑtigkeit. Körperlidg ift es hodg= begabt, läuft jeḩr \{đ̧̣ell, mađ̧t meterweite Sprünge, gräbt im Boden wie ein Ģund und turnt mit großeer (bewandtheit im

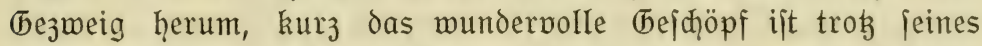
etwas maffigen und gedrungenen Körperbaus in allen Sätteln geredit und bringt namentlid unglaubliḑe Eaufleiftungen $3 \mathfrak{u}=$ itande. Der Appetit iit diejer Regiamkeit entipreḑend; die aller= größten Regenwürmer, die diđkleibigiten Spinnen und jelbjt junge Mäuje werden oḩne Sđ̨̧wierigkeiten bewältigt und zu einer einzigen Maḩzeit ganz bequem 5 bis 6 Dukend (Jrasḩüpfer ver= ipeift. Drollig wirken die von Tofoḩ bejđ̨riebenen paarungs= ipiele. Das Männḑen jenkt den Kopf tief wie ein wütender Stier, buckelt den Rükren wie ein alter Kater, prépt dabei den

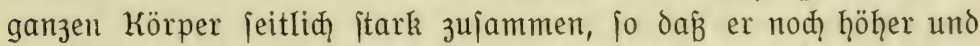
gewölbter ausfieḩt, riđ̧tet die Beine hod empor und ipaziert mun mit gejpreizten, gravitätijḩen Sḑritten liebesouritig auf jeine Auserkorene $z^{u}$ uno um jie herum, fajt ebenjo wie ein

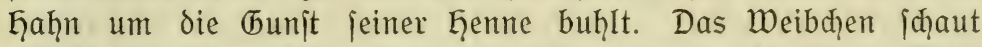
all diejer Reizentfaltung vergnügliø, zu und gibt jeiner Will= fährigkeit durch ungeduldiges $A u \uparrow=$ und Abzappeln mit den Dorder=

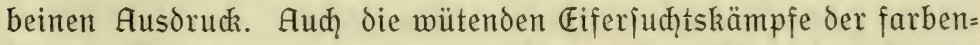
¡đ̈̈nen Männḩen untereinander bieten dem Auge des Tatur= freundes ein geradezu prađ̧toolles Sḑauipiel. Bei warmem Sonnen=

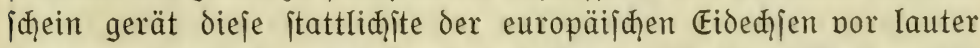
übermut förmliø außer Rand und Band. In Andalufien, wo iđ̆ fie vielfach beobaḑtet ḩabe, gilt fie beim Dolke als blüd propḩetin. Man läß̧t fie über sand laufen und bemüḩt fid dann, aus der Spur des nadigejd]leppten Sḑwanzes die geminn= verheifende Eottonummer herauszulejen.

mit den panzeredyjen oder Krokodilen geht es in unjerer 3eit intenfiniter Kultur aud fđģon allentḩalben unaufḩalt= jam bergab, und aus vielen Eanditriçen, wo jie früḩer eine ganz gewöhnnliḑe Erf̧̧einung waren, find jie heute infolge unab=

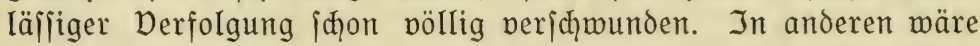
dies woḩl ebenfalls längit der fall, menn niđ̨t religiöjer Aber=

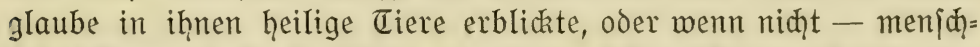

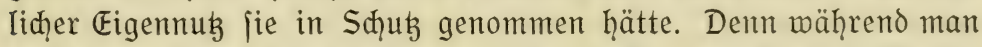
früḩer in den Krokodilen nur die niđ̧̣t genug zu haffenden 


\section{$-60-$}

Räuber und Menjhenfreffer jah̆, hat die Indujtrie der Keuzeit jeḩ bald herausgefunden, dä́ dicje Tiere aud reḑt beträcht= liđ̧̧e materielle werte darjtellen und desḩalb niḑ̧t völlig aus gerottet, fondern wenigitens in halbwildem zujtande erḩalten bleiben follten, um für den Mienjigen nußgbar gemađ̧t zu werden. Bekanntlid ijt das Kitkrokodil Iaḩrtaujende hindurd jozulagen das Wappentier ägnptens geweien, aber es kam im Altertum

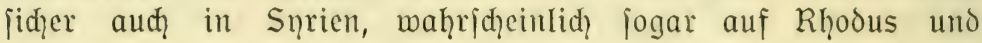

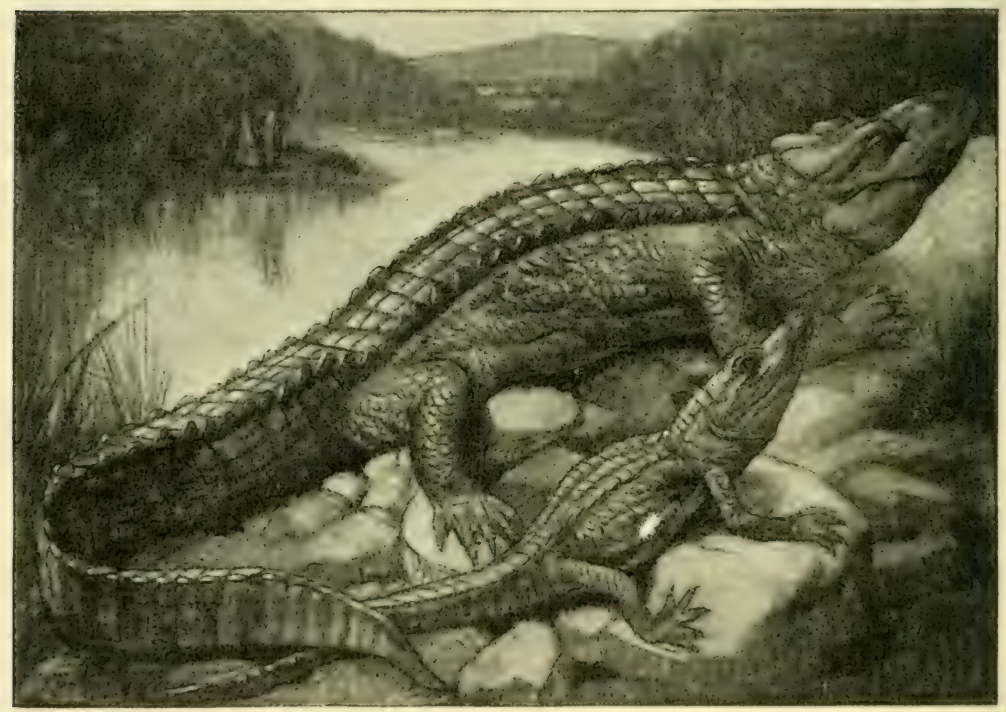

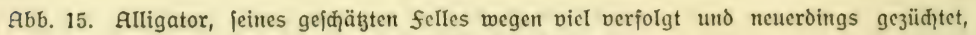
wird bis $4 \mathrm{~m}$ lang.

Sizilien vor. Geute, im żeitalter der Repetiergewehre, iit es jelbjt aus dem pharaonenlande pöllig verorängt. Mid̨̧t viel anders wäre es in Kordamerika dem Alligator (Alligátor mississipénsis) gegangen, der nođ̆ por wenigen Jaḩrzeḩnten die Sümpfe floridas ourd fein maffenhaftes Dorkommen fo unheimlidį maḑte. Aber als man bahinter kam, baß̉ cin erlegter Alligator cinen mert non 25 bis 60 Dollars voritelle, und daßj die एiere rafd immer feltener wurben, da kam der findige V)ankee alsbald auf den Gedanken, die wertwollen Eiere zu züd)ten, Alligatoren= 
farmen anzulegen. Und jieḩe da, die Sađhe ging, erwies fid, logar als reḑt geminnbringend. Geute gibt es in Arkanias iđ̧on eine ganze Reihe von Alligatorenfarmen, deren eine allein jäḩrlid̨ etwa 6000 felle in den handel bringt. Auf einer fold̨en farm finden jiðh in jorgjam eingezäunten und gejiḑerten (be= hegen Taujende von Alligatoren aller Altersitufen. Gerriḑt doch aud) nady ganz kleinen Eremplaren eine lebḩafte Taḑfrage, und niđ̧̧ etwa nur jeitens der đerrariumliebḩaber. Dielmeḩr jind die Zankeeladies auf den finnigen tredanken gekommen, junge Alligatoren als Sḑoß̉tierḑen à la mode zu erklären; ferner bienen in vielen Sçaufenitern bieje lieben Tierḑen als Ausḩänge= jđillder, jo namentlidy in denen des Tabaktrujts. In den farmen werden die Alligatoreneier auf Brutmajđ̧inen ausgebrütet, da die weibḑen, wenn man fie bei i̧̧rem (belege beläß̧t, zu will und gefäḩrliḑ merden. Die Iungen (jelbjt kaum ausgejđ̧lüpfte kojten

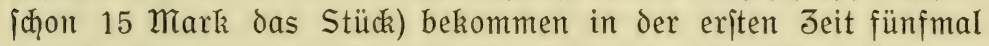

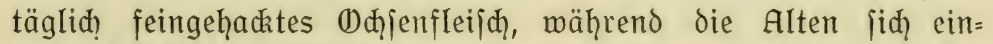

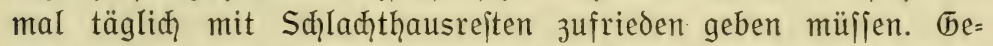

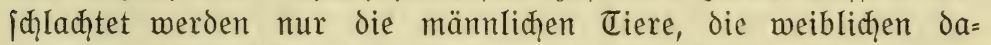

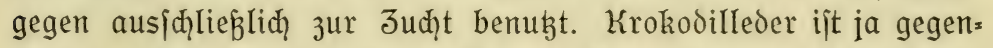
wärtig jeḩr Tooe und wird mit Dorliebe zur Anfertigung von Brief=, Zigarren = und (beldtajđ̧en, DamengürteIn und pan= toffeln vermendet. Die Jähnne dienen zu Jierraten, aus dem fett wird öI gekođ̧t, und die đđ̧warzen Bons effen mit Der= gnügen aud das fleifh, trog des iḩm anḩaftenden Mojd̨us= geruđhs. Die Alligatoren, die reiđ̧liđ vier Mteter lang werden, jind niḑt auf Amerika bejđ̧ränkt, oa jie auffallendermeije in A. sinénsis auđ̆ einen abgejprengten afiatijđ̧en Dertreter bejigen. Ia jelbjt auf deutichem Boden find fie gelegentlid iđ̧̧on als Irrgäite vorgekommen. So itrandete 1879 an ber oldenburgili̧en Küite ein lebender, etwa $2 \frac{1}{2}$ Meter langer A. lúcius, und zwar handelte es fiđ dabei nađ den Unter= juđ̧ungen Wiepkens niđ̧̧t etwa um ein aus einer Menagerie

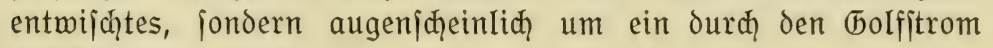
verį̧̣lagenes Stüđk.

Diele Krokodile halten fid ja mit Dorliebe gerade an der Ausmündung der Ströme und an den Meeresküjten jelbjt auf und ¡đhwimmen gern weite Strecken ins Meer hinaus, wie dies 
namentlidy von dem verbreitetiten Krokodil Sübajiens, dem mäd)tigen (es kam neun, in Ausnahmefällen logar fajt zehn meter lang werden!), aber fकllanken und hellfarbigen Eeiften= krokodiI (Crocodílus porósus) bekannt geworden ift. Wie weit dieje Seereijen unter Umitänden führen können, mag man daraus entuehmen, daß̧ ein Eeijtenkrokodil auf den Kokosinjeln erlegt murde (nädjites Dorkommen auf dem 700 englifḑe meilen ent= fernten Japa) und ein Alligator auf Barbados (näd)ites Dor= kommen an der 300 englif̧̧e Meilen entfernten Drinokomün= oung). Daß̧ aber jolḑe ausgedehnte Wanderungen niđ̧̨t ohne Abenteuer verlaufen, bemeift eine Mitteilung mitçells, der bei Trinidad beobaditete, wie ein auf cinem im neere treibenden Baumitamm fiłender Alligator bon Gaifif̧en bedrängt murde. Intereffant ift es, daß̧ die Krokodile bis zu einem gewiffen (brade Brutpflege ausüben. So f̧arrt das Alligatormeibden über den abgelegten Eiern einen mäđtigen Gaufen faulender Degetabilien zujammen, und die bei deren Jerjegung entitehende wärme hilft die allmäh̨lid ganz bräunlid werdenden Eier zeitigen wie in einer Brutmajhine. Das Weibchen bleibt die ganze jeit über bei dem Gaufen als grimmiger Waditpoiten liegen und perteidigt im rotfall fein (belege auf das nad)=

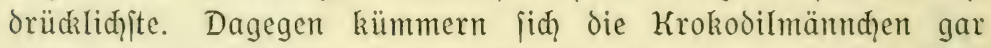
niḑt um ihre Nađ̧kommeniḑaft, bekunden iḩr gegenüber viel= meḩ häufig kannibalifhe (belüite, morauf es mohl aud zurüdi= zuführen ijt, daßs vorjintflutliche verjteinerte Saurier fo oft Iunge der eigenen Art im Eeibe haben. Das Kilkrokodil (C. nilóticus) birgt feine etwa 100 gänjeeiergrof̧en Eier einen halben Meter tief im Sande, lagert fich dam gleiḑfalls darüber und harrt jo lange aus, bis die Jungen nad) 40 bis 45 Tagen Jurd) quakende Eaute zu veritehen geben, daßj fic aus ihrer haft befreit merden möd)ten, worauf fie von der Mutter ausgegraben werden. Sic find dann etwa 15 bis $20 \mathrm{~cm}$ lang und wad?ien anfangs $[\mathrm{eh}$ l idınell, ipäter aber reḑt Iangiam. Aud erwadjicne Krokodile haben dicje quakende Stimme, die allerdings mit zunchmendem Alter immer faudiender wirb. Werner börte von ifnen aud? feltjam girrende, ję̧x laute đöne. Alle Krokodile find über= wiegend Kaḑttiere, die den $\mathbb{E a g}$ mit Sḑlafen oder trägem Sid)= fomen berbringen (wo die (5ewäffer in der heiben Jaḩreszeit 
austrodinen, halten fie im Bodenfhlamm aud einen Sommer= ¡đ̆laf) und erjt mit Einbruđ der Dämmerung zu regerer Tätig= keit fid aufraffen. Dann aber entwidkeln fie namentlid beim fifđfang, den fie mit aufgeiperrtem Rađ̧en betreiben, eine über= raiḑende Munterkeit und Gemandtheit. Aud auf dem Eande jind dieje panzerkolofje keineswegs jo id̨werfällig, wie es uns Eejefibelmeisheit glauben maḑen möđ̨̧te. Id würde wenigitens niemandem raten, jiḑ darauf zu verlaffen, daß̉ das Krokodil (iid) nux unbeḩolfen und langjam ḩerumbreḩen könne. Dies

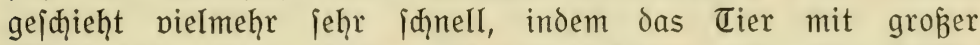
wucht den ganzen Körper auf einmal herummirft. Fine furḑ̧t= bare maffe ijt der kräftige sḑwanz des äup̧erft zählebigen Tieres, und jeine hiebe vermögen reḑt woḩt ein Boot zum Kentern $z^{u}$ bringen. Entgegen der Meinung $\mathfrak{v}$. fijd̨ers ijt Klingelḩöfer der Anjiąt, daß̉ das tauđhende Krokodil durd? die Kidkhaut im Seḩen behindert wird, da jie zwar durḑifheinend, aber niḑ̧t durdyjiḑtig iit. Mad, vorn jeḩen die krokodile viel iḑlechter als nach den Seiten, und desḩalb geiḑieht aud̆ das Ergreifen der Beute immer feitliđh mit den Seiten= und niđht mit den Dorderzäḩnen. Den Alligator iah Klingelḩ̈ffer aud mit tajtender Junge gründeIn wie eine Ente. Geruntergewürgt wird der Biffen dann mit hod erḩobenem Kopfe. Kad einer ergiebigen Maḩlzeit jonnt fich das एier mit aufgefpertem Raḑen, und der Alligator i it dabei bemüḩt, mit den Krallen der Ģinterbeine, die zäḩne von iteckengebliebenen futterrejten $\mathfrak{z} u$ reinigen. Dem $\mathfrak{r i l}=$ krokodil bejorgt diejen Eiebesdienjt ein kleiner, regenpfeifer= artiger Dogel, der jogenannte Krokodilwäđḩter (Cursórius aegyptíacus), den es ruḩig gewäh̆ren läß乃t, wäḩrend es andere Dögel, die fiđ in der Kähe zur 『ränke niederlaffen, gierig wegiḑnappt. Eandausflüge unterneḩmen die Krokodile nur des Kadhts, denn fo frech und räuberifक jie jid im wajןer zeigen, jo furçtiam

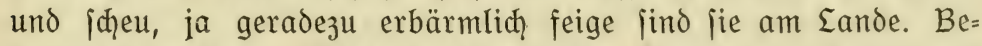
kanntlich galt das Trilkrokodil im alten ëgnpten als heilig, und man findet desḩalb jeine einbaljamierten Mumien zu Taujenden in den Grabḩöhlen an den Ufern des merkwürdigen Stromes. Ģeute freiliḑ will man jelbjt im Sudan pon diejer Ģeiligkeit niđhts meḩr wiffen, verfolgt die Krokodile vielmeḩr jederzeit nađ̆ Kräften und auf jede nur erdenkliđge weife. Tur einige Keger= 
[tämme follen nod) der Sitte ḩuldigen, alljäh̨rlid\} die äItejte frau des Dorfes beil Krokodilen zu opfern, aber fie maḑen fid, Kein Dewiffen dacaus, die als Eeckerbiffen geltenden Eier der panzereḑ̧⿻ auszugraben und zu verzeḩren. Daß̉ übrigens die allzu rüdzidhtsloje Ausrottung ber Krokodile aud bedenkliḑe

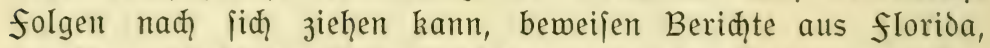

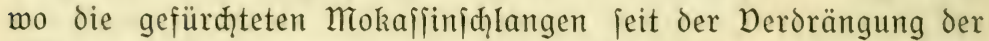
Alligatoren in geradezu unḩeimliḑ̧er beife überḩandgenommen haben. Finer gewiffen Dereḩrung erfreut (id dagegen nod bis zum heutigen Tage bei frommen Indern ber ungemein iḑmal=

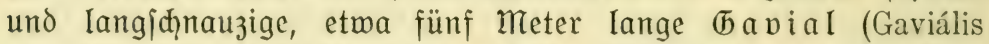
gangéticus) der indiłđ̧en Ströme, deffen Männchen cinen eigentüm= liđ̆ knolligen Aufiał auf der Sdynauzenipize trägt. $\mathbb{E r}$ ift in der Tat woḩl das harmlojejte aller Krokodile, oa er fid fajt

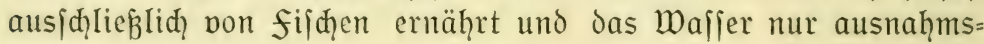
meife verläßst.

Wie der Alligator, fo find aud einige Schildskröten für den menjक̨liḑen Ģaushalt bedeutungsvoll geworden, fo vor allem die

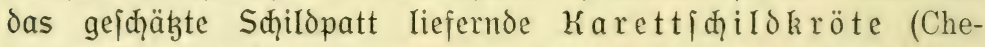
lóne imbrieáta), die mit i̧̧ren zu breiten flofien umgemandelten Dorderbeinen die tropifḑen Meere unglaublid fđhnell und gewandt meḩr ourdffliegt als durdichmimmt. Nur zur Eiablage fteigen dieje Tiere an ganz bejtimmten jandigen Küjten, an benen fie mit groß̧er zäḩigkeit feitḩalten, ans Eand, mur zu oft zu iḩrem Der= derben, denn io rüdrjid\}tslos verfolgt fie überall der habgierige

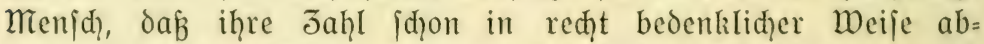
genommen hat. Eeider rommen bei diejen Sd̨̧äd)tereien aud̆ nođ gräßlid̨e एierquälereien vor, indem man dic didien, wunder= voll geflammten Rüdenfḑilder ourd) Einmirkung von Gibje viel= fad) an dem nod lebenden Eiere ablöit. Befonders für reu= guinea und den Bismardiardzipel ift Sd\}ildopatt ein \{ehre wiḑtiger Ausfuḩrartikel geworden. Bei der großzen Sd̨̧wimmfähigkeit des Eieres kann es niḑt weiter wundernehmen, daß̧ vereinzelte uno verirrte Karetten aud fdzon an den englijd̨en und holländifd̨en Küjten erbeutet wurben. Gäufiger ijt das bei ber aud? in ge= mäßigten meeren lebenden Seefdillokröte (Thalassochélys carétta) der fall, der "uneçten Karette", die ḩeutzutage wohl den grö̈ten Eeil des in den Gqandel kommenden Sdhildpatts liefert. 
Sḑon der veriđ̧wenderif̧̨e Carvínius Póllio mađ̧te die Römer mit diejer Art Schildpatt bekannt, und es ḩat feitoem allen Saunen der Mode getrogt und feine Beliebtheit unverändert bis zur (begen= wart beibehalten. freilich ijt es ein reḑt kojtipieliges Material, denn jđjon an (Drt und Stelle kojtet ein mittelgroßes Rücken=

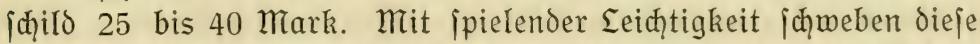

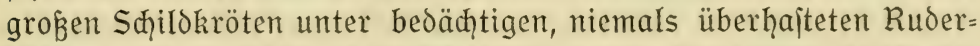
iḑlägen in wundernollem Wajferflug wie Raubvögel durd) die meere, und dieje groß̧artige Bewegungsfreiḩeit gejtattet iḩnen aud, ganz die Eebensweije von Jugnögeln zu füḩren. Im Sommer

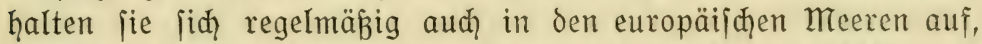
aber mit Beginn der rauhen Jaḩreszeit mandern fie jđlleunigit nad) Süden, und auf dem Markte von Eriejt 3. B. jieht man wäḩrend des Winters keine einzige meḩr. Es jind ausgejproḑene Goḍjeetiere, die nur zum Ruhen und Sonnen in die wärmeren Dberjąiḑten des Waffers heraufkommen, ihre Jagden aber in den tieferen Sđhiđhten betreiben. Somoḩl Seejđhildkröte wie Karette jind vorzügliḑe fifchjäger, und mit lautem Kraḑen zerknadken ihre Gakenkiefer Krebspanzer und Muiḑeliḑalen. Sḑnee jah öfters, daß̧ dieje Tiere fiø an Korallenriffen anklammerten, wenn jie ausruhen wollten. So beḩende fie fiđ im waffer be=

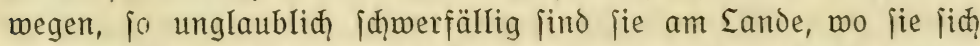
nur mühjelig mit Ģilfe der kurzen, plumpen Ģinterbeine fortzu=

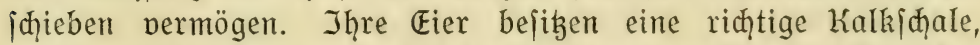
und deshalb jind aud die Embrnonen zum Durḑbreḑen dar Sçale mit einer ipäter wieder perị̧windenden Ģornwarze aus= gerüftet, während die jungen Sd̨langen und Edjen einen folḑen "Eizaḩn" niđ̧̣t nötig ḩaben, da bei iḩnen die Eijđ̧ale von leder. artiger Beiđ̆affenḩeit iit. wäḩrend das fleifđ der Karette für ungenieß̧bar, ja für gejundheits|çädliç gilt, findet das der

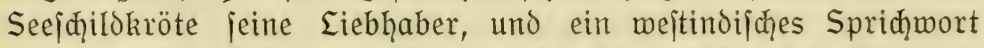

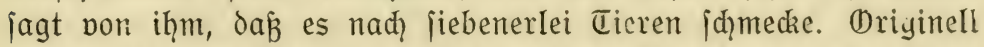
ijt dic art und weije, wie die dortigen Eingeborenen den fang diejer Sḑildkröten betreiben. Wie Ģadson erzählit, benugen fie

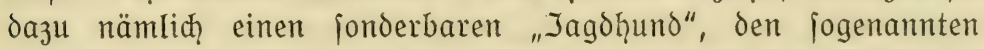
Schiffshalter (Echenéis). Bemerken die Eeute bei pitller See in der 『iefe eine ruḩende Sdịtokröte, fo laffen fie über iḩr einen

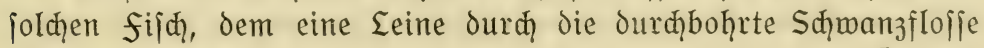

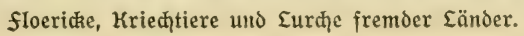


gezogen ift, ins Waffer, und fajt immer wird er fidg an dem Panzer der Sdyildkröte mit feiner am Kopf und Kadken figenden Saugidgeibe anheften und fie jo feitḩalten. Wenn fie aber tiefer taudyt, fo ftellt er dody eine Derbindung ourdy die Eeine her, bis ein Taucher hinabkommt, den Koloß̉ feffelt und die Bootsbefałung nun die iḑwere Eajt an einem एau heraufziehen kann.

Eine nahe Derwandte der Karette, die Suppenidillo= kröte (Chelóne mydas) hat in der ganzen Welt kulinarifhe Berüḩmtheit erlangt. Wäḩrend iḩre Gornidilider fajt wertlos find, ift das fleifd vorzüglid, und dient insbejondere zur $\mathrm{Be}=$ reitung delikater und jeḩr kräftiger Suppen. Aud\} die kugel= runden Fier werden von den Eingeborenen überall gern gegeffen,

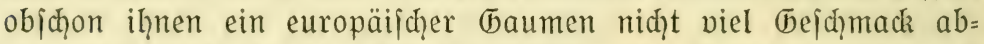
gewinnell wird, da bas Eimeif wäfjerig, der Dotter aber fo grob ijt, als jei er mit Sand verrüh̆rt. Die Eebensweife ijt ber der

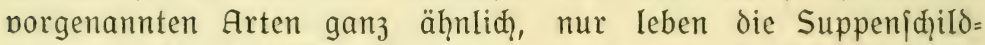
kröten niḑt von meeresgetier, fondern von allerlei pflanzen= ftoffen, $\delta$. দุ. nur die alten, denn die jeḩr \{ḑnellwüd\}figen jungen find auffallendermeife reine Degetarier. Aud ijt die suppen=

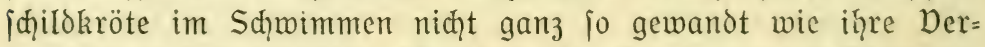
wandten, und insbejonocre fheint ihg das Tauḑen cinige Sdqwierig= keiten zu maḑen. Will jie ausruḩen, fo legt jie nady Sdinee die Dorderflofien von feitwärts über den Rand des Rüdrenidjildes

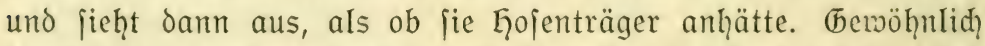
bleibt fic keine minute unter Waffer; dann erfḑeint jdyon wieder ber Kopf, deffen unjäglid) dummes Ausfehen dem Auge geradezu wehe tut. NTur unter kräftigen, ftrampelnoen Bein= bewegungen kann das groke 『ier überḩaupt nad) unten ge= langen, dort aber nid̨t auf dem Grunde herumpazieren, wie etwa unfere Sumpfidildokröten. Alle ihre Bewegungen find von einer gewifjen Sḑläfrigkcit und Tolpatjđjigkeit, auf dem Eande vollends von einer geradezu klägliḑen Unbeholfenheit unt Eang= jamkeit, ber charakter pon cincr blöden Ģalsitarriglicit, und

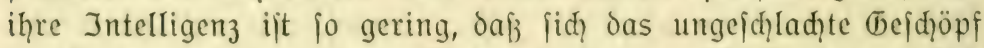
oft ftundenlang an einem Gindernis herumequält, ftatt es cinfad? 3u umgehen. Das frefien geiḑicḩt iḑwimmeno im flaḑen waffer, mobei der kopf nad) unten gehalten wird. Sdynee ver= mutet, daßj bie jd̨madihaften điere früher auf cinjamen Infeln 
öfters durø Seeräuber eingebürgert wurden. So jeḩr folḑe, wie überḩaupt alle Seefahrer, von jeher das fleifd der Suppen=

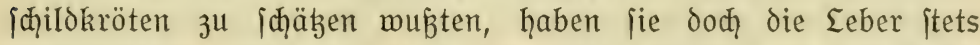
meggeworfen, weil jie dieje für giftig ḩalten; ob mit Reçt, muß einjtmeilen daḩingejtellt bleiben. Im Ģausḩalte der im (bebiete des Amazonenitroms anjäffigen Dölker ppielt die Arrau= $S$ di ilokröte (Podocnémis expánsa) eine hoḑwiđ̧̣tige Rolle, und

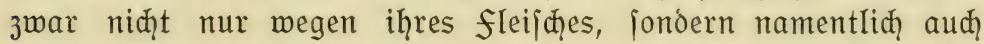
wegen iḩrer zur Geminnung von Eeuđ̧̨töl dienenden Eier. Wir verdanken dem bekannten Erforjḑer Brafiliens, Goeldi, hierüber eine ebenio eingeḩende wie anziehende Sḑilderung. Wäḩrend des winters fühnt das 『ier im Sđ̧wemm= und Eagunengebiete eine jeḩr veriteckte Eebensweife und ernähnt jich pon abfallenden Baumfrüđhten. Die jđ̧arffinnigen Indianer wiffen es jederzeit unter den Käḩrbäumen aufzufinden und trob̧ jeiner groß̉en Mtuskelkraft tauḑend zu ergreifen, wäḩrend Anjiedler und Miejtizen die Jagd mit der Garpune betreiben. Wenn dann die Sçirfokröten in die flüffe zurückkehren, veriperrt man die Gusgänge der Eagunen mit Tegen und veranjtaltet förmliçe đreibjagden, wobei Pfeile zur Derwendung gelangen. Antre Jäger ftellen fiḑ an den genau bekannten Wanderftraß̧en auf den Anitand. Die Ģauptmegelei aber findet dann jtatt, wenn die vorher im Waffer begatteten Weibchen zur Eiablage an die Ufer oder auf hohe Sandbänke kommen. An bejonders günjtigen Stellen eriḑeinen bann die Sḑildkröten oft in folḑer Mrenge, daß jie iḩre Panzer klappernd gegeneinander ftopen und den Kähnen den $\mathrm{Weg}$ veriperren. Jedes Weibḑen iḑarri eine trube von einem halben Meter Tiefe aus, legt 80 bis 200 Eier hinein und dedit jie dann forgfältig wieder zu. früher wartete man wenigitens mit dem Morden, bis dies geiḑeḩen war, und infolgedeffen entgingen aud manḑe befonders gut per= ftedzte Eiergruben der allgemeinen Derniđ̧̧tung. Geute aber will

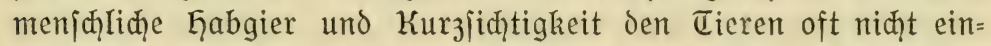
mal meḩr dieje kurze (5nadenfrift gönnen, und jo wird ein großßer Teil jđ̧on vor der Eiablage umgebraḑ̧t, viele audh an ungünjtige Drte veriprengt, wo die Delege zugrunde gehen müffen. Deriḑont wird überḩaupt niđhts mę̧r, und die folgen diejes brutalen Raubbaues, gegen den (5oeló mit Reçt ein takiräftiges Ein= [đ̧̧reiten der Regierung fordert, maḑen fid, denn aud in einer 


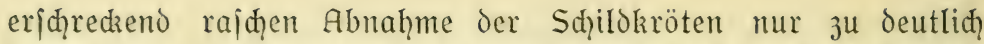

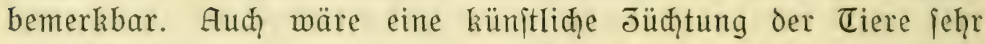
ausfichtsreich und gewinnbringend. Jur zeit der Eiablage fammelt fid die ganze Bepölkerung aus der Umgegend an den flups= bänken an, und auf den Sandbänken entwidkelt fiḑ cin rid̨tiges Iaḩrmarktsgetriebe. In großen Keffeln brodelt überall an ben

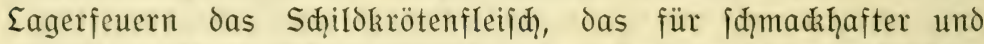

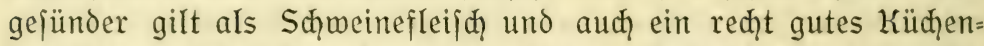
fett liefert. Die Eier dienen in frifđ̧em Jujtande als Erjas für

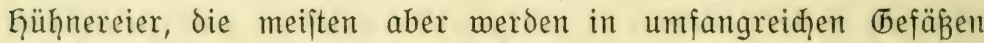
mit den füßen zeritampft, und der entitandene Brei wird unter Beifügung von etwas Wafjer umgerühnt. Das Albumin löjt fiø̄,

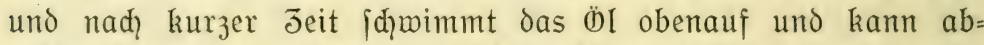
geiḑöpft werden. Aber um 12 Kilo öI zu erḩalten, brauđ̧̧t man 3000 Eier! Wo eine Eiergrube der Aufmerkiamkeit des Menjhyen entgangen ijt, da gräbt, wie (boeldi iḑreibt, "ein Injelit von auben einen (bang zu den Eierlöḑern, um die faulen Eier weg=

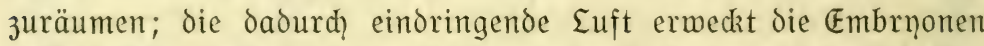
zum Eeben". Im Januar eridgeinen die Jungen an der Erbober. fläḩe, aber gleiđh auf dem kurzen Wege zum Waffer bedroḩt fie eine Unmenge von Thefahren. Den Menjdzen gelten fie als ein bejonderer Eeckerbiffen, die (beier räubern viele meg, und im

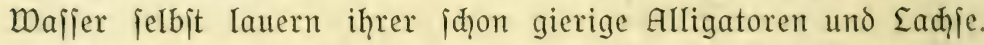
So ppielt fid̄ am größten Strome der Erde ein furḑtbarer Der=

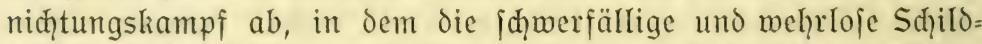
kröte in ję̧r abję̧barer frijt unterliegen muß̧, da fie den đücken diejer zeit niđgt meḩr gewadjjen ijt.

Unter den kleineren Süßwajferiḑildkröten gibt es eine groß̧e 3ah̆ intereffanter und hübfḑer Arten, auf bie näher einzugeḩen

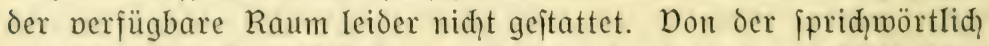
gewordenen Sd̨werfälligkeit und Eangjamkeit der Sđ̧ildkröten

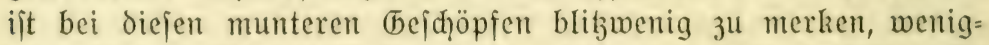
ftens folange fie im Waffer find, denn nur hier entfalten fie in ftändig weḑfehtndem Wogen, Weben und Sd\}weben bie iḩnen eigene Erazie und Eleganz. "Der plumpe Sḑildoträger," fagt Klingelhöffer, "wird zum gefährliḑen und hurtigen Räuber." Selten ift die willde und aufregende Jago nad) fijden, wobei fie fid) oft gegenjeitig fajt planmäßjig unterítüłen, ohne Erfolg. Und 
itaunt". Der lange, muskelkräftige Gals leijtet ił̧r offenbar in meḩr als einer Bezieḩung ganz gute Dienite. Beim Abwärts= kllettern benught fie iḩn als hemmborrid\}tung, und bei der $B e=$ wältigung eines großjen Biffens hält er diejen abwedjelno den

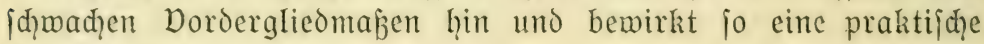
Arbeitsteilung.

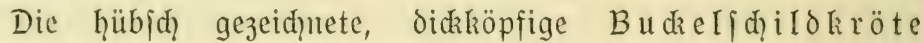
(Damónia réévesi) ergögt durd) iḩre paarungsipiele, wobei das Männd)en ftundenlang im Waffer vor feinem Weibd̨en ḩin und her tänzelt, den Ģals lang ausredit und feine Sḑnauze zärtliḑ an der der ḩerzallerliebjten reibt. Wenn fie in recht naḩrungs= reiḑen Teiḑen lebt, wo fie fiđđ niđ̧̨t viel Bewegung zu madhen

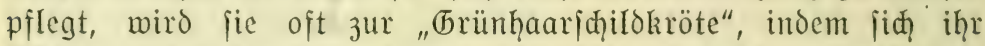
Rüdren mit 3 bis $4 \mathrm{~cm}$ langen Algenfäden bededit, wesḩalb man

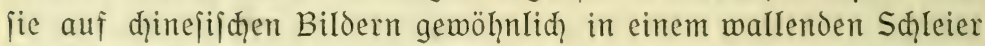
dargejtellt findet. Sie ift in Thina jehr gemein, und jeder bezopfte GandeIsmann, der zum Sḩaḑern an Bord der Sdįffe kommt, ḩat die Tajden mit diejen Eieren vollgepfropft. (5anz bejonders jier= liđ̧̧e und farbenpräđ̆tige, aber auđ̆ zarte und wärmebeoürftige

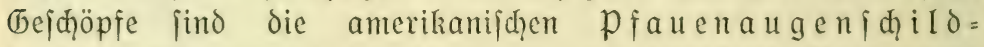
kröten (Chrysémys), bei denen wir eine bejteḑende Dereinigung von Rot, (belb und (⿹勹ün in allen mögliḑen Sättigungsgraden vor= finden. Sie find äuperjt fḑeu, lebhaft und flink und eilen unter zappeInden Beinbewegungen fhlammaufwirbelnt gar hurtig Jurḑs

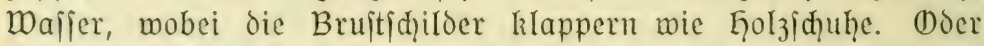
fie laffen fid], wie Kammerer beobaçtete, mit angelegten (6lieo= maß̉en im Sonnenjđ̧ein auf der Dberfläthe des Waffers treiben, wobei der glatt polierte Sąild, das leuḑtende Rot eines heraus= geitredzten fußes und das gefättigte belb der Kopffeiten ganz wundernoll eritraḩlen.

Bei den derb gebauten, einfad)=düfter gefärbten, jeḩr ge= fräßigen und biffigen weid)fd\}ilokröten (Triónyx), die in den flüffen Afrilias, Amerilias und Afiens cine näd?tlid\}=veritedite, aber keineswegs phlegmatifde Eebensweife fühţren, finten fid mur wenige und kleine knöđģerne Sdzeiben in ber Rüdenmitte, rings herum aber eine weiḑe Knorpelmaffe, die mit einer ziemlidy zarten Ģaut bekleidet ijt. (5ekemuzeidentet werden dieje merkwür=

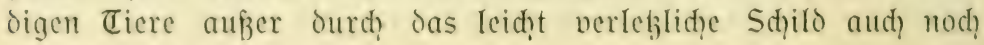




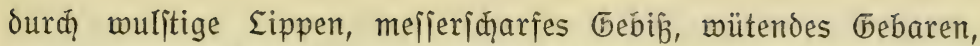
die zu einem Rüffel ausgezogene Kafe, den krokodilartigen Bau

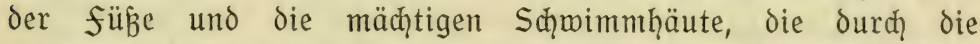
Jeḩen wie durd die Stäbe eines Regeniđhirms ausgeipannt werden können. Wir haben es aljo hier mit einer auß̧erordentlich weit= gehenden Differenzierung $3 \mathfrak{u}$ tun, und alles meift darauf hin,

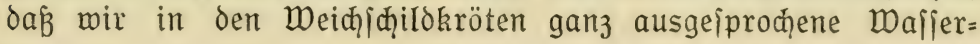

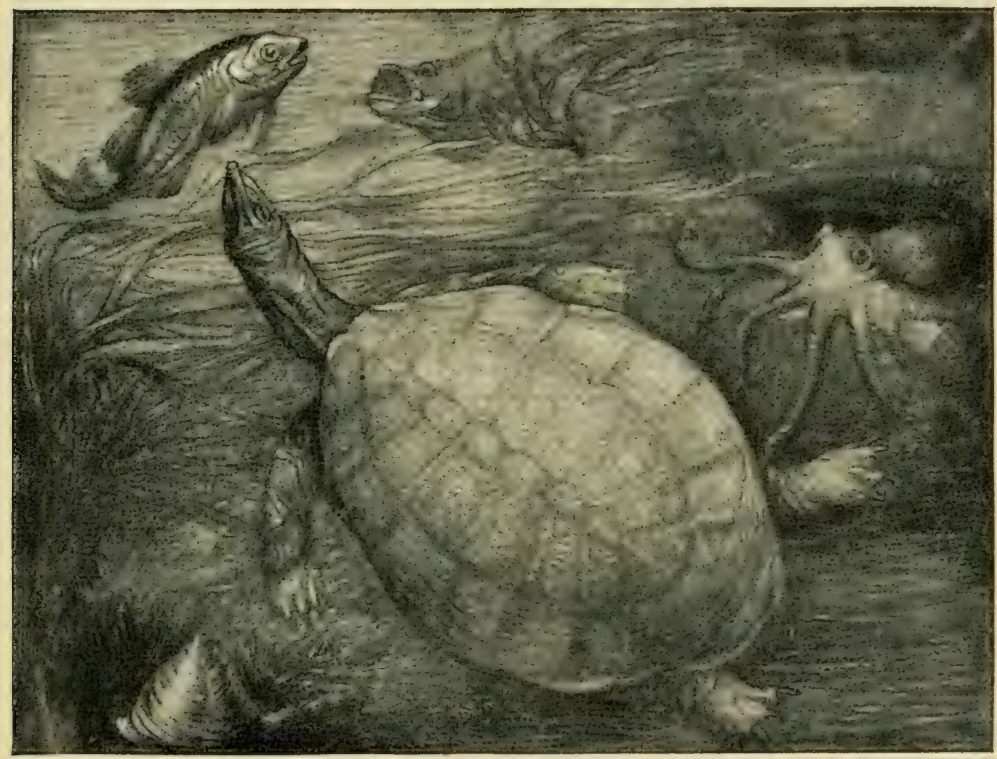

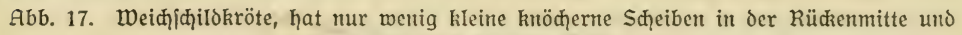

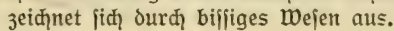

bewohner vor uns haben. Nad, Shierer befigen einige Arten jogar ein kiemenartiges Drgan, das ihnen eine Euftaufnaḩme direkt aus dem wafjer ermögliđht, wesḩalb jie halbe tage lang unter der Dberfläđḩe zu bleiben vermögen, wo fie fiø gern im Sand einpoddeIn und nur die rüffelartige Sđ̧nauze hervorjtredien. Die größeren Arten kragen und beifen ganz ge= ḩörig, wobei jie vermöge des langen Ģaljes blibjđ̧nell bald nađ̆ diejer, bald nad jener Seite jđ̧nappen, und werden dssḩalb itets did̨̧t veriđ̧nürt und mit zugenäḩtem Maule auf den Markt 


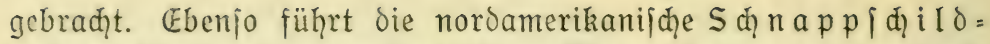
kröte (Chelydra serpentína) į̧ren Kamen keineswegs umionjt.

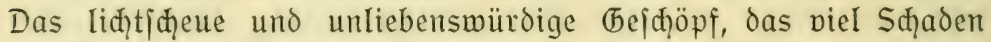
am Wajfergeflügel tut, beiß̧t einen itarken Rohritock glatt ourd, und größere Exemplare können felbjt badenden Menjक̨en ge=

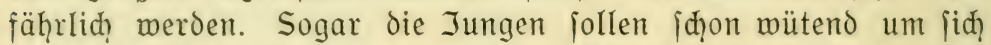

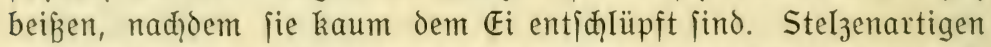
Danges und mit erḩobenem Kopfe geht fie fauḑend jeden (begner an und zeigt fiđ dabei niđ̨t nur mutig, fondern geradezu bosḩaft und heimtüđaif kröten, die iḩren aus brei Stüđken bejtehenoen Bauḑpanzer vorn und hinten nađ̆ oben zuklappen können, aljo gewiffer= maß̧en die Gärteltiere unter den Sđ̧ildkröten voritellen, führen eine rein aquatile, jedod perborgene Eebensweije, indem fie entweder im Sumpf und Morajt haujen, oder [id] tagsüber in den Sand eingraben und erit naḑts zum Dorjhein Kommen. Interefiant ift es, daß̉ fie ein dem Jirpen der Injeḱten äḩ̨n= liđ̨̣es (beräuld ḩervorzubringen vermögen, indem die Männđḩen zur Anlodkung der weibđ̧en den mit zwei obalen Gaufen von Gorn= tuberkeln, aljo Sdyrillorganen, bejeljten Unteridentiel gegen den ebenjo ausgejtatteten Dberiḑenkel reiben: eine im Reid) der mirbeltiere jonjt nur now bei den Gedionengattungen Teratoscíncus und Ptenópus vorkommende Erif̧einung. Bejonders be= kannt geworden ift von den hierher gehörigen Arten die lang=

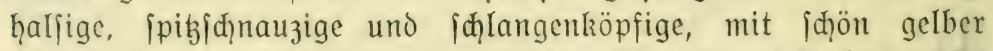

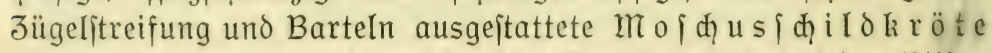
(Cinostérnum odorátum), welḑe dic (bemoḩnheit hat, jeden Biffen vor dem Derzeḩren erjt ḩundeartig jul bejđ̧nüffeln, und die jelbjt einen hödjit eigentümliḑen, vom prinzen wicd mit widerlid) \{tarkem Mojdus, von frau v. Sd̨weizerbarth mit grüner Seife vergliḑ̧enen (berud) ausitrömt. Sie füḩt in den Sümpfen cine

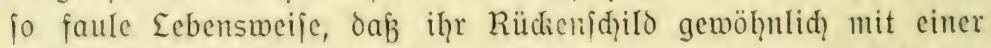
üppigen Algenflora bededit ift. Aud) bei Sternotháérus bejtę̧t der Baudppanzer aus zwei Stücken, deren vorderes heraufgeklappt werden kann und fo kopf und Dorderbeine vollitändig verbirgt. Der im Bradimaffer der Kongomiundung cin träges Dafein fül? = rende St. derbyán us verdient nodh deshalb bejonders erwähnut 3u merden, weil er durd? heftiges Jufammenklappen feiner Gorn: 
Fiefer ein hundeartiges Bellen hervorbringt. Cine indijđ̧e Sumpf= \{đ̧ilokröte, Hardélla thúrgi, hat die hornigen Kiefer aus= gezackt und fo ein dräuendes, raubtierartiges Ђebiß̈ erḩalten, wenn es natürlich aud im hiftologifhen Sinne keine zähne jind. Waḩr= icheintich ernährt fich das Tier vorzugsweife von derben, zelluloje= reidhen und kiejelhaltigen wafferpflanzen, vielleid̨̧ nebenbei auđ̆ nod) von Kruitern und Sdialtieren.

Als ein wahrer Ausbund von Derfrefienheit und Unverjchämt= heit muß die nordafrikanif̧̧e Clémmys leprósa bezeiđ̧net merden, dic logar den Krokodilen Biffen aus dem Rađ̧en jtiehlt und dann davon eilt, als jei fie nom Teufel befeffen. Fine Der= mandte von ihr, die mehr vegetarifa lebende C. japóniae mird in Japan als Sinnbild der Eanglebigkeit in heiligen Teichen gehalten. Kod beffer mürden fiđ dazu freilich die riejenḩaften, kamelhaligen Elefantenfđil nen, die jegt nur nod auf wenigen Injeln (Бalapagos, Aldabra, Senchellen) des Stillen und Indifden Dzeans porkommen, denn unter ihnen findet man in der Tat maḩre Metḩujalems. So jọägte Souzier 1895 die jeit 1810 im hof der Artilleriekajerne von Mauritius lebende und jegt erblindete Elefantenjajildkröte auf 200 Jaḩre. Das Tier mẩ in der Krümmung des Rücken= ¡̧̧ildes $157 \mathrm{~cm}$ und wog 484 Pfund. Das größjte bekannte lebende Eremplar aber befindet fic im Befige des Lord Rothjiçild, und bei ihm Iauten die betreffenden Jaḩlen auf 300 Jaḩre, $194 \mathrm{~cm}$ und 583 Pfund. 『ägliđ verzehrt diejes Ungetüm 17 bis 18 Pfund Weibkohl, für den es eine bejondere Dorliebe be= kundet. Auक ein $1906 \mathrm{im}$ Eondoner 『iergarten veritorbenes Eremplar, das 250 Kilo wog, und auf 400 Jaḩre gej历äht wurbe, benötigte im sommer eine gröBere Tagesration als eine Kuh, während es allerdings im. Winter fajtete. Enolich wurde 1911 eine Elefantenjøillokröte gefangen, die auf iḩrem Rücken eine Injhrift aus dem Jaḩre 1793 trug, dieje aljo 118 Jaḩre lang

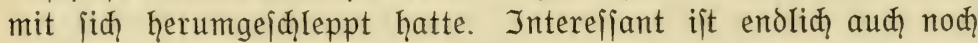

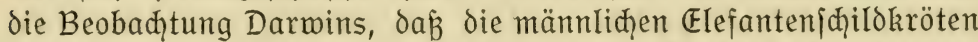
bei der Begattung ein heiferes Blöken und Brüllen hören lafjen.

Den wenigitens teilweije jo bewegliçen und lebhaften wafjer=

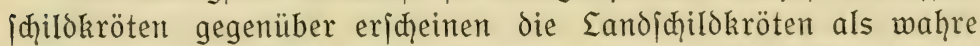
Stiefkinder der natur. Der iđwere, hođgemölbte panzer ver= 
urteilt jie zu bedäd)tigen Bewegungen, uns iḩre vegetabilifḑe

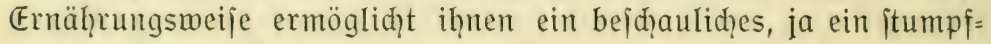
jinniges Eeben. Manḑ̧e find unglaublid unbehilflid, und Sḑnee hat niđ̧̧ fo unreḑt, menn er fie als die "faultiere" unter den Reptilien bezeiđ̧net. fajt möđhte man jiḑ wundern, dá̧ jo

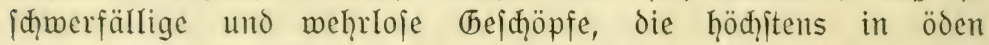
Steppen oder im Dunkel der Urmälder iḩr eintöniges Dajein zu friften vermögen, ił̧re Exiifenz überḩaupt bis heute zu behaupten vermod̨ten. Die Riejenformen, zu denen audh die eben be= iproḑenen Elefantenjđjildkröten gehören, find ja aud, unweiger= Iid) im Ausiterben begriffen, aber bie kleineren Arten in vielen

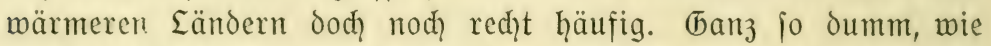
es bei flüd̨tiger Beobaḑtung den Anjḑein hat, find aber aud?

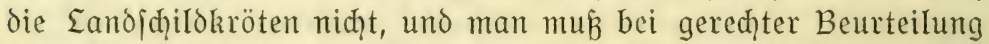
ihres bejens vieles auf Rechnung iḩrer Plumpheit, Sanglamkeit

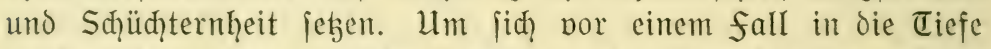
zu bewaḩren, den fie jeḩr fürḑten, gehen fie mit einer unţeug= baren überlegung bor, und ebenfo bekunden gefangene Erem= plare, die übrigens in Klojtergärten aud fdion viele Iaḩr=

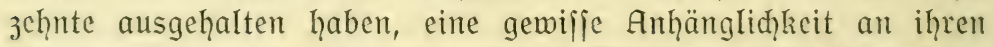
Pfleger, fowie einen unverkennbaren Brtsjinu. Mrit Dergnügen erinnere idy mid] aus meiner Iugend einer im Befitge von Der= wanoten befindliḑen grieđifden Eandjđildrröte (Testúdo gráéca), die in der Woḩnung frei ḩerumlief und hier ił̧re ganz bejonderen Eieblingspläzchen hatte, an denen jie zu bejtimmten Stunden mit Siḑerḩeit anzutreffen war. Sie folgte fogar dem Rufe iḩres Tamens und trabte fo eilig wic möglidy herbei, um Salatblätter in Empfang zu neḩmen. Darüber, daß man dicjem Tiere, das der Eiebling der ganzen familie war, ein gewiffes Erinnerungs= und Drientierungsvermögen unmögliḑ abipreḑen könne, war iḑ mir fđ̧on damals völlig klar. Ebenjo ift ein gewiffer Drang nad) Selbitändigkeit uno Abwedjflung niḑt weg= zuleugnen, fo [đ̧̧⿻а丿) es aud andrerfeits um die Entwidklung ber Sinne bejtellt jein mag. Selbjt in đurnerkünjten fino dicje Sdjilo= Eröten bei all iḩrer plumpheit niḑ̧ ganz unerfaḩren. Sie klettern jogar mit einer wahren Eeidenfḑaft, wenn aud) mit meḩr Ausdauer

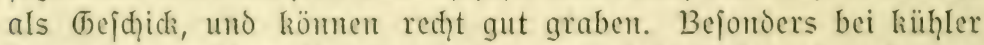
witterung maḑen fie von diefer fertigleit (Tebraudy und ver= 


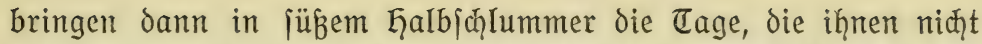
gefallen. Um fo regiamer aber werden fie, wenn bald nađ̆ dem Ermachen aus dem Winterjḩlaf die Allgemalt des paarungs= triebes fiđ geltend mađ̧t. Dann haben die Männđ̧en jogar fürs frefien menig Sinn, wäḩrend bei den weibđhen der futterneio aud jegt jede andere Regung in den Gintergrund orängt. Die burch einen längeren Sđ̧̧wanz mit größerem Endoorn ausgezeich: neten nänndien müffen daher viel நeduld und Ausdauer auf= bieten, um зum כiele zu gelangen. Iḩren Eiebesgefüh̆len geben

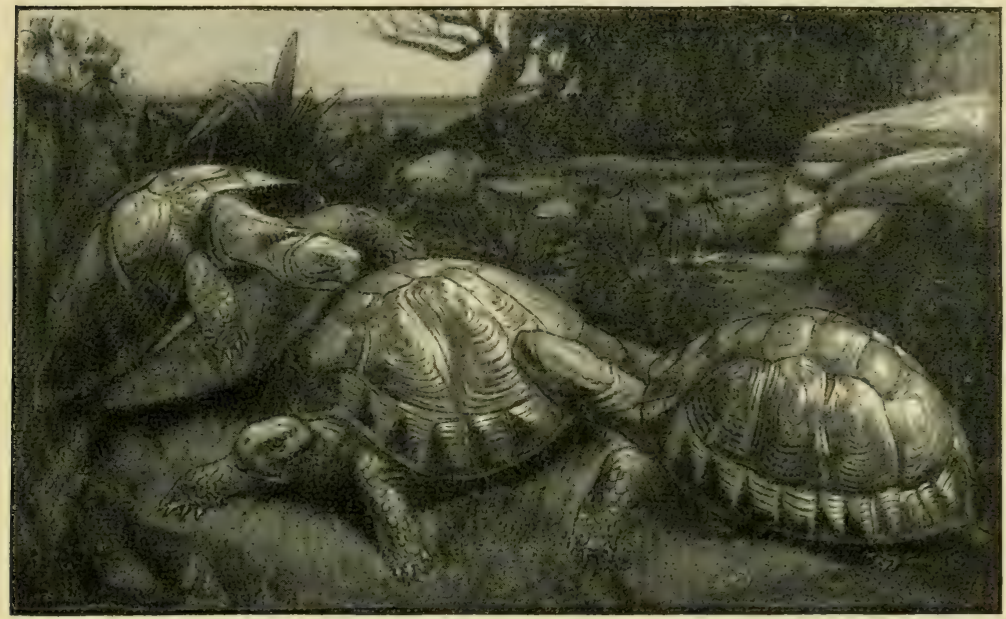

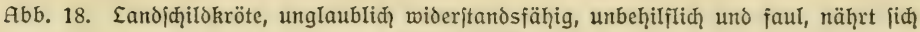
vegetabiliją.

fie durch heftiges Beißen Ausdruck, und halbe Stunden lang Iaffen fie fid jtöhnend und ädzzend von den Weibçen herum=

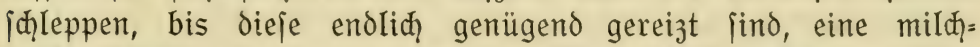
weike flüfijgkeit abjondern und den Rüdkenjḑild ḩod heben. Mit=

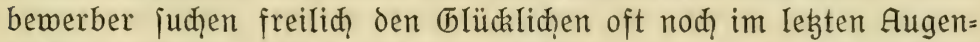
blicke zu itören und pon feinem mühjam genug errungenen Sige herabzumerfen, worüber er dann tros allem ionitigen phlegma begreifliđ̧ermeife in die größste Wut gerät. Die weißjliḑgelben, hartiđ̧aligen Eier werden in einem jhiefgehenden, 10 bis $15 \mathrm{~cm}$ langen Triđhter jorgfältig vericharrt und liefern nađ̆ 2 bis $2^{1} / 2$ Monaten die niedliđ̧en, 3 bis $4 \mathrm{~cm}$ langen Jungen mit nod? 
weid)er Panzerung. Die ge (iø) mit zuneḩmendem Alter infofern, als das Sd̨warz auf Kojten des (belb immer meḩr zunimmt. Unglaublid ift die zäḩe wioer= jtandskraft des Tieres gegen die furḑtbariten Derwundungen und Derftümmelungen, womit aber keineswegs gejagt fein foll, daßß es dabei keinen Sdymerz empfinde. Ģaben dod entjeglid grau= jame und meines Eraḑtens durd niḑts zu reḑtfertigende Der= juđ̧e der Eaboratoriumszoologen gezeigt, daß̉ dieje Sḑildkröten mit ausgenommenem Ђeḩirn nod monatelang herumlaufen! T. gráéca tritt fđłon in DaImatien regelmäßig auf, und iđ habe

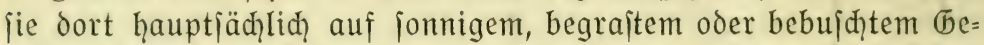
lände gefunden. Sie kann fajt als Allesfreffer (anjdeeinend findet

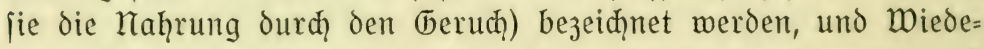
mann ḩat ganz ređ̧t, wenn er fie "oas Sđ̧wein der Ģerpetologie" nennt. Ja - hätte id) bei meiner eriten Balkanreije idjon gewuß̧t, daß̉ fic mit Dorlicbe audy Menichenkot angeht, id würde mir

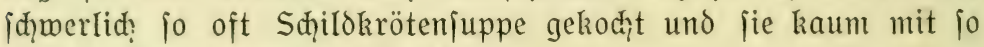
gröem Beḩagen veripeift haben.

Ijt iđ̧on der zwifḩen panzerplatten eingeengte Sdjildkröten= leib keiner übermäß̈gen Differenzierungen fäḩig, fo gilt dies in

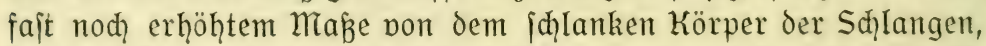
deren Eebensweife aud infolgedefien eine ziemlidh uniforme ift, fo dafj wir uns ḩier kurz faffen können. Dielleiḑt den ergtremiten Inp ftellen die Baum= und peitiđgenfđ̆langen vor, bei denen der Körper ganz unglaublid) in die Eänge gezogen ift, fo

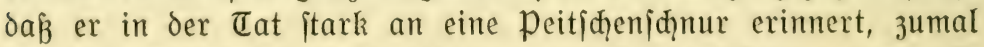
der ein Drittel der thejamtlänge ausmaḑ̨ende Sdywanz ganz all= mäḩlid) in eine fadendünne Spige ausläuft. Bei Himántodes gracíllimus 3. B. verḩält fiđ die Eänge zur Diđie wie $1: 150$ (bei Diperiden dagegen wie 1:25)! Alle Eingeweide müfjen zu den denkbar feinjten Röhren ausgezogen jein, jonjt köunte der kompli= zierte (Drganismus einer Sd?lange unmöglidh in einer folḑen peitjdenjdynur plag finden. In der Tat find audy die Baum= ¡đ̧langen zarte und niđ̧t bejonders kräftige, dafür aber äuß̧erít gewandte (5ejd̨̈pfe. Tur auf dem Eroboden, зи d:m fie frei= willia nur äuß̧erjt felten herabkommen, bewegen fie fid ziem= (id) ungejọidat. Ihr Reid) find die Wipfel oer Bäume, wo fie entweder träge und etmas fđ̧laff in Brejelform von den J̈weigen 
herabḩängen oder mit ipielender Eeiḑtigkeit meḩr gleitend als kletternd über fie hinmegeilen, bis jie eine Baumeidengle oder dergleiḑen eripäḩt ḩaben und nun in plöbliḑ̧em Doritó mit $S=f o ̈ r m i g$ erḩobenem, ftark aufgebläḩtem halje und offenem Raḑen auf jie losjḑieß̧en. Den meiften Baumiḑlangen, insbejondere den Angeḩörigen der (battung D ry óphis kommt beim Beiळ̧leiḑen der Beute auch die blattgrüne färbung zujtatten, die um jo täuiđ̧ender wirkt, als fie matt ift, aljo niđht glänzt. Wenn jo die fabel= haft geitreckten, nur bleiftiftoicken, leuđhtend grünen Gejtalten mit dem blattartig zugeipigten Kopf in itilvollen Wendungen ourḑs Blattwerk gleiten, müffien fie als ḩoḑmoderne Tiere bas Auge eines Sezeffionsmalers geradezu entzüdien. Die erḩajø̨te Beute

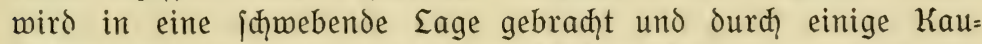
bewegungen jo meit vorwärts gejđ̧oben, $\delta a \hat{B}$ die weit hinten

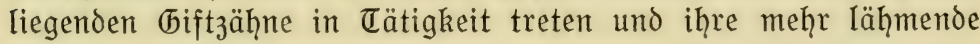
als tötende wirkung geltend mađ̧en können. Die Sd̨lingfäḩigkeit ift enorm, aber der Schlingakt wirkt trobjem niḑt fo widerlid wie bei anderen Schlangen. An dem gewaltig fiḑ ausdeḩnenden

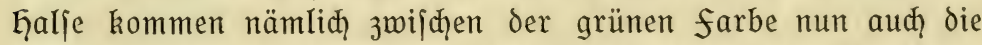

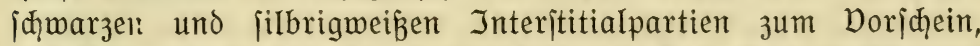
und Bera meint, daßj der farbeniḑillernde ḩals dann meḩr einer Drḑideenblüte gliḑe, in die die Eidedj]e iđgeinbar freimillig ḩineinkrödhe, ein DergIeid, den woh̆l nur eine gewiffe Dorliebe für dieje jđ̈̈nen und eleganten Sđ̧langen bewirkt ḩaben kann.

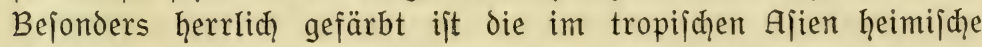
(boldbaumiḑ la nge (Chrysopheléa ornáta), die man niđ̣t mit

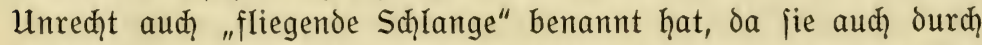
die Euft pon einem Baum zum anderen zu gleiten vermag. Sie jtreckt dabei den ganzen körper iteif und gerade aus und zię̧t den Baud zwijḑen den beiden an feinen Seiten entlang laufen= den Kaḩtlinien jȩ̣r jtark nad innen ein: jo entîteḩt eine Eängs. rinne oder দ̧oh̆lkeḩle, und - der bleitflieger ift fertig. Tharaktes

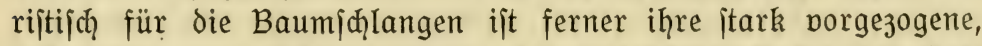
fajt rüffelartige Sđ̨nauzenipize, die maḩrł̧̨einliđ bei der Guf= naḩme der Waffertropfen von den Blättern irgendmelḑ̧e Rolle \{pielt, denn zum Tajten kann fie ¡đ̧̧werlid\} verwendet werden, da jie mit dicken Schildern bejeght iit. "Baumiḑnüffler" ift wegen diejer Rüffelfønnauze aud̆ kein übler Kame für unjere 
Sḑ̧ Iangen, dic mand?̧mal mit farbholyladungen in einzelnen lebenden Stüdien verjehentlid) aud nad) unjeren Gafenjtäbten ver= [đ]leppt werden. Jur Erleiđ̧terung der F̧äutung fondert Dryóphis wie fo viele Sdzlangen ein klebriges Sekret aus, das aber hier niḑt gerade woh̆lriechend und bejonders reid)lich ift, wohl weil der Sḑlange bei iņrem ausgeiproḑenen Baumleben felsgeitein zum Abjtreifen der Ķaut niđ̧t zur Derfügung iteḩt. Die gleiḑe Urjaḑ̧e

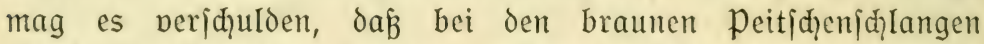
(Oxybelis) Amerikas die Ģaut niḑt in Gejtalt des bekannten

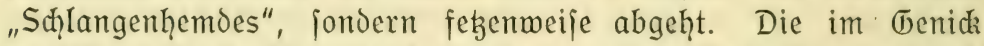
ergriffene Beute läßt Oxybelis frei in der Euft iđjweben uno eroroffert fie jo ganz langlam nach einem oft eine Dierterftunde wäḩrenden एodeskampf. In der färbung gleiḑt dieje Sḑlange

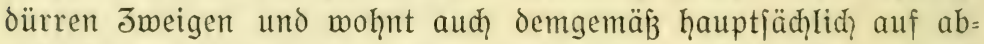
geftorbenen Bäumen, denn fo ausgefprodzene Sd\}ubfarben es aud?

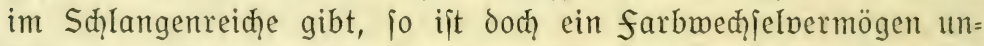
bekannt, objdzon es den Tieren manḑ̧mal ję̧r von Tugen wäre.

Eine andere, für Sd̨langenverḩältniffie ziemlid] weitgeḩende An= pajiung an eine bejondere Eebensweije ftellen die $S$ e e d $_{\text {l }}$ a $n g$ e $n$ (Hydróphis) vor, worunter natürliđg niḑt die ricjigen fabel= ungeheuer abergläubijđ̧er und phantafievoller Secfahrer zu ver= iteḩen jind, die fị̈ aus den Wanderzügen von Sḑwertfijd̨en oder Delphinen viel einfaḑer und harmlojer crklären. Die wirks=

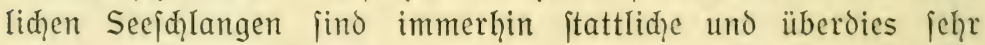
giftige Sḑlangen vom Ģabitus der Muränen, aljo mit jeitlid?

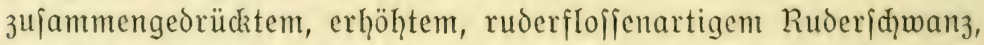
der fid̄ vorzügliḑ zum Steuern in oen Meeresfluten cignet. Don den Matrojen werden dieje zuzeiten reḑ̨ manderlujtigen Sd̨langen niḑt jelten an mit Sdpweinefleijd) geköberten Angeln gefangen. Interefianter als die von ingnen in Umlauf gebradįten uno teil= meije aud in die Katurgeidjiḑtsbüd)er übergegangenen aben= teuerliđ̧en Erzählungen find aber dic Unterfud\}ungen, dic wejt an einer Art, ber Plättḑenโḑlange (IIydrus platúrus) ant geitellt ḩat. Der (belehrte fand nämlid) runo um die Jähnne des Dber = wie Unterkiefers herum eine Menge von jehre itark ge= mundenen und ganz eritantidy entwidielten Blutbahnen, die

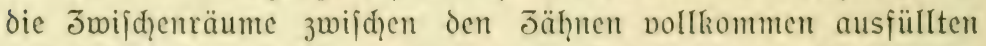
und fict) and nody ïber einen grofen Teil der beiden Kiefergeiten 
eritreckten. Es ijt kaum anzuneḩmen, dak das in iந̨nen enthaltene Blut zur Ernährung der Jäḩne dient, denn andere Sçlangen, die verḩältnismäßig weit größ̧ere Jäḩne befigen, ḩaben doch keine Spur diejer Einriḑtung aufzumeifen. Dielmeḩr liegt die Waḩr.

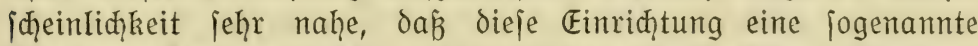
wafferatmung ermögliḑt, alio als ein akzefiorifhes Atmungs= werkzeug aufzufajien iitt, äh̨nlid wie die zottigen fortjäge im Taule der peidj]đjildkröten.

Als dritte biologijhe Anpajfungseriheinung aus dem Sđ̧langen= reiche fei endich nod die fhon in Südoiteuropa porkommende

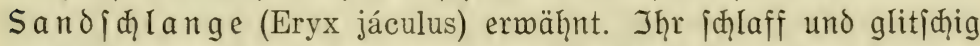

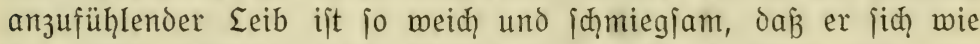
der einer Sdqnecke jeder Unterlage anpaßjt, trogdem aber un= gemein muskelkräftig. Bei unfreundliđ̧em Wetter ganz im Sande vergraben, ftreckt fie bei Somenj̧⿻ein das köpfḑen jo weit ḩeraus, daßs Auge und Kajenlöđ̧er freiliegen. Erblidat jie jo ein fürs wigiges Mäuslein oder Exḩslein, fo fäḩrt fie plöglid wie eine los=

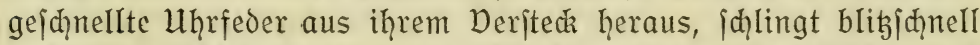
nach Riejenichlangenart einige Windungen um das Dpfer und

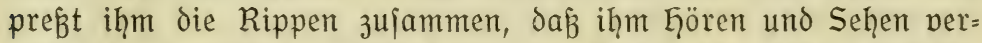
geḩt; io ungeitüm verfäḩrt jie bei diefen Angriffen, daß̧ fie perjehentlid bisweilen aud einen Teil des eigenen Leibes mit verknotet und dann zujehen muß, wie fie fich wieder herauswickelt.

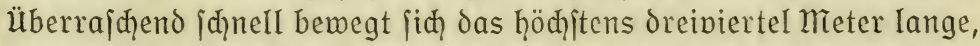
harmloje Sḩlängelchen, das die Araber für giftig halten und das

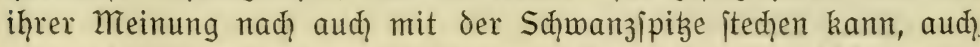
unterirdijø im lockeren wüjtenjande fort. Die Sandjक̨lange ift eben in jeder Bejieḩung eine dem Sandleben angepaß̧te Miniatur=

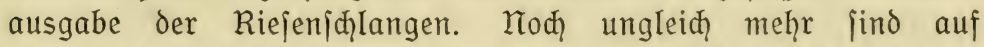
eine unteriroijhe Eebensweife freilich dic burmidllangen (Typhlops) eingeriḑ̧tet, die in der Tat weit meḩr an Regenwürmer als an Sđ̨langen erinnern, kein erweiterungsfähiges Maul und nur rudimentäre Gugen haben.

Um nun zu den Rieienfd]langen jelbit überzugehen, jo jind jie naturgejđ̧iđhtlid namentlid infofern merkmüroig, als die

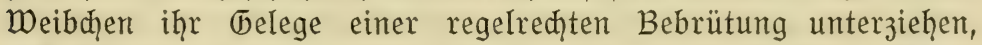
und dabei iḩre eigene Körpertemperatur eine mejentliḑe Steige= rung erfäḩrt, die bei ber in diejer Bezieḩung am bejten beobs 
aḑteten Tigerfdilange (Python molúrus) Indiens nad) den Mefiungen Marihalls 8,25 (brad beträgt. Die mit ciner didien, ledrigen Gqut verjehenen Eier find bei diejer Art jo grof wie Ђänjeeier und werden kegelförmig aufgebaut, worauf die bejorgte und daher wäḩrend diejer Jeit jehr reizbare Mutter die Sdylingen ihres gigantifjen seibes derart darauflegt, daß̧ fie ein fladhes (bemölbe bilden und der Kopf die höajte Stelle in der Mitte ein=

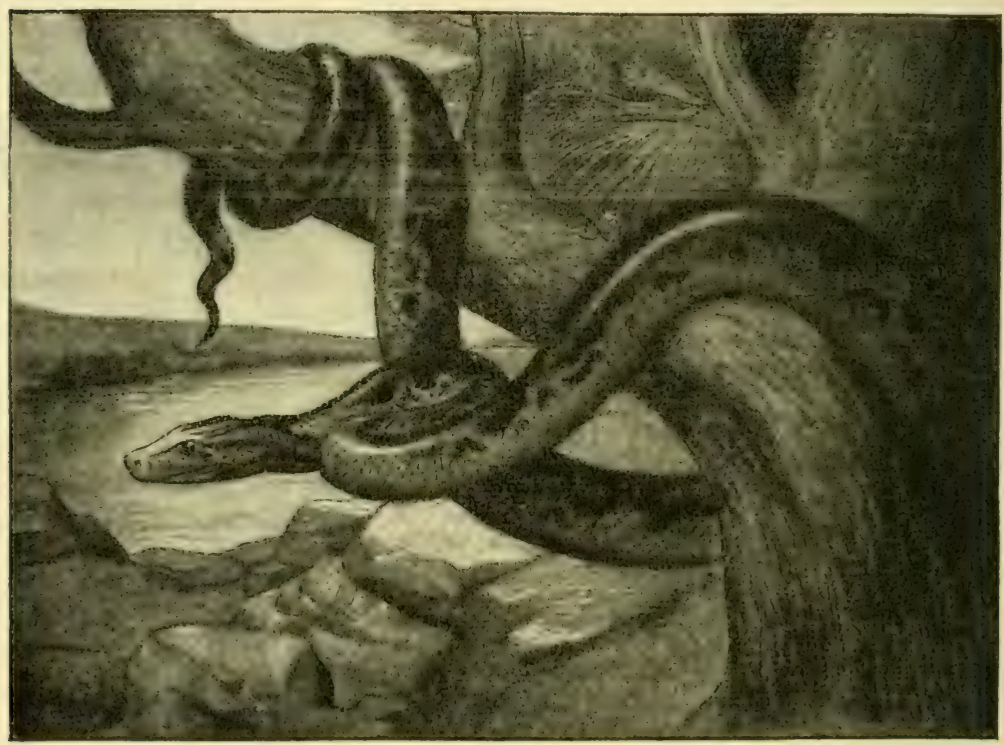

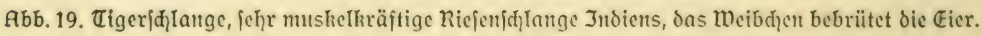

nimmt. Jhr Seib vollfüḩrt dabei öfters liurze, zudiende Bewegungen, und dem raule entfährt cin merkwürdig dumtpfes 3ijh̨en.

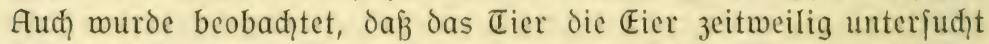
und die abgejtorbenen mit der Sḑnauze aus dem Gqufen entfernt. Die Brutbauer betrug in einem falle 82, im anderen 57 Cage. Um die ausgejd̨lïpten, etma daumendidien, 60 bis $70 \mathrm{~cm}$ Iangen, praḑtooll gezeiḑneten Jungen riümmert fid) die Mutter niḑ̨

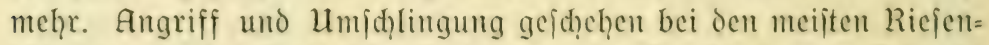

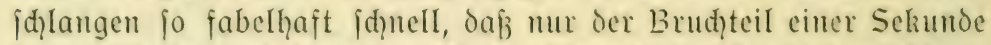
oazu nötig ijt, und das zur größeren Sicherheit nođ) mit den Jähnen 
am Kopfe gepackte Beutetier in Ser Regel niđt einmal Jeit be=

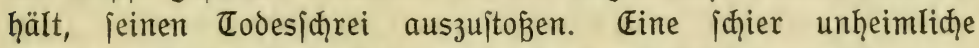

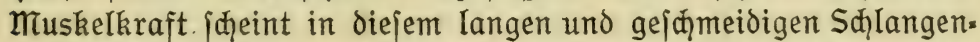
leibe aufgeipeidhert zu jein, die bei gezähmten Eremplaren jelbjt dann gefährlich werden kann, wenn fie gar niđhts Böjes beabjich=

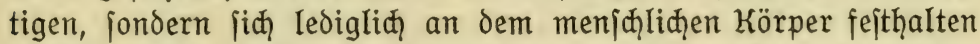
wollen. Meift müfien mittelgroßze, warmblütige điere herḩalten, aber die Anakonda (Eunéctes notáéus) jagt auch im Wajier auf fijđ̨e und junge Krokodile, die fie wie in einen Sąraubjtock einprept. Don den gewaltigen Biffen, die dieje Shlangen zu be= wältigen vermögen, wie auđ̆ von ihrer erjtaunliđhen Derdauungs: kraft, geben die im Gagenbeckinen Tierpark zu Stellingen an= gejtellten und von Sokolowskn bejक̣riebenen fütterungsverjuçe einen guten Begriff. Eine jieben Meter lange Kebidiange (Python reticulátus) aus Borneo nahm einen Sđipan von 17 Pfund und orei Tage ppäter einen fibirifđen Reḩbock von 67 pfund зu fiđ̆; eine andre innerḩalb zwei Tagen zwei Jiegen von 28 und 39 Pfund und wenige Tage ipäter eine Steinziege von 71 pfund,

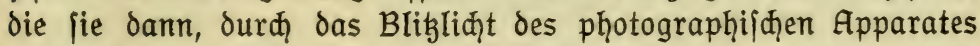
erjdireckt, innerhalb einer halben Minute wieder ausipie. Aljo innerhalb neun Tagen 138 Pfund! Ein SÆ̧wein von 45 pfund wurde in einer halben Stunde herabgewürgt. Da erjheint es

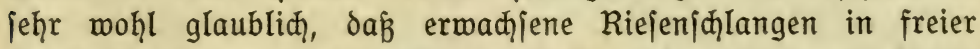
Matur Tiere von 3entnerjळwere anfallen und veriđlingen. Finige Arter follen logar aus reiner Bosheit weit über Bedarf morden.

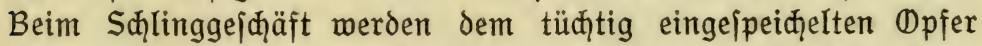
alle Rippen gebrođien und alle Knodien ausgelenkt. Die Ģarn= ausiḩeidungen beitehen aus fajt reiner Garnjäure und finden des= halb für đemijđ̨e präparate Derwendung. Der den Riejen.

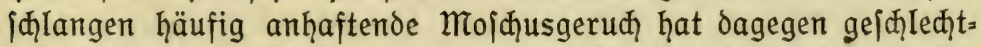
liđ̧e Bedeutung. Mađ einer guten Mahlzeit und ebenjo por der দäutung legen fie fiđ gern für längere Jeit ins Waffer und find dann am friedfertigiten. Werner, der jahrelang in der eigenen

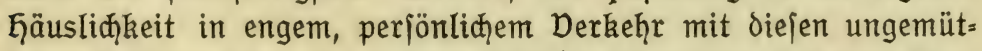

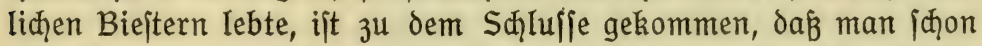

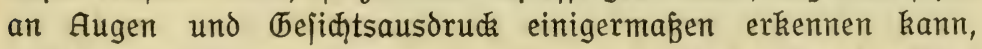
weffen man fiđ von ihnen zu verjehen hat. Je ounkler die Jris= farbe, je hundeartiger der (Бejiđtsausoruds, dejto gemütliđjer find

floeriđke, Krieđ̧tiere und Eurđ̧e frember Eätder. 
fie. für befonvers gutmütig gilt P. régius, oie fiđł gern tätichelı und ftreiḑeln läß̧t und von den Tierwärtern "Ball=

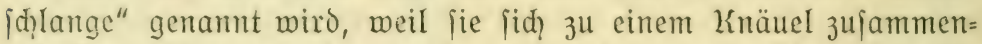
juballen pflegt und dann alles mit fiđ gefđehen läß̧t. Bei den Tierbändigerinnen aber heift iie "Armbandjąlange", weil fie ohne alle (befaḩ zu den bekannten Kunititüdiden in den Jah̨r= marktsbuden verwendet werden kann. Fin reht angriffslujtiger charaliter ift dagegen die maffige Bóa constríctor, deren Jähne böfe Bifpunden hinterlaffen und die auđ unabjiḑtlid iḩren fofort jteinhart merdenden Eeib jo fejt an die UnterIage anpreßst, daß

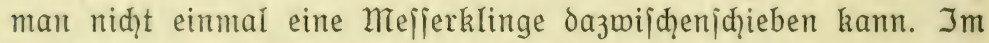
übrigen hat aber Werner (id)̧er red,t, wenn er den Riejen[d]langen meḩr indiniouelle als artliche charakternerjhiedenheiten zujđreibt, und der aufnterkjame Beobahter wird gerade bei diejer (5ruppe auf die merkmürdigiten Joiojnnkrajien und Eiebhabereien jtoben. Äuberlid) bejonders jąön find die amerikanifhen Boaarten, und

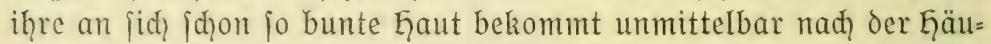
tung einen ganz prađ̧tbollen blauen oder grüngoldigen Sdimmer. Die forjt niđ̨t bejonders farbenprädhtige, fehr träge und majfer= licbende Epicrates cénchris iteigert dieje Sđ̧önheit nod?

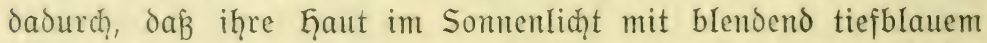
Sḑimmer in hohem நrade irifiert. übrigens gibt es unter diejer (bruppe aud kleinere und harmloje formen. So findet man in Brajilien eine hödjitens vier Meter lang werdende Boa der Ratten= plage megen vielfach als gern gefehenes Gaustier, uno die nod beocutend kleinere Ungália maculáta vollends crnährt fid hauptiäd)lid) von frölḑen, deren Eebenszähigkeit iḩr beim $\mathbb{E r}$ r= orofieln genug zu iḑaffen macht, jo daßs fie fid oft cine volle Stunde mit ihnen herumquälen muß̧.

über, die 3ahl der giftigen Sḑlangenarten gibt fid der Eaic gemöhntich jehr übertriebenen Dorjtellungen hin. ITad) Bou= langets grumblegendem Catalogue of the Snakes (18:6) kemen wir 165) (inzmijhen find es einige Dutzeno mehr gemorien) fiḑere Sdįlangenarten. Dawon fint jedod) nur giftig die 55 Secjọlangen, die 138 (biftnattern, die 106 (1)ttern und Klapperje)langen, aljo insgejam: 299 Arten gegen 1340 ungiftige. Das Derhältnis ijt demmad nut wie 2:11! Jil) kam hier nur ganz menige diefer

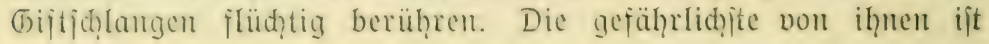


woh̨l unitreitig die gefürḩtete Brilleniđlange (Nája tripúdians), oder es fallen ihg dod wenigitens die meiften Menjhen= leben zum (1)pfer, da jie in zum Teil diđt bejiedelten Gegenden haujt. Die indijhen Statijtiker geben allerdings erjąreckende 3ahlen an. Es follen dort alljährliç now heute gegen 20000 Menichen an Shllangenbíb iterben und 400000 Brillenichlangen= köpfe gegen eine Belohnung von 50 Pfennig für das Stück $a b=$

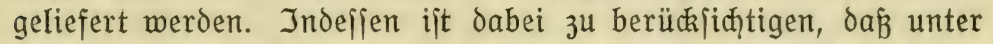
den Getöteten ein jehr grofer Prozentiał von folḑen Menidien entḩalten jein wird, deren plögliche Todesurjache oder deren ipur=

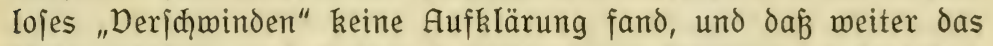
Prämienjnitem auđ hier mal wieder feine Kehrieite zeigt, indem neueren und durđ̧aus glaubwürdigen Maळ̧riळten zufolge pfiffige Indier allein der für iḩre Derḩältniffe hoḩen prämien wegen die

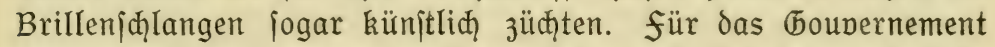

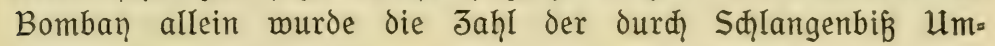
gekommenen auf 1209 beziffert, denen eine (be= jamtíterbliç̧keit von 381450 gegenüberiteht, wovon 272403 auf das Konto des fiebers ent= fallen. Daß̉ aber das giftige Reptil aud in unjerem wohlgeoroneten Deutichland unter $\mathbf{U m}=$ jtänden riefigen Sçaden perurjachen kann, das beweift der Münđ̧ner "Brillenichlangenroman" aus dem Jaḩre 1882. Damals war im dortigen Aquarium ein 1,4 Meter langes Exemplar, dem obendrein, wie fiđ ipä= ter herausitellte, die (biftzähne ausgebrochen waren, feinem Behälter

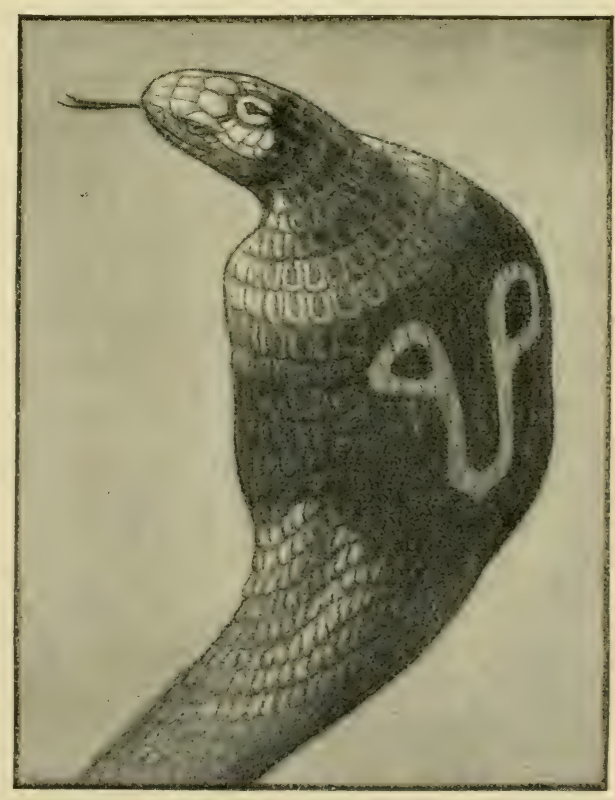

Gbb. 20. Kopf der Brilleniłl]lange, der gefürđ̧tetiten und giftigiten Sç̧lange. 
cutkommen. folgen: woḑenlange Sḩ̧lief̧ung des Injtituts, voll=

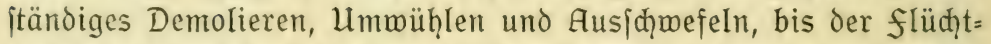
ling endid zur Strecke gebrad)t war. Kojten: 30000 Mark. So kam jeder Jentimeter diejer Unglüdisjhlange dem bedauerns= werten Bejiger auf 214,29 Mark zu ftehen! Sie hatte (id bei diejer Saḑe als auberordentlia lebenszäh erwiejen, und das ijt überhaupt eine ihrer hervorragenditen Eigenjafaften. Sind dod Beifpiele bekannt, daß̧ fie volle zwei Jaḩre ohne jede Kaḩrung ausḩielt. Bekannt ijt iḩre Kampfitellung mit hoch aufgeriđ̧tetem Dorderleib und flad und edaig aufgeblähtem Ģalsiḑild, in dem der Kopf fajt verjḩwindet, wäḩrend gleiđhzeitig auf der Rüdi= peite dis ominöle Brillenzeiđnung erjđeint. Dann folgt unter itarkem zijhen der jähe Doritob. Die viel beiprodienen Sđ̧au= itellungen der indijđ̨en und arabijđ̨en (baukler (bei diejen ḩandelt es fich in der Regel um Nája haje oder N. nigricóllis)

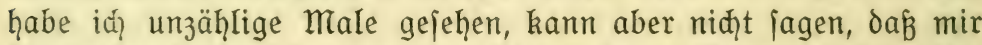
die Saçe fonderliđ̄ imponiert hätte. Das "区anzen" iit weiter niđ̨ts, als ein ந̧erumkriechen mit aufgeriđhtetem und aufgeblähtem Dorderkörper, und die entjegliđ̧e "Mujik" dazu ledigliđ ein überflüffiges Blendwerk. In den allermeijten fällen find ja den Tieren überdies die (biftzähne ausgebrođgen, und felbjt wo dies niđht der fall iłt, muß man iḩre überaus träge Katur in Rechnung ziehen. Die Kojaken in Transkajpien zeigten bor dem faulen Ђejdiöpf gar keine furçt und haben mir öfters Stüdie gebrađ̧t, denen fie einen Stridi um den Gals befeftigt hatten und die fie jo zu pierd hinter fid orein zogen. Die beiden fdon genannten afrikanifhen formen bezeidnet man gern als Speifd] langen, und diejer hame rollt eine alte herpetologijhe Streitfrage auf. früher haben wohl nur die allermenigiten (beleḩrten an die Waḩ = heit von Beriđ̧ten geglaubt, naḑ denen folḑe Sḑlangen iḩr bift bem Bedränger aud auf eine gewiffe Entfernung entgegenzu= Iprizen vermöđhten. Diel eher war man geneigt, fold̨e Erzäh= lungen cinfach in das (bebiet der fabel zu verweifen. Reucre forjhungen haben aber doch gezeigt, dak etwas Wahres daran ift. Afrikareifende bom Range Gühnels und falkeniteins haben fid̄ dafür verbürgt, daß̧ dieje Reptile im Jorn nad) einigen kauenden

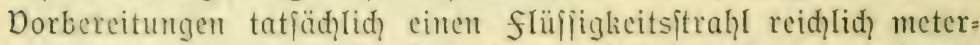
weit gegen den Angreifer id̨leudern und dabei fḑarf nad) defjen 
Thejiḑt zielen. Treffen fie das Auge, fo kann diejes ernjtlidg gefähroet merden, andernfalls gibt es nur ziemlidy belangloje Entzündungen an den empfindliḑeren Gqutitellen. Dffenbar find alle Körperiäfte des Tieres iņwad giftig, und in den eigentliçen (biftorüjen ift das Gift nur in größerer Konzentration vorhanden.

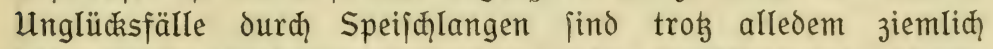

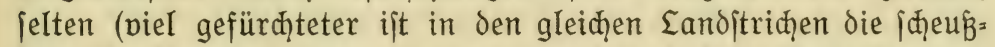
lidge puffotter), denn in der Regel find dieje faulpelze zum Beiß̧en oder Speien viel zu träge. In den kïhl̨en Morgenjtunden find jie überdies geradezu erjtarrt und können dann oḩne alle Gefaḩr aufgeḩoben merden. wäḩrend meines Aufentḩaltes in Marrakejd hielt iđ in einem alten Wafferbehälter längere Jeit hindurd woh̨l ein Dugend der unḩeimliđ̧̧en Gejellen, von denen

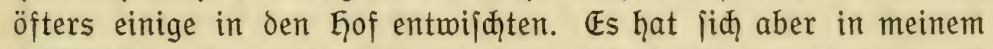
vielköpfigen hausḩalt niemand fonderliđ darüber aufgeregt, uno fie wurden nađ längerer oder kürzerer zeit aud immer wieder nađ̆ kalten Käh̆ten in halb eritarrtem Jujtande dingfeit gemađ̧t.

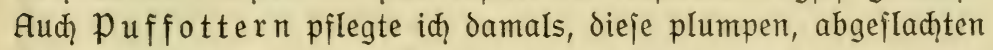
Sḑlangen, die mit ihrem breitgedrückten Kopf von einer geradezu

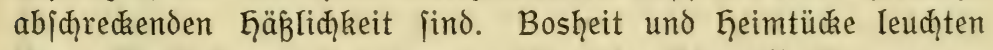

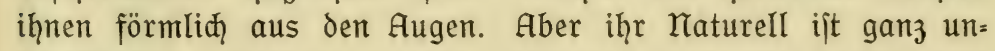
bereḑenbar. wäḩrend manđ̧e jähzornig find wie एeufel, find andere die denkbar itumpffinnigiten Sinnbilder apatḩijḩer Eräg= heit. Mußste Doffeler es doch erleben, daßj die als futtertiere zu ifnnen gejegten Ratten auf dem Rüđken der Sçlangen ganz gemütlid Ju Junge warfen!

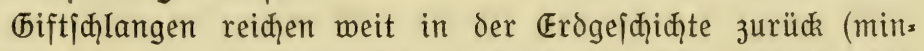

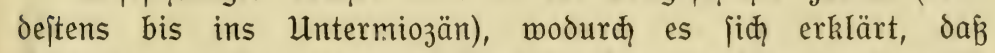
Gujtralien als der altertümlidjite Eroteil am reidjiten an ingnen ift. Indeffen feḩlt es hiier an Raum, auf die dortigen Arten näḩer einz̧ugeḩen, menn wir dem tbegenitüd der altweltliḑen Cobra,

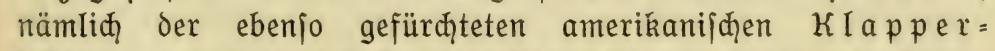
¡ đ̧ I a nge (Crótalus) noç einige Worte miomen wollen. So ḩäufig

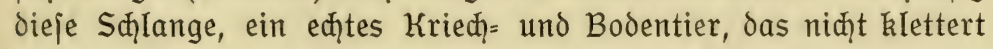

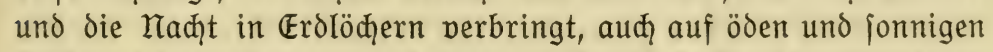
Galden feiner heimat vorkommt, find wir dod über ił̧re fort=

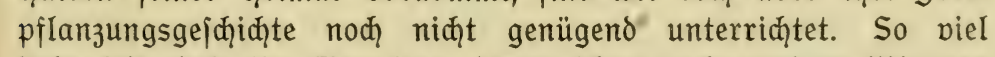
jteḩt fejt, daß̉ fie Eier legt, denen jđ̆on naḑ wenigen Minuten 
die Iungen entiđlüpfen. Aber während die älteren Beobađ̧ter übereinftimmend angaben, oab die Mutter (id) nad) Sd)langenart nid) $\mathrm{t}$ weiter um iḩre Kaḑ̧ommenidhaft bekümmere, hat neuer=

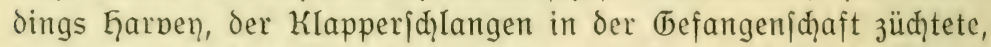
ganz merlimüroige Mitteilungen gemađ̧t. Danad foll die Mutter um ihre zu einem Knäuel zujammengeballten Iungen jeḩ bejorgt jein, (id) um jie herumwidieln und diejenigen, die zu weit weg= krieḑen, wieder herbeiholen. Ia, die Jungen follen das Innere der Alten als jiđ̧eren Jufluḑtsort anjehen und ih̨r bei Störungen in den Raḑen krieḑen, aus dem dann manḑ̧mal mehrere gleid)= zeitig mit iḩren Köpfđen herausfehen. Wir hätten hier aljo ein herpetologijh̨es Seitenitüd zum Känguruh vor uns! Be= itätigungen diejer höđj̧ auffallenden Beobaḑtungen (denn im

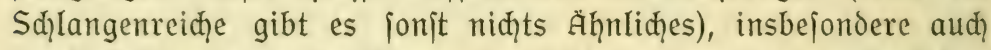
ourd folds: in freier natur, habe id) in der mir zugängliḑen Siteratur nicht finden können, und jie bleiben jedenfalls abzu= marten. Dolkstümlid gemorden ijt die überaus träge Klapper=

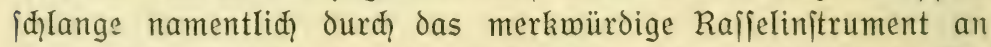
ihrem Schmanzende, das fie hod hält und in klappernde $B e=$ wegung verjest, wenn jie jid] tellerförmig zur Abweh̨r зu= fammenrollt, und das fie aud beim forthried)en ourd God)=

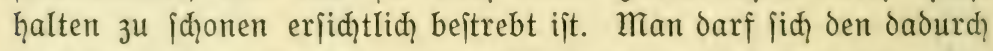
erzeugten Ton, den König mit dem Raffeln einer wediuhr oder mit dem zirpen von Grillen vergleid̨t, keineswegs bejonders laut voritellen. Er ift aud bei größjter Stille höd)itens 20 meter weit vernehntbar und hält 3 bis 5 minuten an, um ie nad̆ den Umitänden mit einer Mimute jwijđ̧enpauje nod mehrifad wiederḩolt 3 werden. Die Rafiel jelbjt ift eine vielgliedrige,

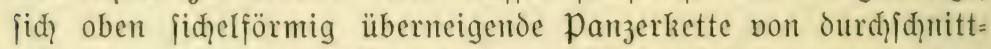
Iid) $5 \mathrm{~cm}$ Eänge, und ihre einzelnen (blieder bejtehen aus Karton= papierjtarken, trodzenen Gormplatten mit je einem Millimeter Jwifdenraum. Die frifd dem (Fi entjd̨lüpften Jungen haben nod) keine Rafiel, fondern erit nady der eriten Läutung zeigt fid? das erite Rafielglied (es ift nidhts als die nidht von ber Gqüutung betroffene Sdywanzipize) in form eines kleinen uno zarten, fajt ungejd̨nürten knöpfd̨ens. Bei jeder দqüutung miederh̨olt [id) der gleiḑe Dorgang, es bildet fid) aljo jedesmal ein neues Rafiflglied, und die Lllapper wird immer länger, da die bereits 
fertigen Бblieder als völlig abgeitorbene Ģautgebilde dem Ģäu= tungsprozeb niđ̧t meḩr unterworfen find. Man würde aljo aus ber Jaḩז der Raffelglieder fiđher auf das Alter des eieres

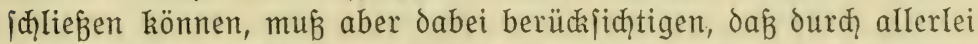
Jufälligkeiten leiđ̧t einige blieder verloren geḩen, insbejondere beim Gerumkrieç̧en die ipröden Endglieder trog aller Dorjid̨t des Tieres leiđht abjpringen, dá̉ ferner mit dem voriđ̧reitenden Alter die paujen zwifhen den einzelnen F̧äutungen immer größer werden. In der Regel trifft man niḑt meḩr als zwölf Raffel= glieder an, felten 15 bis 20. Was darüber hinausgeht, beruḩt auf fäliđ̧ungen, wie fie ḩäufig gemađ̧t werden, da die Klappern gern als Anulette getragen und um jo ḩöher gejđä̧̈t merden, je länger fie find, je meḩr blieder fie aufzumeifen haben.

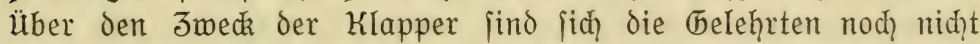
reçt einig. König faß̉t das Rafjeln als paarungsgejang auf, der ebenjo wie ein didkbreiiges, mojđhusduftendes Sekret uriprüng=

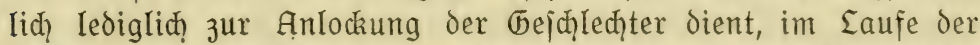
zeiten aber, äḩnliḑ wie der Dogelgejang, zu einem Dolmetiḑer der Gefüḩlserregung überhaupt geworden ift und fo gewiffer= maß̉en einen Erją̧ für die feḩlende Stimme darjtellt. Garven

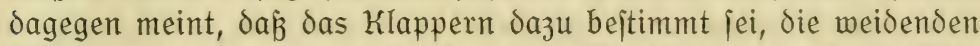
Büffel zu warnen, damit jie das zum wegkrieḑen zu faule Gift= reptil niđ̧̧ zertreten und dabei jelbjt einen Biß̧ abbekommen.

fajt meḩr noch als die Klapperiḑlange hat der japanifđ̧e Riejenjalamander (Megalobátrachus máximus) zu den aben= teuerlidjiten Sagen, Märçen und Miß̧סeutungen Deranlafjung gegeben, bis die forjḩung der Teuzeit das über dem fabel= wejen lajtende Dunkel zerrís und ih̨n einfach hinitellte als den

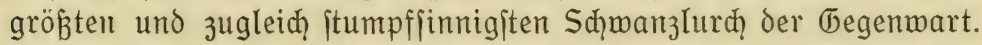
Er erregte içon 1731 ungeheures Auffehen, als der gelehrte Shyeudzzer fein verjteinertes Skelett auffand, es frijđ̨weg für das des vorjintflutliđģen Menjđ̧en (Homo dilúvii testis) erklärte und alio apoitrophierte:

„Betrübtes Beingerüitt von einem alten Sünder, Erweiđge Stein und Ęerz der neuen Bosḩeitskinder!"

Später deutete man den fund auf einen foffilen fifh, und erit Cuvier erkannte 1811 in ihm riđtig einen riefigen Salamaner, 
den (oder deffen näd]iten Dermandten) $\mathfrak{v}$. Siebold dann in Japan now lebend auffand. freilid find die Tage des plumpen und un=

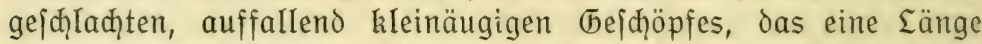

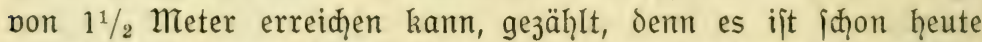

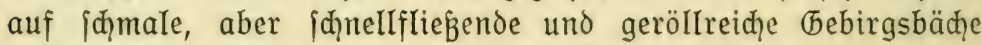
des mittleren Japan (etwa vom 34. bis 36. Breitengrade) be=

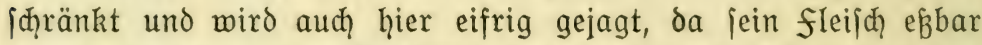

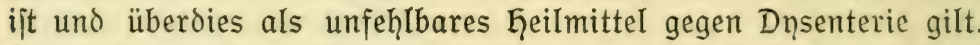
So wird aus dem "Homo dilúvii testis" woḩ bald ein "Animal humánae crudelitátis testis" werden, und damit kommt der Riejen= jalamander ja nur in eine ebenjo zaḩIreiḑe wie vorneḩme (bes

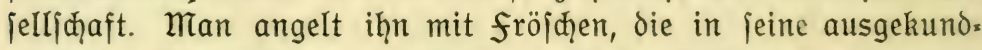

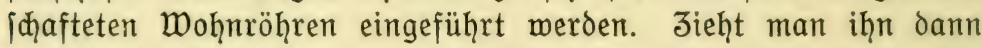
heraus, io jondert er ein eigentümlidjes Schleimjekret $a b$, das

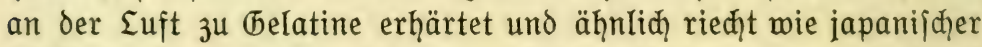
pfeffer. Er verträgt übrigens ¡đ̧were Derlegungen und füḩrt feinen japanijđ̧en Kamen "Ganjaki" wegen feiner enormen Re= generationsfäḩigkeit. 『räge liegt er in feinen Sçlupfwinkeln auf der Eauer und wartet geduldig, bis ein günjtiger Jufall ein Beutetier an jeinem breiten Maul vorüberfüḩrt, oas er dann

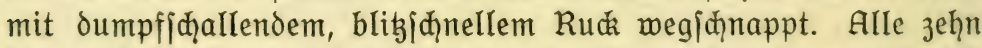
bis zwölf Minuten kommt er zum Atemḩolen hernor. 1829 bradite v. Siebold den eriten Riejenjalamander lebend nađ) Europa, und diejes Eremplar lebte bis $1881 \mathrm{im}$ Amjterdamer Tiergarten, naḑbem es inzwijhen ein iḩm zugejelltes weibḑen veripeift hatte und einen Meter lang geworden war. Das mir feit langen Jaḩren bekannte Eremplar des Breslauer Eiergartens mar, als

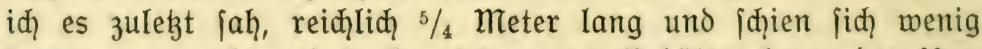
daraus zu mađ̧en, daß̧ iḩm jein enger Beḩälter kaum das $U m=$

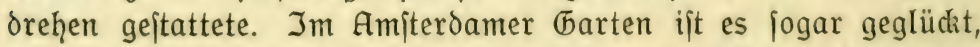
den Riejenjalamander zu züđz̧ten, und wir haben dadurd die intereffante एatjaḑe erfaḩren, daß̧ das Männḑen Brutpflege übt. Es werden 5-600 rojenkranzartig 3ujammenhängende Eier an felsitüdzen im Waffer abgelegt, deren jedes in eine Kapjel von veriḑiedenen häutigen Ģüllen eingebettet ijt. Das jeł̧t \{ehr biffige männḑen beḩütet eiferjüḑ̧tig diejen Sḑą̧ und ift bemüḩt, den Embrņonen durd] pendelnde Körperbewegungen ftets frifdes Atmungswaffer zuzuführen. Die nad\} 8 bis 10 Wod\}en 
ausfd̨lüpfenden, etwa drei 3entimeter langen Sarven Iaffen ¡đ̆on einc deutliḑe Anlage der Ertremitäten erkennen, ḩaben aber die Mundöffnung nod ventral. In den gleiden (begenden Japans lebt aud ein Erallenbewehrter Eandjalamander, Onychodáctylus japónicus, der in gedörrtem 3ujtande als unfehl= bares Wurmmittel gilt und desḩalb fleikig gefammelt wird.

Don den Sđ̧wanzlurđ̧en der Mittelmeerländer verdient der namentliç bei (benua häufige Brillenialamander (Salamandrína perspicilláta) unjere bejondere Aufmerkjamkeit. Diejes lang= gejtreckte, nur 6 bis $8 \mathrm{~cm}$ mej[ende, kleinbeinige, überaus jierlidie, am Bauche Ieuđhtend zinnoberrote, auf dem (Dberkopf mit einer meḩr

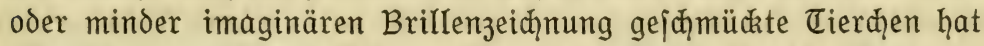
nämlich, obmoḩl es auf fejtem sande gejellig in feuđhten (bejteins= ipaiten oder vermodernden Baumitämmen lebt, gar keine Sunge, atmet vielmeদ̨r ourch die gejamte Körperhaut, insbejondere ourd? die der Rađ̧enḩöhle. ITur nađ reiḑlidhen Regengüflen im früh̆= jahr und Gerbit kommen die Brillenjalamander aus iḩren Der= itecken ruḩig kriechend oder in unbeḩolfen ¡đ̆längelndem saufe zum Dorjđein, denn die direkten Sonnenjtrahlen töten jie, objđon iḩre lederartige, niđht [alleimige Ģaut jie jonjt jiemlich gut gegen das Austrodenen iđüht. Ins wafjer gehen fie nur zur fort= pflanzungszeit. Sie ernähren fiø von allerlei kleinem நemürm und lieben dabei viel Abwedilung, wie überhaupt der (bejळ!mack auf Koiten des (bejiđts entwidkelt zu jein ¡đ̧eint, die übrigen Sinne vollends ftumpf find und von Intelligenz kaum die Rede jein kann. Noळ weiter getrieben exjheint die Gautatmung bei dem

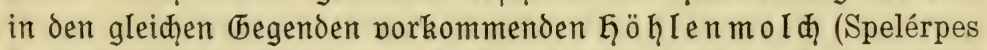
fuscus), indem bei diejem aud jąon die Earpen darauf angewiejen find, aljo ebenjomenig Kiemen bejigen, wie die Alten sungen. Infolgedefien ijt denn auḑ die Gaut äukerjt zart und empfindlia,

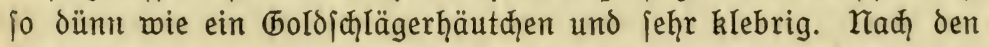
Beobachtungen Comeranos wird die Sđllundatmung ourch un= regelmäßige Bewegungen der Kehllhaut unterjtügt. Katürliç Kann diejes merkmürdige Ђejđ̄öpf nur an feuđ̧ten, kühllen und dämmerigen Drten gedeiḩen, denn 『rockenheit bedeutet ihm đod.

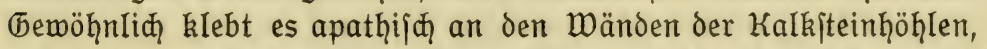

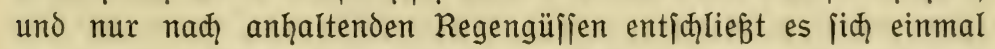
zu einem kleinen abendausflug, wobei es unter plumpen und 


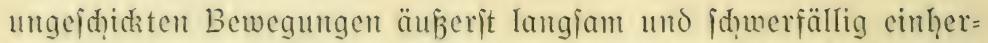
kried)t, indem es alle Augenblidie wieder halt mad)t und mit weit ausgeipreizten Beinen und Jehen eine fiḑelförmig gekrümmte Stellung einnimmt. Ie eilfertiger das đier vorwärts itrebt, um jo unbehilfliḑer "ficht jein Marjdieren aus. Die färbung ijt kaffeebraun mit großen, gelblichen fledien, der (bejiḑtsausorud naḍ der köptliden Sdillderung Bergs der eines "feijten Mopjes mit perlenäuglein", das ganze Tier der perjonifizierte Stumpffinm. Seine Beute (Käfer, Afleln, fliegen, Spinnen, Taujendfüße, jelbjt kleine Skorpione) erjagt es fid teils auf der pürid, teils auf dem Anitande. Der Ģöhlenmolđ befigt nämlid eine eritaunliḍ lange, raid voritredbare Junge, deren Shaft am Ende einen pilzförmigen, klebrigen Knopf trägt. So "đđ̧ię̧t" der unanjehılı

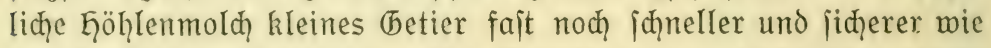
das berühmte Thamäleon. Die fortpflanzung gleid̨)t der unjeres Alpenjalamanders, indem zwei lebende Junge abgejegt werden. Red)t lange war man über die fortpflanzungsgejdidite einer dritten Eurchkuriojität Südeuropas im unklaren. (Es handelt iid) um den (brottenorm (Próteus anguínus), diejes blaß̉ fleifa)=

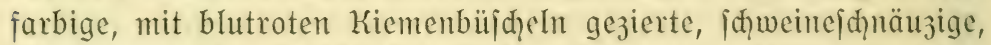
regenwurmartige (bejdöpp mit $\delta \mathrm{cn}$ kleinen, weit auseinander= itchenden Beinpaaren, das in maffergefüllten Karithöhlen des Adriagebietes eine fo veritedite, aber anjd̨einend reḑt einförmige Eebensweije führt. Es wird aud, non den Eiebhabern der Merk= würdigkeit halber gern im Aquarium gehalten, obgleid es eigentlid der ftumpffinnigite $1: 10$ Iangmeiligite patron von der

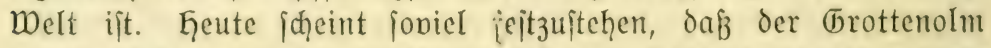
im freileben bei der konjtant niedrigen Gählentemperatur feine beiden großäugigen Iungen völlig austrägt, währent in der (De= fangenfalaft gehaltene Exemplare durd die wärmere Eemperatur oes Aquariummaffers peranlapt werden, die Embrnonen fdyon im Eizuitande abzuitoßen.

Einer nod gröferen Beliebtheit erfreut (id) feiner leiḑten Jüd)tharkeit megen der mexikanifhe Ax̧olotl (Amblystoma mexicánum) bei den Aquarienfreunden. Der Arolotl (dejer indianiface rame heipt foviel wie "Wafferipiel") ift eigentlid\} gar kein fertiges Tier, fondern mur bie Earve einer moldqart, ift aber merk= würoigerweije fảon fortpflanzungsfähig, fo daß man die aus= 
gebildeten Irolḑe, won denen man ḩerzlid wenig weiß̧, überhaupt nur noch felten findet. দqumboldt möchte das Jujtandekommen

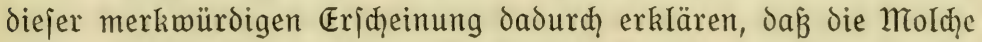
früher in dem ehemaligen Waldlande Meriko zwar ein gutes fortrommen fanden und jïç regulär fortzupflanzen vermođiten, ihre Exiftenzbedingungen jedoch verloren und in lot gerieten, als mit der fortiareitenden Entwaloung das fejte sand zu einer jonnigen Einöde wurde. Die mit iদ̣ren Kiemenbüpđeln aufs Wafjerleben angewiejenen Earven wurden davoin weniger be= troffen, und als fie jiđ aud jo bei vorgerücktem Alter als

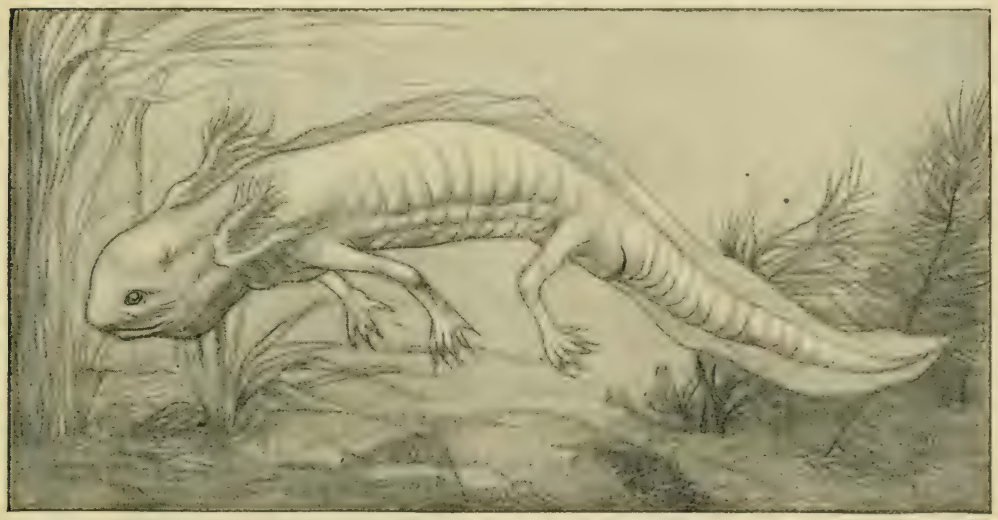

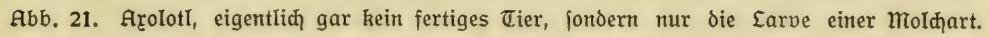

fortpflanzungsfähig erwiejen, bedeutete das nidh̨t mehr und nid̨̧t weniger als die Rettung der Art. Die Weibđhen elfajien mit den Ginterfüßen geeignete Wafferpflanzen, orüken ihre Kloake dagegen und prefien nun unter itarken Krümmungen des Eeibes 3 bis 4 Eaidpakete von je 6 bis 10 jąon norher befrudteten Fiern heraus, die an den Pflanzen kleben bleiben. Megdorf hat darauf aufmerkjam gemaht, wie dankbare und lehrreidie Be= obaditungsobjekte foldhe Arolotleier find. Unter dem Mikrojkop kann man die Spermatozoen in der Mähe des Dotters fehen, ja

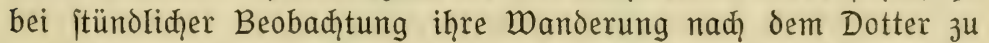
beobaḑten. Sogar die ganze weitere Entwicklung läß̧t iid auf einent Dbjektträger mit etwas Wajfer, das öfters erneuert 


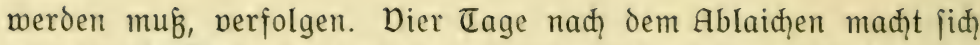
eine ipindelförmige Strediung geltend, bald darauf eine deutliḑe

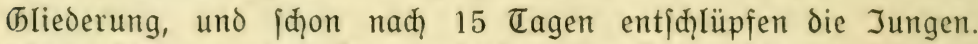
Wenn dieje an der Glaswand des Aquariums hängen, ift mit der Supe deutlich die Gerspulfation fowie der Blutitrom in den Kiemenbüideln und im Sđ̧wanz zu erkennen. Im übrigen ift

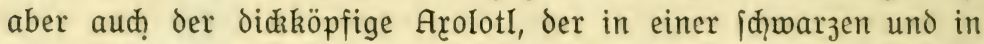
einer fleifhfarbigen Darietät auftritt, ein herglid langweiliger Gejelle. Unterhaltender wie er und der (brottenolm, aber aud reçt liątįeu ijt der bedeutend größere ArmmoId) (Síren

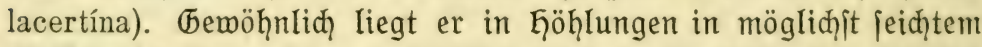
Wajfer, da er aud zum Suftj̧nappen niđ̆t gerne jein Derjteds verläßt. Iur das mit jđönen Kiemenbüjḩeln gezierte Köpfden itedit er aus jeinem finjteren Winkel hervor. Kommt er aber doch heraus, fo jąwimmt er unter eleganten uno hajtigen

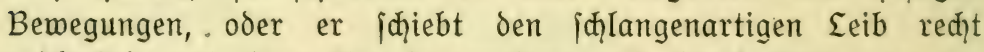
geiḑwind auf dem Grunde entlang und durđ̧wühlt wie ein Sḑwein den Sand nah etwas Geniebbarem mit der Sdinauze, wobei aud die Dorberbeine tüđtitig mitarbeiten.

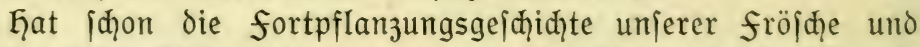
Kröten Lebensbilder mit wunderbarem wedjjel und wandel auf= zumeijen, io werden fie dod in diejer Beziehung nod weitaus übertroffen von gewiffen exotifhen formen, bei denen wir oft eine jehr meitgehende Brutpflege antreffen. Den meiften Sefern dürfte aus "Brehms Tierleben" das abjonderliđge Bild der Waben. kröte (Pípa americána) bekannt jein, die iḩre Jungen in bienen= zellenartigen Gauttajken auf dem Rüdien herumidleppt. Aber es gibt nod biel merkwürdigere Dinge im Reid der froid)= lurche. So zeitigt das Männđhen (bei Pipa ift es das Weibdien) des Kajenfrofąs (Rhinodérma darwíni) die Jungen in dem $3^{u}$ einer Bruttajd̨e umgemandelten Kehliadk. Plate fuḑt dies dadurd? zu erklären, daß̧ in den dortigen Wäldern alle Niederiḑäge von ber hohen humus\{ḑid̨t aufgejogen werden, es infolgedeffen nid)t zur Biroung von 区ümpeln kommt, und die mur orei jentimeter langen, bunt gefärbten fröß̨lein deshalb auf den Ausweg ver= fallen find, die der feud\}tigkeit beoürftigen Eier in die Mund=

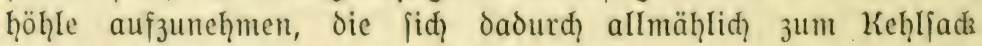
erweiterte. Wenn bas đier, defjen Sdyauze in einen fpitzigen 


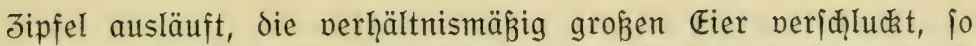
gelangen fie nađh werner niđ̧, in den Rađ̧en, fondern ourch einen jederjeits der Junge gelegenen Sđ̧lił̧ in den erwäḩnten dünnhäutigen und fid nađ̆ und nađ̆ immer meḩr vergrö̈ßern= den Kehliack. In iḩm entwidkeln jiø̆ die Eier zu Quappen, indem

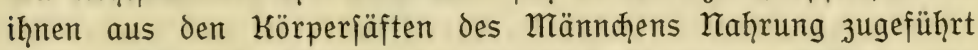

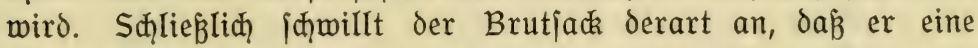
Trierenfđ̧rumpfung bewirkt und fo den opferwilligen Dater zur Einftellung der Kaḩrungsaufnaḩme zwingt. Dann gefällt's aber auḑ der Kinderiđ̧ar niđ̧t meḩr, und jie arbeitet fiđh nun aus dem Maule des Daters heraus. Mođ meḩr erinnern die gleidffalls

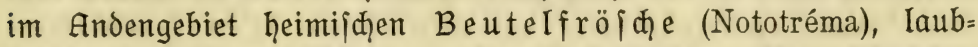
frofḑartige Baumfröfhe, an die Wabenkröte. Iḩre weibđhen befigen eine geräumige, tornifterartige Rückentajḩe, in der die Eier und Iungen iḩre Entwidklung ourđ̧mađ̧en. Bei manđ̧̧en

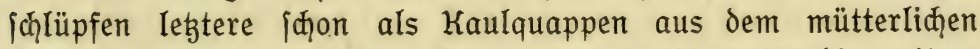
Ruđ๔jaç, um zur riđtigen zeit in den waldjümpfen die weitere Derwandlung durdłzumađhen, bei anderen Arten aber erit als fertige, wenn aud minzige fröjhllein. In jenem falle find die Eier zaḩlreid, aber klein, in diejem menige (15 bis 16), aber leḩr großj. Das nur 25 milllimeter lange Weibḑen des venezo= Lanijḩ̧en Nototréma pygmáéum ḩat nur 4 bis 7 Eier zu

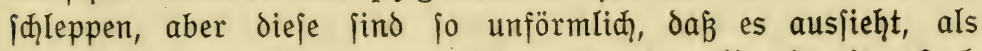
trïge es einen mit ein paar riefigen KugeIn vollgepfropften Sack

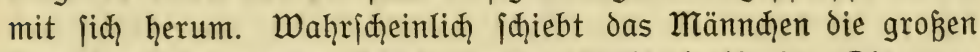
Eier durd den engen Sçlity in den Rukjad hinein. Die aus= gebildeten Iungen bringen iḩn dann ourḑ heftige Bewegungen zum plagen, die Rudera oorren $a b$, und die Grundflähte des Ruckjackes wiro zu einer neuen Rückenḩaut. Đb nun im nädj̧ten Iaḩre eine Teubildung des Sackes möglid ift, oder ob überḩaupt nur eine einmalige fortpflanzung itattfindet, iit nođ̧̧ niđ̧, aufgeklärt. Jeden= falls haben alle dieje merkwüroigen Anpajfungserjheinungen den 3wed, das ans wajfer gebundene Stadium der Entwidklung zu modifizieren und fomit das fortpflanzungsgejđäfft von den unregel= mäßigen Regengüffen unabḩängig zu maăhen. Der gleiđ̧̧alls in Südamerika auf feuctem Wiefenland lebende Dendribates

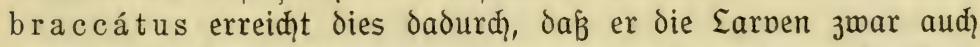

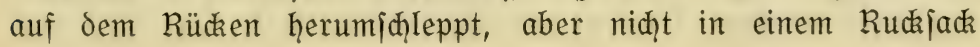


oder in Bienenzellen, fondern indem er fie nady Smith mit einem cigentümliḑen Sekret aufklebt. Ein großer Baumfrojd bejt= afrikas, Hylámbates bréviceps, bringt die Fier, äḩnliđ̧ wie der Iajenfrojd, im Maule zur Entwidalung, nur daß̧ hier bas

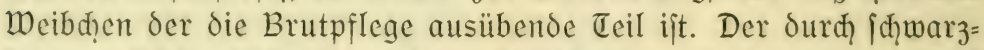
braune Rüdrenfärbung uno metallifđ̧en, xnlophonartigen Ruf ausgezeidnnete Riefenlaubfrofd (Racophórus dennysii) aus Thina hü̈llt bie Fier in einen ourd ein Rüdienfekret erzeugten Sçaum und দ̧ängt dann dieje weiß̧liḑen Sđ̧aummafjen im Gezweig folḑer Bäume, die fiđh über ein waffer neigen, auf, damit die

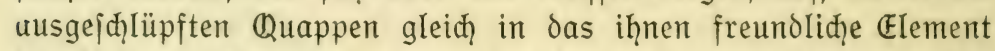
ḩinabfallen. Die für einen Eaubfrofd fo auffärlige Rüđken= färbung hält Krenenberg für eine Art Mimikrn, weil bie Blätter

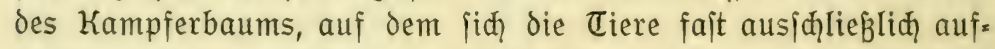
halten, fajt jtets mit braunen piljflecken verjehen jind. Auffallend find auch die groß̉en hände und die riejigen Sđ̧wimmḩäute diejes dod) nie ins maffer gehenden frojđ̨es, die daḩer woh̨l nur den Jెwed ḩaben können, bei weiten uno gewagten Sprüngen im (Je= zweig ausgejpreizt als fallidirme zu wirken. Aus Java kennen wir ja auḑ einen riḑtigen $f \mathfrak{l} u g f r o f d g$ (Polypedótes reinwárdtii), bei dem zu den oben genannten (Drganen audg noḑ auss ipambare Ģautfalten an den Körperjeiten ḩinzulkommen, fo daß̉

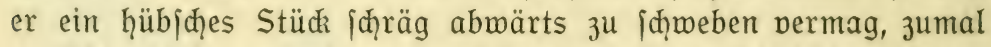
er (id) mit den mäđ̧̧tig entwidkelten und jtark geknidaten Finter= beinen einen tüđţtigen $A b$ itoß gibt, vorher aud nod den Körper jtark aufbläḩt und mit Euft füllt, aljo wejentlid\} crleiḑ̧tert. Aud?

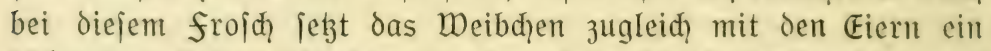
¡đ̆leimiges Sekret $a b$, das von dem befruchtenden Mänuđ̧en ganı regeIred)t zu Eieriḑnee geid]lagen wiro, indem es dic Eallerte mit den finterbeinen fo lange tritt und knetet, bis fie eine did]t

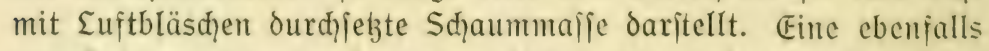
3ur Tattung Rhacophórus gehörige Art laid̨t dagegen unter= iroijd, indem die kopulierten paare am Ufer des (bewäfjers einen (bang graben unọ dabei bafür forgen, Daß̧ bie bem Eaid)= klumpen entiक̧lïpfenten Quappen ohne allzugroße Sd̨wierig= keiten ins Waffer gelangen kömen. Damit fino wir zugleid bei den nejterbauenden fröjdzen angelangt, denn aud jolḑe gibt es. Das Wunderbarite in diejer Beziehung ijt woht ein brafilianifḑer 
Eaubfrofä (Hyla resinifíctrix), non dem (boeloi feitgejtellt hat, daß̧ er geradezu mit feiner Ģände Arbeit für die Brut jorgt, indem er Baumb̧ar jammelt, damit Ajtlöḑer verpiḑ̧t und fo mafferdid̨te Rejernoire jajafft, in denen er jeine Fier abjegen kann, fobald jie der näḑ̧te Regenguß gefüllt hat. Das auf auf= oringlich grüngelbem Grunde mit ¡đ̧warzbraunen Querbinden gezierte Tier foll jogar das Garz pon gemiffen aromatifchen Bäumen (wie Prótium heptophyllum) entiđ̧ieden bevorzugen uno auf jeinen Brutbaum übertragen. Es wird jąwer halten, alle dieje unzweifelhaft von einem unierer beiten forider nađgewiejenen Dor= gänge ledigliđ durळ die neuerdings wieder fo beliebt gemordene "Reflermajक̨ine" zu erklären. Ein äußgerit interelfanter Burjđ̧e ift ferner die in Paraguan heimijḩe Phyllomedúsa hypochon-

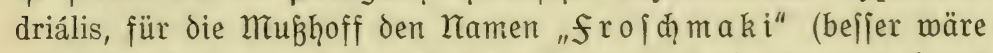
"Makifrofø") vorgeidlager hat, weil dieje Art als ausgejproḑenes

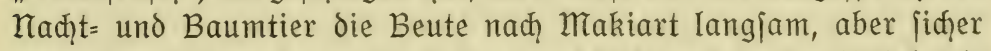

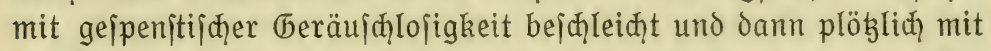
der Klebrigen Junge wegklappt. Dazu Kommt der mopsartige Ђe=

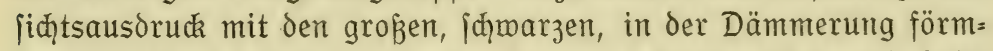

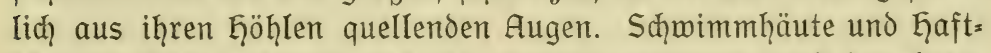
¡đ̧eiben fehlen, damit auch das Sprungvermögen, und das lang= fame hodbeinige Gehen, das äuperit bedäळhtige Klettern und das krampfhaft=ängitliç̧e fejtḩalten an dem mit den Greiffüßen um= klammerten 3weige erinnert weit mehr an das Chamäleon als an irgendeinen frojø. Im übrigen aber ijt Phyllomedúsa ein ganz entzüđkendes frölø̨lein: oben leudtend hellgrün, unten blendend

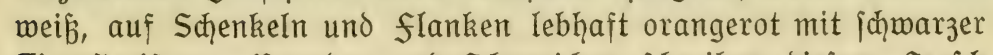

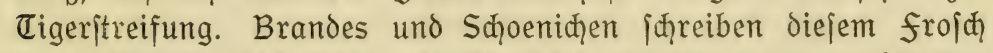
ein aukerordentlid itarkes farbwedjelvermögen zu, was aber von andere: Seite (Muß̧hoff, ciffe u. a.) lebhaft bejtritten mird. Auch

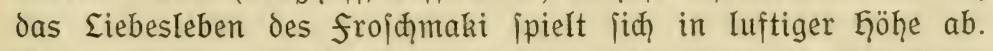
Das perbundene pärḩen genießst feine Godhzeitsfreuden auf einem größeren Blatte und biegt dabei mit den Ginterbeinen defjen Ränder

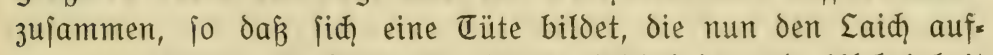
nimmt. Defien Gallertmafie bejigt fejtigkeit und Klebrigkeit genug, um den Blatttriạter jujammenzuhalten, in dem jich die Earven bei allmäḩliḑer Derflüfligung der Gallerte entwickeln können, bis fie enoliá) ein itärkerer Regenguß ins nächite Waffer 
¡đ̧wemmt. Fine andere Art geht nad einem Berid̨te Agars nod weiter, indem fie eine ganze Anzaḩl von Blättern mit einer aus leeren Eikapjeln gebildeten belatine zujammenklebt und oann

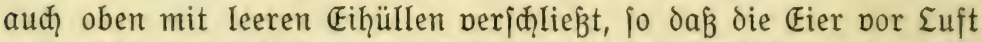

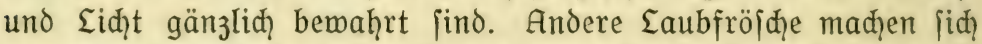
die Saçe bequemer und begnügen jiđ̆ damit, ił̧re Fier in tüten= artigen, vom Regen mit wafjer gefüllten Blatthüljen abzujezen. Als eine vergröß̈erte und reiđ\}lid plump geratene Ausgabe unjeres gewöḩnliḑen Eaubfroids ift ber aujtralijø̨e Korallenfinger (Hyla coerúlea) anzujehen, der jiđ̆ niđ̧t mit der Mü̈ßenjago be= gnügt, jondern gierig aud hinter Eidedjjen und kleineren fröichen, ja jelbjt ḩinter Mäujen uno Dögeln ḩer ift. Seine Stimme klingt

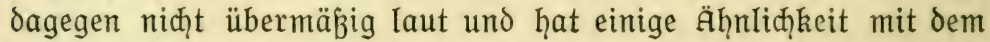
heiferen Bellen eines geärgerten நqundes. Ein kreuzkrötengroßßer Ditindier, Cállula púlchra, ift dadurđ intereffant, daß̉ er bei Beorängnis zu grotesker Aufgeblajenheit \{eine Jufluđ̧t nimmt

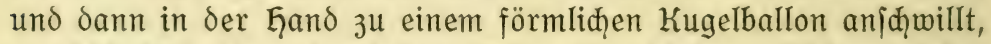

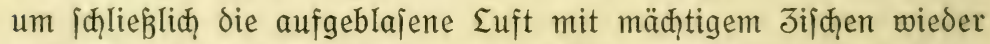
zum Taule herauszujtoßen. In unjerer ojtafrikanijß̨en Kolonie gibt es eine fülle der merkwürdigiten fröiđ̧e, fo Geckolépis multícolor mit wundervollem, aber mildem Metallif̧immer und füß̧en, die ausfehen, als ḩätten fie gar keine Sḩenkel. ferner ganz winzige fröfd̨lein (Nectophryne torniéri uno Pseudophryne vivípara), die ḩöđjit auffallenderweije lebende Iunge

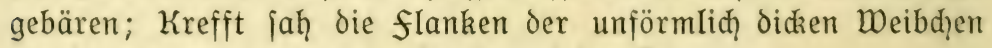
geradezu wogen unter dem (bewimmel der Quappen.

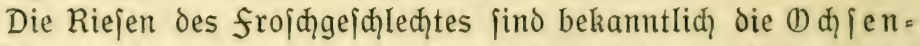
frö¡đ̧e, und eine der gewaltigiten Arten (Rána góliath) ijt in unjerer Kolonie Kamerun zu Ģauje. Die (Defräßigkeit jolḑer Diđabäuđ̧e entipriđ̧t iḩrem Eeibesumfang. Minke faḩ einen folḑen Dielfraß̧ innerḩalb 24 Stunden zu jiđ neḩmen: 23 Mai. käfer, orei frößđ̧e, ein küdzen, einen juntgen Sperling und cine Maus! Dor diejer rejpektablen Eeiftung wog das Tier bei ciner Eänge von $19^{1 / 2} \mathrm{~cm}^{3 / 3} / 4$, naḑher zwei pfund. Dod gibt es aud praḑteremplare bon orei pfund Ecúendgewiḑt. Mit wilder (bier klatichen foldhe Koloffe ins Woffer, wenn fie etwas benieß̧bares eripäḩt haben, und wählerifd find fie waḩrḩaftig niḑ̨t; vielmeḩr erjḑeint ihnen alles Eebende reḑt, was fie zu verid)lingen ver. 
mögen. In kultivierten begenden riß̨ten jie an dem Ģausgeflügel viel Sthaden an, und deshalb wird namentliđ die nordamerikanijąe Art ( $\mathrm{R}$ ána múgiens) pon den farmern bitter geḩaß̉t und iđjonungslos verfolgt. Dođ hat iiđh auđ hierbei mieder heraus= geitellt, dak man die Dezimierung niđht zu weit treiben darf, weil jonjt eine itarke Junahme der Moskitos die unausbleibliçe folge

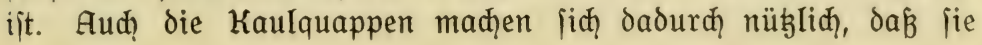

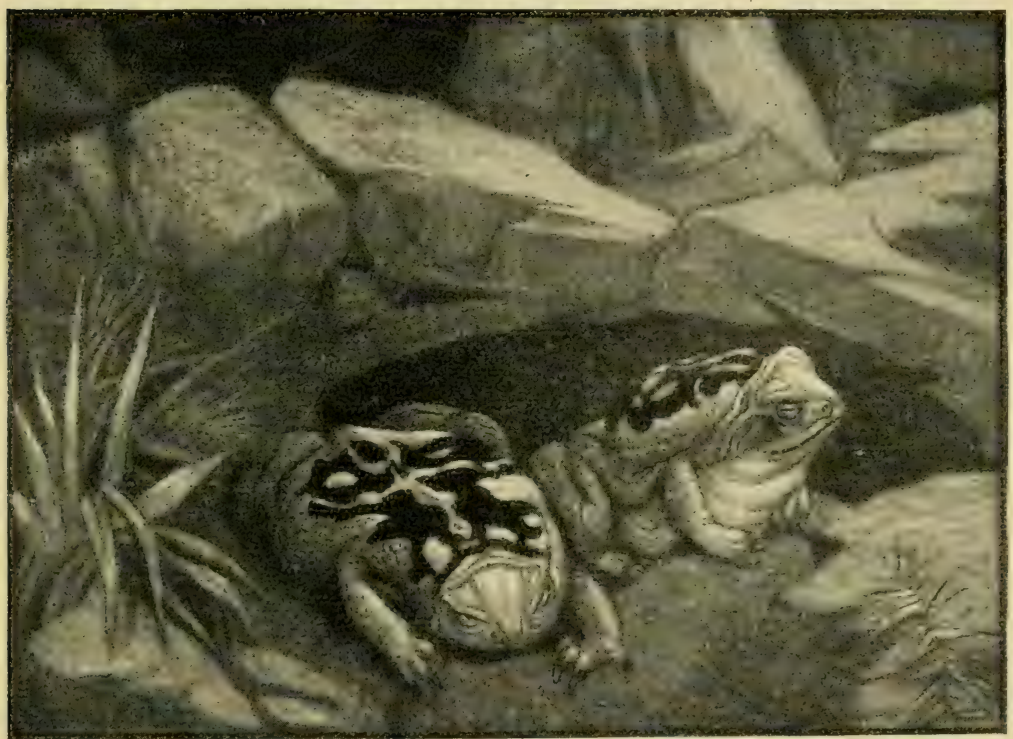

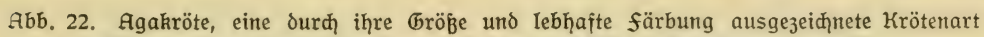

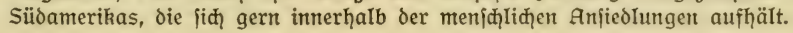

die (bemäffer von allerlei Unrat reinigen. Aber aud die frofą)= idenkel find in Amerika in Aufnaḩme gekommen und dürfen

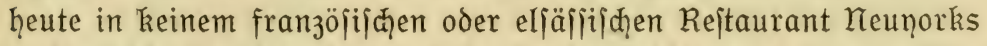

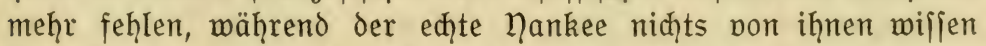
will und jie ipöttelno "franzos" nennt. Iad) den Bereळnungen mulerths überiteigt die Jufuḩr wäḩrend der "Saifon" allein in Keunork eine Million paar Sđhenkel wöđhentlid, Drei bis vier Paar Shienkel wiegen ein pfund und kojten 2.60 mk., aljo jo viel wie die bejten forellen. Seit fo die Yankees dahinter ge= floeriake, Krieçtiere uno Eurळ̧e frember Eänder. 
kommen jind, ein wie gutes (bejđ̧äft die frojajagd ijt, huldigt man ihr allenthalben aufs eifrigite mit kleinkalibrigen themeḩren, Angeln (der bejte Köder foll ein Stüđ rotes flanell fein), har= punen, Sḑleppnegen, fallen uijw. Theḩt es in der gegenmärtigen Deife weiter, fo wird aud der Ddjenfroid iid bald zu Büffel und Wandertaube gejellen können. Das krötengejd̨leḑt hat eben= falls ganz mäđ̧tige Kerle hernorgebraḑt, jo die Aga (Búfo marínus) Sü $\delta=$ und Mittelamerikas. Sie ift zwar iḑeu uno mürrijd, aber doch von wejentlid gemütliderem oharakter als

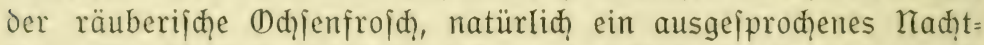
tier. Mit Dorliebe hält fie fid in der Kähe des Menichen auf, und niđ̧t felten begegnet man iḩ abends mitten in den Straß̧en der Stäote und Dörfer. Gat man jid erit einmal an den gemüt=

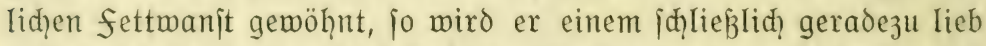
und vertraut. Sein afrikanifḩes (begenjtüdz, die hüubid gefledite pantḩerkröte (Búfo mauritánica) hat miḍ mäḩrento meines marokkanijąen zeltlebens oft aus dem iḑönjten Sḑ̣lafe empor= gefdịedit, wenn fie in plumpen Sprüngen patidęend über dic Jeltitridke itolperte, währeno iđ von der fernen deutiḑen Geimat träumtc. 


\section{Saçregitter.}

Acanthodáctylus syriacus 49 .

Aga (Búfo marínus) 98.

Agáma caucásica 54 .

Agáma inérmis 11, 54.

Agáma sanguinolénta 54 .

Agamen 53.

Alligator (Alligátor mississipénsis) 60.

Alligátor lúcius 61 .

Alligátor sinénsis 61 .

Améiva chrysoléma 42 .

Anakonda (Eunéctes notáéus) 81.

Anolis 6.

Anólis cristatéllus 9.

ArmmoIm (Síren lacertína) 92.

Arraujhiliskröte (Podocnémis expánsa) 67.

Grolotl (Amblystoma mexicánum) 90.

Bartagame (Amphibolúrus. barbátus) 17.

Baumichlangen 76.

Beutelfrölne (Nototréma) 93.

Bóa constríctor 82.

Brillenjalamander (Salamandrína perspicilláta) 89.

Brilleniđilange (Nája tripúdians) 83.

Brüđenechie (Hattéria punctáta, Sphénodon punctátum) 21.

Buđkeliđ̧itlokröte (Damónia réévesi) 70.

Buntwaran (Varánus várius) 35.

Cállula púlchra 96.

Chalcídes ocellátus 43.

Chalcídes tridáctylus 43.

Chamäleon 9.

Chamáéleon basilíscus 15 .

Chamáéleon mélleri 12, 14.

Chamáéleon vulgáris 11 .

Clémmys leprósa 73.

Crotaphytus colláris 41 .

Dendróbates braccátus 93.

Dorniđgnanz (Uromástix acanthinúrus) 32.

Dorniđmanł, indijđer (Uromástix hardwickei) 34.

Dryóphis 77.
Dünnfinger (Stenodáctylus guttátus) 50.

Elefantenjđhilokröten (Elephantópus) 73.

Epicrates cenchris 82.

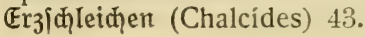

flofienfuß (Pygópus lepidópus) 21. flugorađhe (Dráco vólans) 55.

flugfroß̣) (Polypedótes reinwárdtii) 94

frołđ̨maki (Phyllomedúsa hypochondriális) 95.

Ђavial (Gaviális gangéticus) 64 . Gecko monárchus 48.

Geckolépis multicolor 96 .

(beckonen 43.

Ђol১baumiłhlange (Chrysopeléa ornáta) 77.

(brottenoIm (Próteus anguínus) 90. Gymnodáctylus kótschyi 45 .

Hardélla thúrgi 73.

দ̧aroun (Agáma stéllio) 53.

Hemydáctylus mabúia 48 .

Himántodes gracíllimus 76 .

Ђ̆öh̆lenmold (Spelérpes fuscus) 89.

Hyla resinifíctrix 95 .

Hylámbates bréviceps 94 .

Karettinildokröte (Chelóne imbricáta) 64.

KIapperiđjlange (Crótalus) 85.

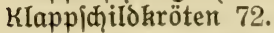

Korallenfinger (Hyla coerúlea) 96.

Kragenteḩe (Chlamydosáúrus kingi) 17.

Krokodile 59.

Krötenechje(Phrynosóma cornútum) 25.

Krötenköpfe (Phrynocéphalus) 30, 51.

Kru|tened\}ie(Helodérma suspéctum) 26.

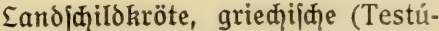
do gráéca) 74 .

Eeguan (Iguána tuberculáta) 39. 
Eeiftenkrokodil (Crocodilus prirósus) 62.

Lygodáctylus lugúbris 48 .

Lygodáctylus picturátus 48 .

mauergecko (Taréntola mauritánica) 46.

Moloch (Móloch hórridus) 18.

Mo[đusið̧ildkröte (Cinostérnum odorátum) 72.

Nája haje 84.

Nája nigricóllis 84 .

rajenfrojđ (Rhinodérma darwini) 92.

Mashornleguan (Metopócerus cornútus) 40.

Nectophryne torniéri 96.

Nectophryne vivipara 96.

Keeşąlange (Python reticulátus) 81 . rỉlkrokodil (Crocodilus nilóticus) 62.

nilmaran (Varánus nilóticus) 38.

Nototréma pygmáéum 93.

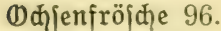

Onychodáctylus japónicus 89 .

Ophióps 30.

Oxybelis 78

\section{Paláéohattéria 22.}

pantherđjamäleon (Chamáéleon pardális) 12.

pantḩerkröte (Búfo mauritánica) 98.

peitidhenjhlangen 76.

perleided,je (Lacérta ocelláta) 58. Pfauenaugenjđild kröten (Chrysémys) 70 .

Phelsúma madagascariénse 43.

Phrynocéphalus helióscopus 5 .

Phrynocéphalus interscapuláris 51.

Phrynocéphalus mystáceus 52 .

Phyllodáctylus europáéus 48 .

plättcheniđilange (Hydrus platúrus) 78.

Ptenópus gárrulus 45 .

puffotter 85.

Python régius 82.

Rána góliath 96.

Rána múgiens 97.

Rhacophórus 94.

Riejenlaubfrojđ (Racophórus dennysii) 94.
Riejenfalamander (Megalobátrachus máximus) 87.

Riejenjaylangen 79.

Riejenjkink (Macroscincus coctáéi) 31.

Ringelagame (Oplúrus torquátus) 54.

Rotkehlanolis (Anólis carolinénsis) 9.

Sandj̧̧lange (Eryx jáculus) 79.

Sđ̧eibenfinger (Hemydáctylus túrcicus) 48.

Sdilangenhalsidilokröte (Hydromedúsa tectifera) 69 .

Sđ̆nappidilldkröte (Chelydra serpentina) 72 .

Sđönedjje (Calótes cristatéllus) 55.

Seejđillokröte (Thalassochélys carétta) 64.

Seeidzinngen (Hydróphis) 78.

Sheltopufik (Pseudópus apus) 57.

Siedleracame (Agáma colonórum) 53.

Skink (Scincus officinális) 28.

Speifdlanyen 84 .

Stame!-, Dorn = und franjenfinger (Acanthodáctylus) 49.

Sternotháérus 72.

Sternotháérus derbyánus 72.

Suppeniđhildkröte (Chelóne mydas) 66.

Stułeđ̧̧e(Trachysáúrus rugósus)20.

Taggedios 43.

Taréntola annuláris 47 .

Teju (Tupinámbis teguixin) 41 .

Teratoscincus scincus 45 .

Tigeriđ̧lange (Python molúrus) 80. Tuatera 22.

Ungália maculáta 82.

Varánus bengalénsis 36 .

mabenkröte (Pípa americána) 92.

Darane 35.

mafferagame (Physignáthus lesuéúri) 18 .

weiđhidildokröten (Triónyx) 70.

wurmidlangen (Typhlops) 79.

purmiđleidenen (Trogonóphis wiegmánni) 56.

wiiltenwaran (Varánus gríseus) 35. 



\section{Die Pflanże}

\section{im Dienste des Menschen}

ist obne frage ein für jeden Menschen interessantes Chema, hängt doch unsere gesamte Kultur von der Verwertung der pflanzlichen produkte ab. In hochinteressanten plaudereien erzählen bedeutende fachmänner in unserem grossen Caerke von allen Verwertungsmöglichkeiten.

(O)

26 riefe-

rungen

z̧u je

1 Mark

(O)

Die Pflanzen u.der mench

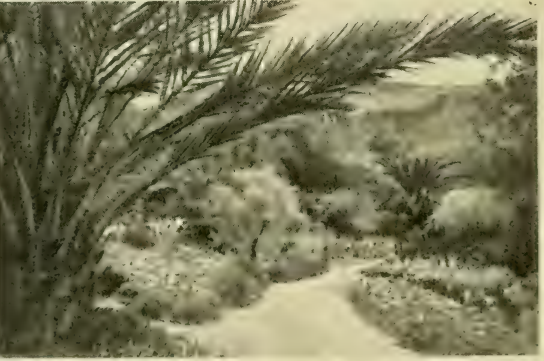

(O)

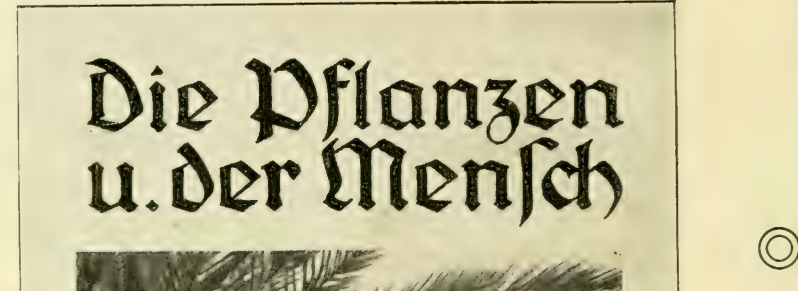

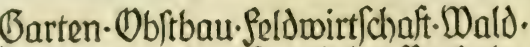
Derwertung der pflanzlichen Produkte

Drof. F. Brüggemann. 6. Ferenczi. Prof. Dr. G. fränkel. Drof.Dr. E. Frumirth.Dr.Did.Grafe.Drof.Dr.G. fausrath. willy Eange. 5.6 dhuly. Feing Delten

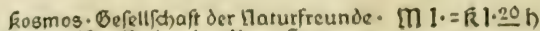

Sranceh' fate Oerfagshandiung. Gturtgart.

Später in

2 Bänden

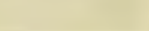

\section{$\equiv$ Glänz̨end illustriert}

Gunderte von Cextbildern, viele schwarze u. Farbige Cafeln. 






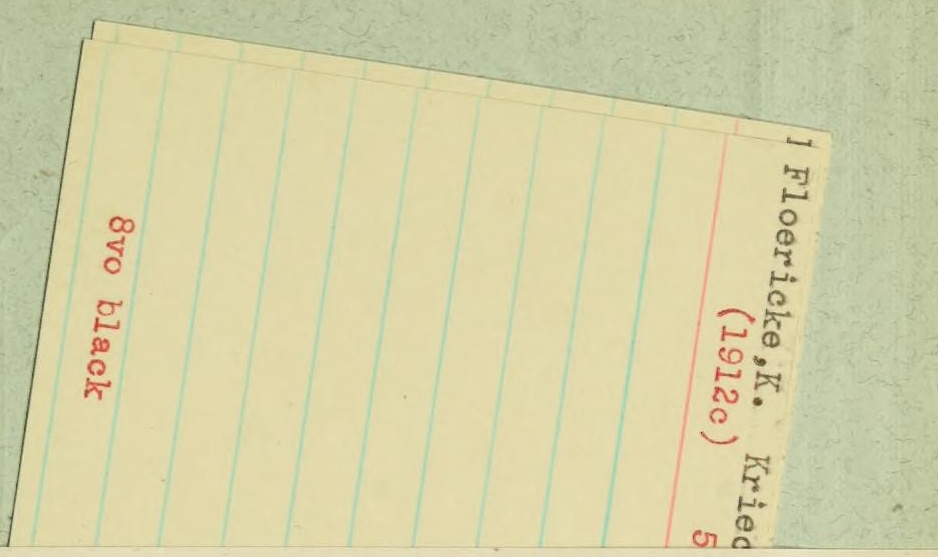


